Universidad Nacional de La Plata

Facultad de Ciencias Médicas

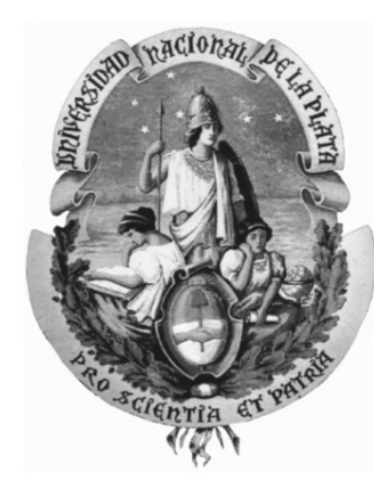

Tesis doctoral

\title{
Estadificación Videolaparoscópica en el Cáncer Colorrectal (CCR)
}

\section{Alberto H. Cariello}

Director de tesis: Juan Ángel Basualdo Farjat

Co-director de tesis: Jorge Defelitto 


\section{Estadificación Videolaparoscópica en el Cáncer Colorrectal (CCR)}

\section{1- Introducción}

La Estadificación Laparoscópica de los tumores previa a su tratamiento quirúrgico con el abdomen abierto, sólo debería usarse en aquellos casos en que sus resultados cambien el curso del tratamiento a realizar a los pacientes, y por lo tanto su pronóstico.

Como en la mayoría de los portadores de Cáncer Colorrectal (CCR) la conducta terapéutica indicada es resecar el tumor primitivo en cualquier estadio en que se encuentre, y para extirparlo es necesario hacer una laparotomía, durante la cual se puede realizar la exploración con el abdomen abierto, el uso de la Estadificación Laparoscópica preoperatoria fue juzgada "a priori"como innecesaria.

Sin embargo, entre los afectados de CCR existe un grupo de pacientes, conformado por aquellos casos de enfermedad muy avanzada, con:

- Carcinomatosis peritoneal, la diseminación celómica del tumor que ocurre en 10 a $15 \%$ de los casos de CCR, y las

- Metástasis hepáticas múltiples o muy extendidas, que no pueden ser resecadas quirúrgicamente, lo que ocurre en otro $15 \%$ de los CCR. (1), (2), (3) y (4)

Este grupo de pacientes, se beneficiaría cuando la estadificación laparoscópica ponga en evidencia condiciones de inextirpabilidad, y evite la realización de una laparotomía no terapéutica en pacientes inmunodeprimidos por su enfermedad neoplásica. De ese modo, se limitaría el número de complicaciones postoperatorias (dolor, sepsis, eventraciones y 
evisceraciones, etc), se acortaría la internación y se apuraría el comienzo de un eventual tratamiento radiante y / o con citostáticos, si estuviese indicado. (5), (6), (7) y (8)

En el mismo acto, se podría utilizar el laparoscopio para realizar una colostomía proximal videoasistida en los pacientes con obstrucción del tránsito colónico debido al tumor o con posibilidades de obstruirse en el corto plazo; o bien se podrían colocar bajo visión, las agujas de Le Veen para tratar mediante radiofrecuencia las metástasis hepáticas irresecables.

En nuestro medio, la estadificación videolaparoscópica del CCR cobra aún más relevancia, ya que no disponemos de los costosos y más precisos métodos de diagnóstico por imágenes de reciente desarrollo, con que cuentan los centros asitenciales de los países dearrollados, con cuya utilización podríamos mejorar la detección preoperatoria de lesiones avanzadas, sobre todo, determinar con precisión la magnitud de la extensión hepática de la enfermedad y así evitar la realización de laparotomías no terapéuticas. (9) y (10)

Ejemplos de esos potentes métodos diagnósticos, de los cuales no disponemos, son: 1- la tomografía axial computarizada con detectores múltiples (MDCT - Multidetector row CT) que permite adquirir 64 cortes superpuestos de $0,6 \mathrm{~mm}$ en cada rotación, en lugar de los 16 cortes que logran los actuales aparatos; con lo que mejora sustancialmente la definición de sus imágenes, tanto en las reconstrucciones tridimensionales como en las "multiplanares" (11), (12) y (13), 2- la resonancia nuclear magnética de alta resolución (HRMRI - High-resolution Magnetic Resonance Imaging) que utiliza la recepción de 24 canales independientes que "adquieren" el efecto en paralelo, para mejorar la "nitidez" de las imágenes obtenidas (14) y 3- la utilización sistemática de la tomografía por emisión de positrones con fluoro-deoxi-glucosa (FDG-PET) en la estadificación y reestadificación de los tumores colorrectales, que podría determinar con certeza si las imágenes, y algo más importante aún, podrían anticiparnos con más precisión que ningún otro método por imáge- 
nes la presencia de Carcinomatosis Peritoneal o de recidivas locales, lo cual cambiaría nuestra estrategia para el tratamiento en este grupo de pacientes (Estadio IV, inextirpables), evitándoles la realización de prácticas excesivamente invasivas. Existe además la posibilidad de combinar sus imágenes, poco definidas anatómicamente, con las obtenidas por TAC que son más topográficas, y lograr de ése modo la mejor información posible de todos los métodos por imágenes existentes acerca de la existencia de enfermedad neoplásica avanzada.. (15)

En contraste, en nuestro país tenemos está muy difundida la utilización de técnicas videolaparoscópicas para el tratamiento de ciertas enfermedades gastroenterológicas prevalentes, como la litiasis biliar y la hernia hiatal, lo que hace que en casi todos los quirófanos haya un equipo y cirujanos entrenados para su uso, lo que nos presenta a la exploración videoscópica para la estadificación preoperatoria de los tumores colorrectales, como una técnica accesible, sencilla, rápida y de bajo costo. (16), (17) y (18)

Actualmente, teniendo en cuenta los buenos resultados obtenidos por estudios cooperativos que compararon los resultados oncológicos de las resecciones colorrectales video-asistidas, con los de la cirugía abierta para el tratamiento del cáncer colorrectal [COST (19), COLOR(20), y otros (21),(22)y(23)], la comunidad científica autorizó a practicar extensivamente ésta técnica, lo cual implicaría la realización de una exploración o estadificación, en éste caso intraoperatoria, previo a los tiempos operatorios destinados a la resección. Sin embargo, el alto costo de la cirugía colorrectal video-asistida, debido al uso de varias suturas mecánicas específicas para ligar los pedículos y para realizar las anastomosis, y de otros insumos costosos que no se fabrican en el país y deben importarse con un cambio desfavorable; y además, la necesidad de un largo período de entrenamiento de los 
cirujanos que la van a realizar, han hecho que en nuestro medio asistencial, las resecciones colorrectales video-asistidas no se realicen con habitualidad.

Esta circunstancia, hace que la estadificación videolaparoscópica de los tumores colorrectales previa a la laparotomía para la exéresis del tumor primitivo, se presuma como un procedimiento útil para evitar laparotomías no terapéuticas; y de allí la necesidad de realizar un estudio prospectivo que determine su sensibilidad.

Asimismo, antes de relatar la experiencia, se hace necesario hacer una revisión de los conocimientos más recientemente adquiridos acerca del Cáncer Colorrectal (CCR), una entidad nosológica prevalente de dispersión universal, acerca de la cual, los conocimientos científicos están en permanente expansión. 


\section{2- Cáncer Colorrectal (CCR)}

\section{2-A - Epidemiología}

El Cáncer Colorrectal (CCR) es una enfermedad muy frecuente. En los Estados Unidos de Norteamérica (EUA), país que tiene un registro centralizado del cáncer desde hace muchos años, se ha detectado una incidencia de 57 nuevos casos por cada 100.000 habitantes cada año, y es la segunda causa de muerte por cáncer, provocando unas 55.000 muertes cada año (24).

En nuestro país, donde no hay registros estadísticos certeros ni centralizados de pacientes con cáncer, sólo se pueden hacer aproximaciones a la incidencia del Cáncer Colorrectal (CCR) a partir de datos de registros parciales, como los obtenidos en la Provincia de Buenos Aires durante el período 1996-98 , que muestran una incidencia de la enfermedad de 40 a 45 nuevos casos por cada 100.000 habitantes por año. (25)

Sin embargo, el CCR es tratable y aún "curable" cuando se halla confinado al intestino, no así cuando la evolución de la enfermedad ha trascendido el órgano primitivo, con invasión linfática regional y/o metástasis a distancia, lo que puede observarse claramente en las tablas de sobrevida a 5 años luego del diagnóstico y tratamiento del CCR, cuando se discrimina la sobrevida por estadios de la enfermedad.. 
Tabla 1 : Sobrevida a 5 años de Cánceres Colorrectales diagnosticados en 1995 y 1996, (según reportes de 1735 Hospitales en EUA)

\begin{tabular}{|c|c|c|c|}
\hline Estadio & № Casos & \% Sobr. 5 a & 95\% Intervalo Conf. \\
\hline $\mathbf{0}$ & 9477 & $\mathbf{7 1 . 3} \%$ & $70.26-72.38$ \\
\hline I & 25461 & $\mathbf{6 9 . 6} \%$ & $68.91-70.23$ \\
\hline II & 37396 & $\mathbf{5 9 . 9} \%$ & $59.34-60.50$ \\
\hline III & 30690 & $\mathbf{4 4 . 4} \%$ & $43.79-45.07$ \\
\hline IV & 24161 & $\mathbf{5 . 1} \%$ & $4.73-5.37$ \\
\hline Total & 136360 & $\mathbf{4 7 . 5} \%$ & $47.23-47.83$ \\
\hline
\end{tabular}

Fuente: NCDB, Commission on Cancer, ACoS/ACS. Survival Reports

De lo dicho se infiere el enorme valor de establecer, con la mayor precisión posible, el estadio evolutivo de la enfermedad con la finalidad de planificar los tratamientos y para establecer el pronóstico. Asimismo, es conveniente hacer diagnósticos cada vez más tempranos para mejorar los resultados de los tratamientos, que aumentarán la sobrevida global y la sobrevida libre de enfermedad de los pacientes

Para hacer diagnósticos tempranos y aún subclínicos, se han identificado grupos de población con riesgo más elevado de padecer la enfermedad, que deberán estudiarse estando asintomáti$\cos$.

En ese sentido, todas las personas mayores de 50 años, pertenecen al grupo de edades con riesgo aumentado y deben ser estudiados; así como aquellos otros, de cualquier edad, que tengan antecedentes de: (27) 
* Cáncer Colorrectal en parientes de primer grado (padres, hermanos o hijos)

* Cáncer Colorrectal o ginecológico previamente tratado (tumores metacrónicos)

* Pancolitis ulcerosa de más de 10 años evolución

* Pólipos adenomatosos aislados (secuencia adenoma-carcinoma)

* Poliposis Heredofamiliar

* Síndrome de Gardner, Síndromde de Peutz-Jeghers, Síndrom de Turcot, Poliposis.Juvenil, Enfermedad de Crohn 


\section{2-B- Detección subclínica del Cáncer Colorrectal}

Durante el Congreso Argentino de Gastroenterología del año 2000 se realizó un consenso de especialistas, que más tarde se publicó como la "Guía de recomendaciones para el tratamiento del Cáncer Colorrectal”, en la cual se consideran tres grupos de riesgo. (17)

Esta Guía fue adoptada posteriormente por las siguientes sociedades: - Sociedad Argentina de Gastroenterología (SAGE),- Sociedad Argentina de Coloproctología, - Federación Argentina de Gastroenterología (FAGE), - Asociación Argentina de Oncología Clínica, - Federación Argentina de Asociaciones de Endoscopía Digestiva (FAAED) (18)

ACRÓNIMOS:

$$
\begin{aligned}
& \text { SOMF }=\text { Sangre Oculta en Materia Fecal }(\text { Hemoccult II) } \\
& \text { ERS }=\text { Endoscopía Recto Sigmoidea }(\text { con instr. Flexible) } \\
& \text { ETC }=\quad \text { Endoscopía Total del Colon } \\
& \text { CxE }=\quad \text { Radiografía de Colon por Enema }
\end{aligned}
$$

\section{A- Grupo de riesgo promedio $(70-80 \%$ del total)}

Individuos con más de 50 años de edad, asintomáticos y sin otros factores de riesgo.

De acuerdo con las posibilidades y preferencias del paciente se puede optar entre:

1. SOMF anual + ERS cada 5 años: $\longrightarrow$ si es positiva $\longrightarrow$ ETC.

2. ETC cada 10 años

3. Rx. Colon por Enema (CxE) cada 5 años

4. SOMF anual sola $\longrightarrow$ si es positiva $\longrightarrow$ ETC

5. ERS cada 5 años $\longrightarrow$ si es positiva $\longrightarrow$ ETC $\left\{\begin{array}{l}\text { Sólo si no pueden } \\ \text { hacerse } 1,203\end{array}\right.$ 
B- Grupo de riesgo moderado $(20-30 \%$ del total)

a. Antecedente personal de pólipo adenomatoso menor de $1 \mathrm{~cm}$ :

Recomendación: ETC a los 3 años, si es normal incluir en grupo de Riesgo bajo

b. Antecedente personal de adenoma mayor de $1 \mathrm{~cm}$., con componente velloso de más del $25 \%$, displasia,o varios adenomas (no poliposis) Recomendación: ETC cada $\mathbf{1}$ a $\mathbf{3}$ años (más frecuentemente si es Velloso)

c. Antecedente personal de cáncer colorectal resecado con intento curativo: Recomendación: ETC cada 1 años

d. Antecedente cáncer o pólipo colorrectal en 1 familiar 1er grado, menores de 60 años o en 2 de cualquier edad:

Recomendación: ETC a los 40 años y luego cada 5 años

C- Grupo de riesgo elevado ( $5-10 \%$ del total)

e. Antecedente de poliposis adenomatosa familiar:

Recomendación: ERS a los 12 años y luego cada año. Consulta a un centro especializado para realizar test y asesoramiento genético.

f- Antecedente de cáncer colorrectal hereditario no políptico ( Síndrome de Linch )

Recomendación: ETC cada 2 años desde los 21 años. Asesoramiento genético en un centro especializado

g- Antecedente de enfermedad inflamatoria intestestinal (Rectocolitis UIcerosa, Enfermedad de Crohn)

Recomendación: $\quad$ ETC c/ biopsia cada 1-2 años después de los 8 años de evolución de una CU Pancolítica

ETC c/biopsia (con displasia) c/ 12-15 años en CU Izquierda y Enfermedad de Crohn. 


\section{2-C- Cáncer Colorrectal Temprano (CCT)}

Se considera CCT a las lesiones que involucran solamente la mucosa y la submucosa del intestino sin invasión de la muscularis mucosae, haciendo una analogía con lo que sucede con el ampliamente estudiado cáncer gástrico temprano. La incidencia del CCT varía en distintas comunidades según los estudios de detección subclínica (prevención secundaria) que se utilicen en cada una de ellas; un ejemplo es el aumento de su incidencia en USA, desde que en 1998 se le recomendó una colonoscopía a las personas mayores de 50 años sin otro factor de riesgo. (28)

El interés por la identificación y el diagnóstico del Cáncer Colorrectal en estadios tempranos se debe a la presunción de la existencia de diferencias en el pronóstico de los pacientes con CCT y en el de aquellos otros con Cánceres Colorrectales avanzados (CCA). Estas presunciones quedaron probadas con las evidencias obtenidas de un trabajo que comparó los especimenes y la evolución de 90 CCT con la de otros 1704 CCA luego de ser resecados, constatando en los CCT un menor tamaño tumoral, una mayor diferenciación histológica, y un menor número de metastasis linfáticas (8.9\% CCT vs.46.2\% CCA) y a distancia.(29)

Existe acuerdo en cuanto a las características y evolución de las lesiones polipoideas, como veremos más adelante, sin embargo existen controversias con respecto a las lesiones superficiales. Para los autores japoneses se trata de carcinomas superficiales "de novo" sin componente alguno de adenoma, en tanto los occidentales afirman que casi siempre asientan sobre un adenoma, (30) Probablemente la diferencia se deba a que los japoneses detectan más lesiones confinadas sólo a la mucosa que en occidente, pero de confirmarse pondría 
en tela de juicio la secuencia adenoma-carcinoma como el mayor productor de Cáncer Colorrectal. En la actualidad, todavía no hay evidencias de diferencias genéticas en la carcinogénesis entre las lesiones polipoideas y la no polipoideas o superficiales, pero sí se ha demostrado que existe una menor tasa de la mutación K-ras en las superficiales, lo que aún necesita ser reafirmado mediante nuevas investigaciones .(31)

Para comprender la conveniencia de detectar el CCT lo más precozmente posible, es útil conocer la historia natural del CCT y del CCA. Se sabe que el tiempo de duplicación (TD) en los CC que afectan sólo la mucosa es mayor (unos 31 meses), que en aquellos CCT que afectan además la submucosa (unos 25 meses). En los CCA (invasor), el patrón de crecimiento es siempre mayor (aunque variable entre sujetos y cambiante para el mismo tumor). Contra la creencia que los CCA provenían más frecuentemente de lesiones deprimidas, hay estudios que demuestran que aproximadamente el $70 \%$ de ellos provienen de lesiones protruídas y superficiales elevadas .(32)

Con la finalidad de estandarizar el estudio del CCT, la Japanese Research Society for Cancer of the Colon and Rectum ha propuesto una sistematización morfológica (33)

Figura 1: SISTEMATIZACIÓN MORFOLÓGICA del CÁNCER COLORECTAL TEMPRANO

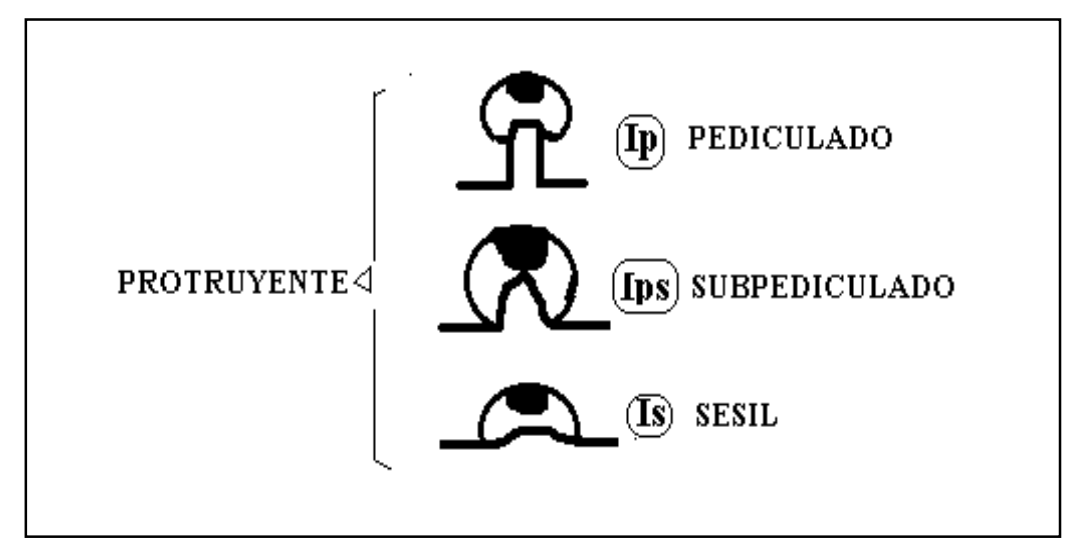




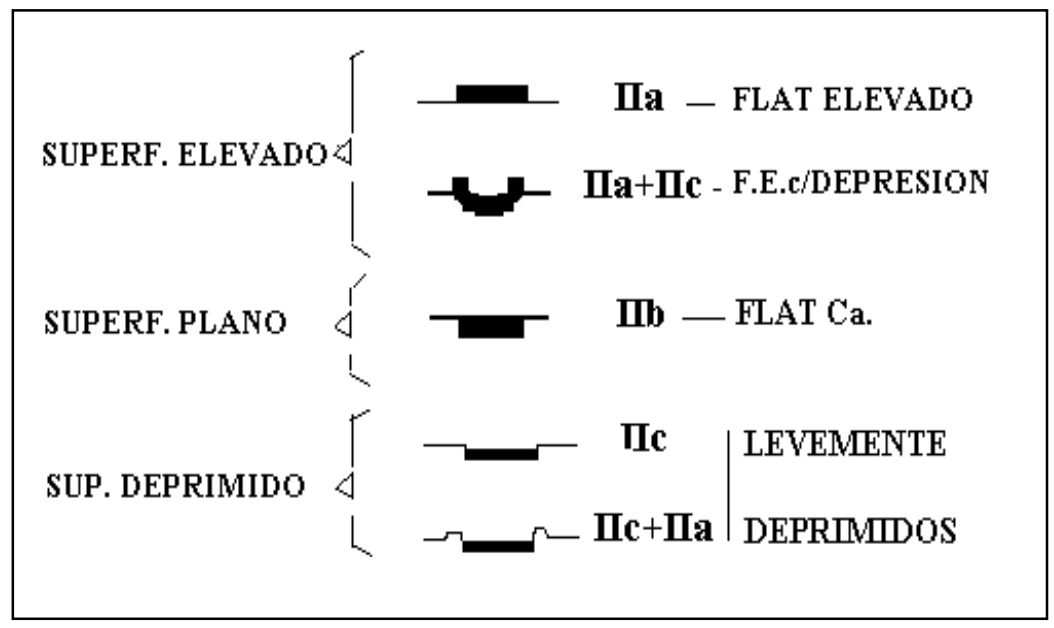

Tomado de Japanese Research Society for Cancer of the Colon and Rectum, World J. Surg 2000

En CCT de tipo polipoideo, es conveniente considerar además el grado de invasión del Carcinoma, que fuera esquematizado por Haggitt y cols. en 4 niveles, correlacionadolos con la posibilidad de resección por vía endoscópica, su posterior evolución y su pronóstico.

Figura 2: GRADOS DE INVASIÓN DEL CARCINOMA COLORRECTAL

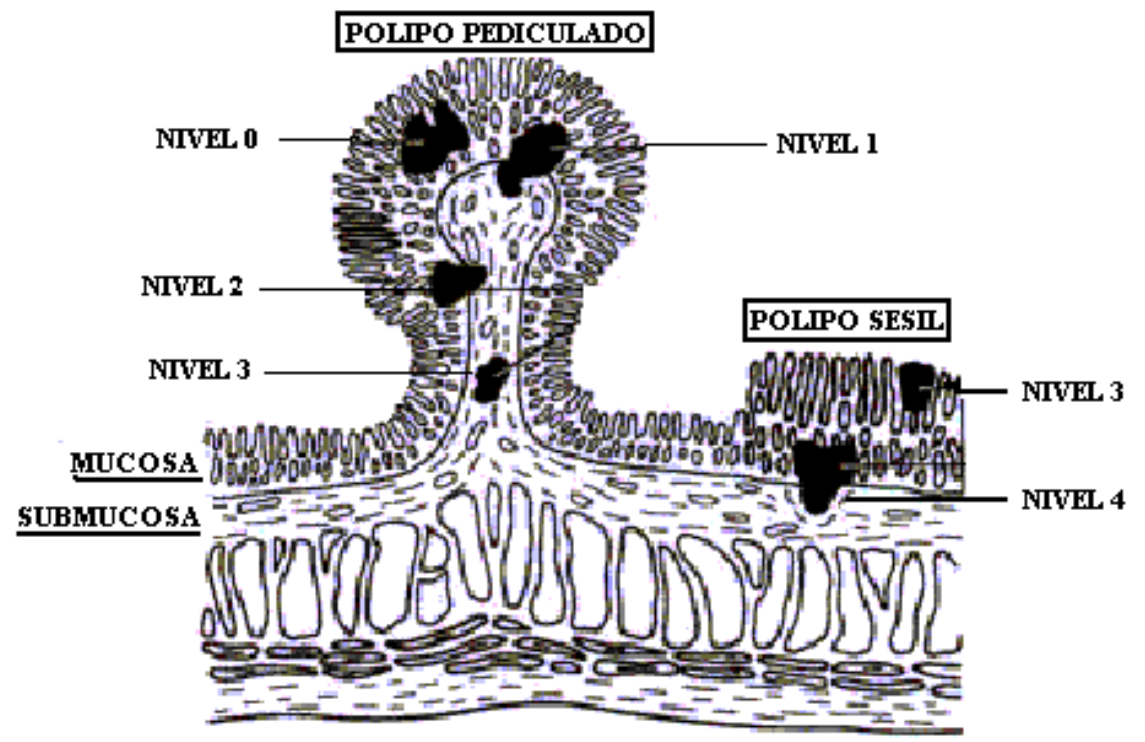

Tomado de Haggitt, R. et al -Gastroenterology 1985 (34) 
Nivel 0: Carcinomas ubicados por encima de la muscular de la mucosa. Cáncer No Invasor.

Nivel 1: Invasión de la mucosa y de la submucosa, pero limitada a la cabeza del pólipo.

Nivel 2: Compromiso del cuello del pólipo (zona limitada entre la cabeza y el pedículo).

Nivel 3: Invasión de la submucosa en el pedículo.

Nivel 4: Invasión de la submucosa de la pared del colon por debajo del pedículo. Los pólipos sésiles con cáncer invasor siempre son nivel 4

El nivel 4 de invasión de Haggit en las lesiones polipoideas, es conveniente subdividirlo de acuerdo con el grado de invasión de la submucosa en 3 grados: SM1, SM2 y SM3.

Dicha división se correlaciona con la evolución, ya que los SM1 rara vez recidivan o se acompañan de ganglios positivos y pueden ser resecados endoscópicamente aún cuando sean planos, en cambio las lesiones SM2 y SM3 de tipo plano o deprimido tienen alto riesgo de recidiva y de compromiso linfático por lo que la resección local endoscópica es insuficiente. (29)

Figura 3: GRADOS DE INVASIÓN en la SUBMUCOSA (Nivel 4 Haggit)

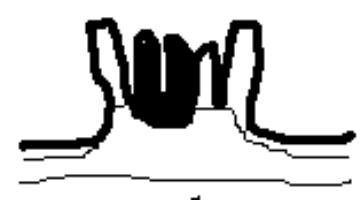

SM1

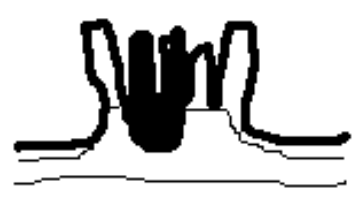

SM2

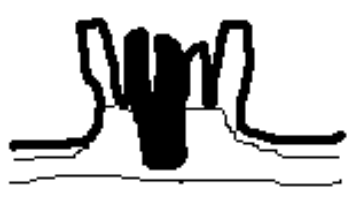

SM3

Tomado de Nivatvongs S. - World J.Surg 2000 
El problema entonces, parece resumirse a diagnosticar el CCT, polipoideo o no polipoideo, en su etapa más temprana e implementar el tratamiento que la localización, el tipo morfológico y el grado de diferenciación histológica del tumor hagan más aconsejable.

Para ello nos valemos de una secuencia de diagnóstico y tratamiento que incluye

1- la detección de las lesiones mediante "screening" sobre poblacionales de riesgo.

2- la excéresis local o la biopsia de la lesión (según el tipo morfológico)

3- el tratamiento final adecuado al tipo de lesión y al informe histopatológico.

Para el diagnóstico se cuenta con:

1- Estudios poblacionales de sangre oculta en materia fecal (SOMF) Permiten delimitar el gasto y realizar una colonoscopía en aquellos que son positivos. Por razones de costoefectividad se tienden a utilizar universalmente el test Hemoccult II.

2- Radiología contrastada por enema: Se trata de hacer el estudio con el contraste al $70 \%$ de su dilución habitual, lo que permite una mejor definición de las lesiones más pequeñas. El grupo del Cancer Institute Hospital de Tokio, bajo la dirección de M. Maruyama, realizó un estudio en el que demostró la buena sensibilidad del método, logrando el diagnóstico en el 84\% (32/38) de los CCT Superficiales ( IIa, IIa + IIc, IIc y IIc + IIa) y en el 95\% (77/81) de los CCT de tipo Polipoideo (Ip, Ips y Is). (35) 
3- Colonoscopía completa, que debe llegar hasta el Ciego para ver la totalidad de la mucosa del colon. Nos permite detectar, con gran sensibilidad, las lesiones elevadas y superficiales, sobre todo cuando se utilizan videoendoscopios que permiten magnificar y/o utilizar coloraciones para distinguir las áreas neoplásicas de las normales. Una vez localizada la lesión, la técnica nos permite utilizar un transductor ultrasonográfico para estimar la penetración de la misma y realizar con seguridad la exéresis de la lesión, con margen libre si fuera posible.

4- Ecotomografía Endoscópica (EE) o Transanal (ETA), técnicas muy útiles para estimar la penetración de las lesiones y determinar si estamos ante un CCT. En el caso de la ETA, también es útil para obtener información de la presencia de adenomegalias en la grasa perirrectal. 


\section{2-D- Patogenia del Cáncer Colorrectal (CCR)}

Con los conocimientos actuales, el cáncer colorrectal debe ser considerado como un problema genético, teniendo en cuenta los mecanismos subyacentes que condicionan su evolución,.

En éste caso, el término genético no es sinónimo de hereditario, y se refiere a una serie de alteraciones "genéticas" que condicionan la secuencia de los pasos que transforman a una célula del epitelio normal, en una célula cancerosa.

Los tumores colorrectales proporcionan un sistema excelente para estudiar las alteraciones genéticas implicadas en el desarrollo del cáncer. En éste sentido, estudios clínicos e histopatológicos sugieren que la mayoría de los carcinomas del colon, serían transformaciones de adenomas preexistentes. (36)

A diferencia de lo que ocurre con otros cánceres humanos, es posible obtener tumores colorrectales en varias etapas de su desarrollo para estudiar sus alteraciones genéticas, lo que ha permitido apreciar la progresión de las alteraciones genéticas somáticas (mutaciones), en los oncogenes y en los genes supresores de tumores. Para llegar al tumor maligno (carcinoma), pueden ser necesarias cuatro a cinco mutaciones en los genes; en cambio, sólo unos pocos cambios pueden ser suficientes para la formación de un tumor benigno (adenoma), y aunque las alteraciones genéticas ocurren a menudo en una secuencia definida, la acumulación de los cambios, más que su orden relativo, parece ser el determinante de las características biológicas del tumor neoformado . (36) y (37)

El estudio de los genes involucrados en la mutación somática de estos tumores, puede permitirnos conocer, no solamente la patogenia de la enfermedad, sino también el 
origen de las mutaciones y de los potenciales factores ambientales y dietéticos involucrados en el desarrollo de los tumores colorrectales. (37)

Figura 4: ESQUEMA de la FORMACIÓN de un ADENOMA en el COLON

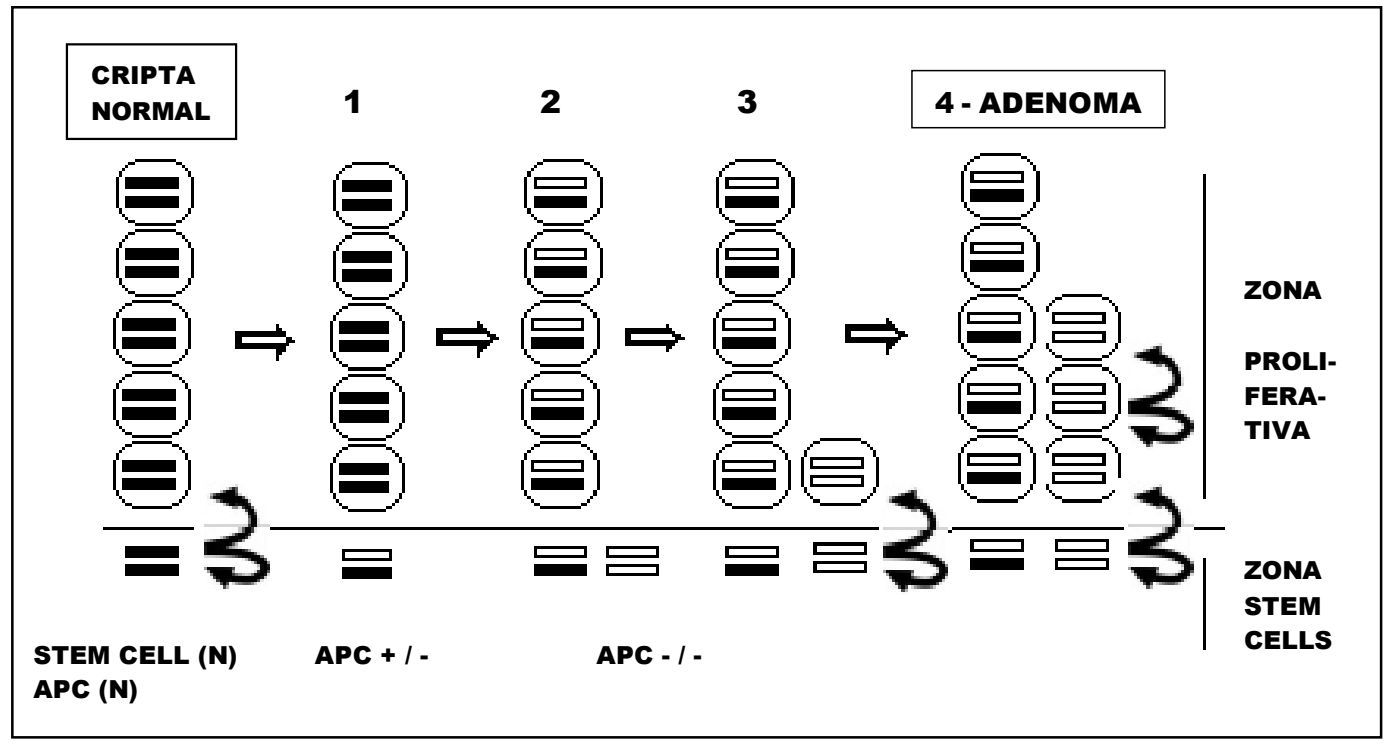

Adaptado de: Luebeck EG \& Moolgavkar SH, 2002 (37)

Paso 0- A la izquierda, se muestra una sección de una cripta normal del colon, donde la división normal de las Células Madre (Stem Cell) mantienen la cripta

Paso 1- Una rara mutación en las Células Madre inactiva un alelo del gen APC. A no ser que la célula madre normal sea inactivada o muera, se transforma en un "mosaico", mezcla de células con el gen APC +/+ normal, y otras con el gen APC + / -

Paso 2- Otra raro evento lleva a la una inactivación del APC en ambos alelos de la Célula Madre, (todavía en la Zona de Steam Cells)que ahora es APC -/- 
Paso 3- Las frecuentes divisiones asimétricas de la población de Células Madre, en éste caso defectuosas, alcanzan la Zona Proliferativa de la cripta, con su progenie de células con APC - / -, capaces de producir la expansión clonal

Paso 4- Expansión clonal de células defectuosas para formar el Adenoma(38), (39)

Por otra parte, los estudios de Fearon y Vogelstein en 1990, develaron los aspectos más íntimos del modelo genético de la oncogénesis colorrectal, y confirmaron la secuencia pólipo-cáncer, cuya vigencia se proyecta hasta la actualidad. La descripción esquemática de los sucesos es como sigue: (39) y (40)

Figura 5: MODELO GENÉTICO de ONCOGÉNESIS COLORRECTAL

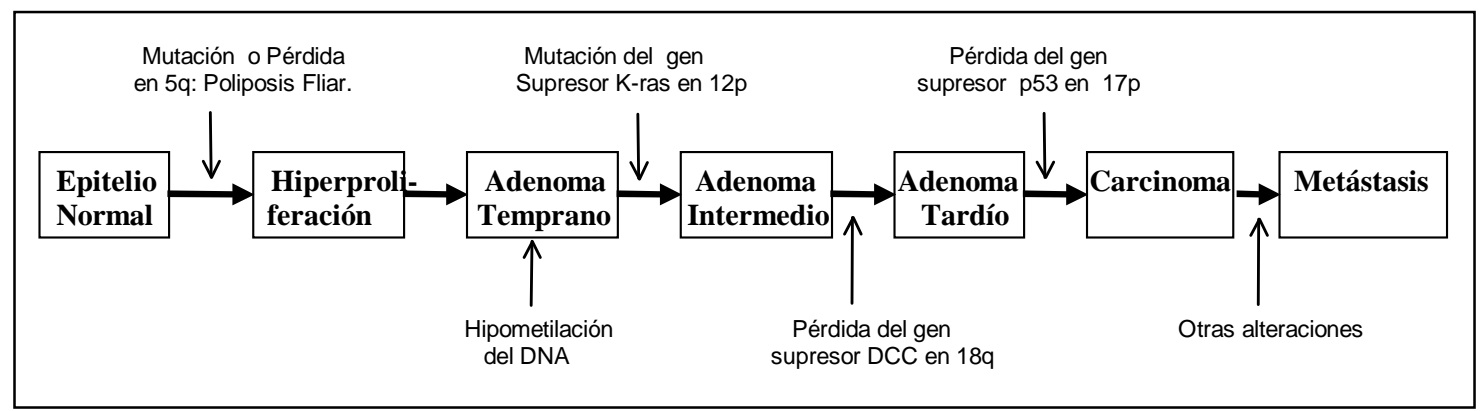

Tomado de Fearon ER \& Vogelstein B, 1990 (40)

Ésto abre un campo muy importante en la prevención del desarrollo de éstos tumores, al permitir la identificación de los individuos portadores de las variedades hereditarias, 
y el mantenimiento de una vigilancia activa ante la aparición de pólipos, lo que nos permite proceder rápidamente con el tratamiento adecuado en cada caso.

\section{2-E - Clínica y diagnóstico del Cáncer Colorrectal avanzado}

Los síntomas con los que se presenta el Cáncer Colorrectal con mayor frecuencia son: - hemorragia o anemia (sobre todo en los tumores del colon derecho), - algún grado de obstrucción, que va desde cambio del hábito intestinal hasta verdaderas oclusiones, pasando por episodios "suboclusivos" (preferentemente en los tumores del colon izquierdo), y síndrome rectal con pujos, tenesmo y en ocasiones sangrado por el ano (en el cáncer rectal)

La presencia de cualquier síntoma sugestivo, debe poner en marcha un detallado interrogatorio y un cuidadoso examen físico, los que deben ser completados con estudios radiológicos contrastados por enema del colon, para mostrar las características y la topografía de la eventual neoplasia, y con una endoscopía del colon en su totalidad, para visualizar el aspecto de la lesión, tomar biopsias y descartar la presencia de lesiones sincrónicas. La ecotomografía habitualmente es suficiente para demostrar o descartar metástasis hepáticas y la ecografía endoanal nos da una información muy precisa de la penetración de los tumores rectales, de su relación con el aparato esfinteriano y de la presencia de ganglios perirrectales. (41)

Las decisiones terapéuticas se realizarán en base a una estadificación, que puede ser: A- estadificación clínica, en el preoperatorio, que define el estado local del tumor (T), de acuerdo con la radiografía contrastada del colon, la colonoscopía y mediante ecoendoscopía, o ETA en los tumores del Recto; el factor N con cierta dificultad en los tumores de colon, y mediante TAC helicoidal dinámica pelviana y ETA en los tumores del recto, y finalmente el factor M, mediante la ecotomografía y/o TAC hepática dinámica del abdomen con 
contraste oral y EV . B- estadificación quirúrgica, es la que surge de la semiología intraoperatoria, y define si se deben indicar o no tratamientos complementarios en el postoperatorio, y C- estadificación de retratamiento, cuando ha ocurrido una recidiva, una enfermedad residual por resección incompleta o un tumor metacrónico, es necesario reestadificar al paciente para decidir el re-tratamiento, de acuerdo con el pronóstico determinado por dicha eventualidad

Figura 6: ESTADIFICACIÓN CLÍNICA del CÁNCER COLORRECTAL

SÍNTOMA

ESTUDIO

UTILIDAD

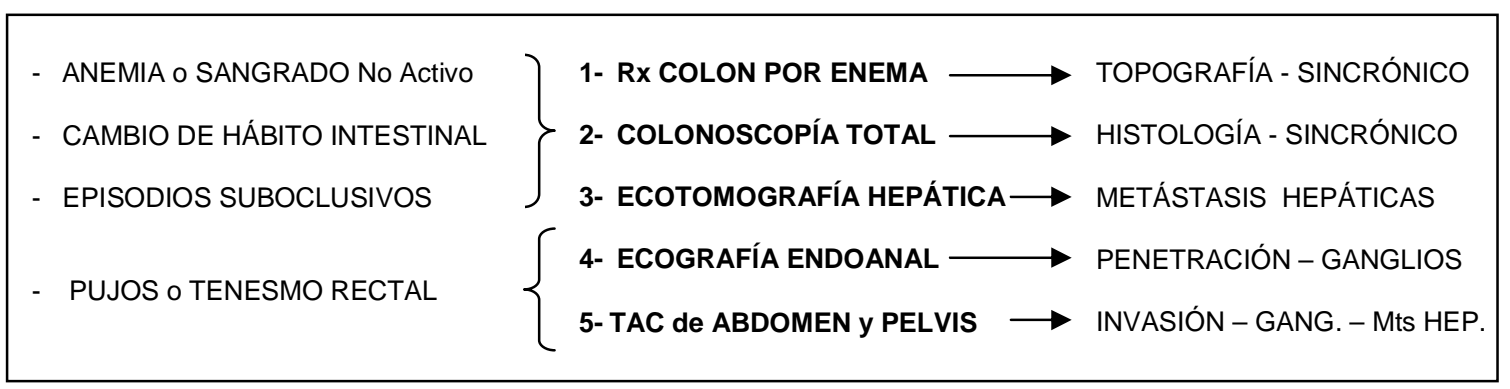

En los últimos años se ha desarrollado un estudio menos invasivo que la fibrocolonoscopía convencional, la Colonoscopía Virtual mediante TAC helicoidal con un programa informático que permite generar imágenes tridimensionales con los datos obtenidos por el tomógrafo, el cual es muy útil para diagnosticar tumores colorrectales en poblaciones de personas asintomáticas. Sin embargo, si en el estudio se encuentra una lesión, es necesario tomarle una biopsia para confirmar mediante el estudio histopatológico si se trata de una neoplasia y cuál es su estirpe celular, para lo cual es preciso realizar una colonoscopía convencional (42) 


\section{2-F - Estadificación}

\section{2-F-I- Acerca de la estadificación de tumores}

La acción de "estadificar", impone la tarea de colocar un caso particular en una serie finita de estados definibles de la enfermedad, cada uno con determinadas consecuencias pronosticas. La determinación previa de dichos "estados" de la enfermedad, implica un estudio estadístico de la evolución de un gran número de casos, en los cuales se intentará relacionar las variaciones de algunas de sus características (tamaño o penetración de un tumor, existencia o ausencia de invasión linfática, presencia o ausencia de metástasis a distancia) con la evolución de la enfermedad en lapsos prolongados (sobrevida libre de enfermedad a los 5 años, tiempo entre el diagnóstico y el fallecimiento, etc). Para ello, es frecuente el uso de estadísticas descriptivas, cálculos de sobrevida actuarial (Kaplan-Meyer) y modelos de regresión proporcional al azar (Cox)

Cuando la estadificación se hace en el preoperatorio, incluye el procesamiento de una serie compleja de datos clínicos, de laboratorio, imágenes, etc), con la finalidad de establecer en que "estadio" de la progresión continua de la enfermedad se halla nuestro paciente, para implementar el tratamiento más adecuado que nos permita mejorar el pronóstico calculado para ese estadio.

\section{2-F-II- Historia de la estadificación del CCR}


En el caso del Cáncer Colorrectal, fue Percy Lockart-Mumery del Hospital St. Mark de Londres, quien por primera vez construyó una clasificación clínica en 3 estadios (A, B y C) de los cánceres rectales y la publicó en 1927, en su trabajo acerca del tratamiento quirúrgico del Cáncer Rectal con exéresis perineal del recto. Dicha publicación tuvo gran difusión, ya que estableció una controversia con los trabajos de Ernest Miles del Hospital Gordon de Londres, quien por entonces ya proponía y practicaba la exéresis abdominoperineal del recto, lo cual ayudó a difundir su clasificación de los tumores rectales.(43)

En 1924 se incorporó al Hospital St. Mark de Londres el patólogo Dr. Cuthbert Dukes, quien, junto al Dr. William Gabriel, comenzó un trabajo que estudio las piezas de resección y correlacionó los hallazgos con la evolución clínica de los pacientes, construyendo de ese modo una clasificación en 3 estadios de acuerdo con la penetración parietal del tumor, que publicó en 1932.(38) Esa clasificación ha pasado exitosamente la prueba del tiempo y se mantiene en la actualidad vigente para la evaluación del tumor primitivo, sólo con ligeras modificaciones, luego de más de 70 años. En 1956, poco antes de su retiro, Dukes publicó la validación de su clasificación aplicada sobre más de 2000 casos.(43)

El sistema descriptivo TNM, fue el producto de un ambicioso proyecto para generar un sistema de estadificación útil para todo tipo de tumores, llevado a cabo en Francia por en grupo liderado por P.Denoix, que lo publicó en 1954. Posteriormente, el sistema fue adoptado por la Union Internationale Contre Cancer (UICC), y la American Joint Comitee for Cancer Staging and End Resulting Report (AJCC). Se trata de un sistema que integra la progresión local, con la regional y a distancia de la enfermedad. Esta clasificación, actualmente en uso, es sometida a revisiones periódicas. En el caso de los Cánceres Colorrectales son evidentes algunas deficiencias, por ejemplo, la escasa información que brinda acerca de las metástasis a distancia (M0, M1),y sobre el tipo y magnitud de la enfermedad residual 
que hace insuficientes a la sola categorización en R0, R1 y R2, en la clasificación postoperatoria, entre otras deficiencias. (44)

Entre sus revisiones más recientes, se halla el trabajo realizado por un grupo de investigadores promovidos por el Cancer Program del American College of Surgeons y publicado en el año 2002 (45), en el cual analizaron la evolución de 50.042 pacientes afectados por Cáncer Colorrectal en estadio III (cualquier T, cualquier N, M0) reclutados entre 1987 y 1993. Probaron que esa cohorte podía descomponerse en 3 subgrupos con diferente pronóstico:

Figura 7: SOBREVIDA a 5 AÑOS en 3 SUBGRUPOS del ESTADIO III

\begin{tabular}{|c|c|c|}
\hline ESTADIO & TNM & $\begin{array}{c}\text { Sobrevida } \\
\text { a } 5 \text { años }\end{array}$ \\
\hline Estadio III A & $\mathrm{T} 1 / 2-\mathrm{N} 1-\mathrm{M} 0$ & $59,80 \%$ \\
\hline Estadio III B & $\mathrm{T} 3 / 4-\mathrm{N} 1-\mathrm{M} 0$ & $42.0 \%$ \\
\hline Estadio III C & $\mathrm{T} 1 / 4-\mathrm{N} 2-\mathrm{M} 0$ & $27.3 \%$ \\
\hline
\end{tabular}

Tomado de Greene F. et al, 2002 (45)

por lo que propusieron incorporar éstos subgrupos a la clasificación para la estadificación pronostica de los pacientes portadores de Cáncer Colorrectal en la $6^{\mathrm{a}}$ edición del American Joint Comité on Cancer (AJCC)

\section{2-F-III- Estadificación de pacientes con Cáncer Colorrectal}


De las estadificaciones, la más extensamente usada en la actualidad es la producida en su actual $6^{\mathrm{a}}$ edición por el American Joint Committee on Cancer (AJCC). (46)

Figura 8: CLASIFICACIÓN T-N-M en el CÁNCER COLORRECTAL

\section{T- TUMOR PRIMARIO}

Tx El tumor no puede ser convenientemente definido.

T0 No hay evidencia del tumor primario

Tis Carcinoma "in situ", solo toma la mucosa.

T1 Tumor que invade la submucosa

T2 Tumor que invade la Muscularis Propia

T3 Tumor que invade hasta la subserosa y/o zonas periintestinales subperitoneales

T4 Tumor que perfora peritoneo visceral y/o invade órganos vecinos

\section{N - GANGLIOS LINFÁTICOS REGIONALES}

Nx Los ganglios regionales no pueden ser bien definidos

N0 No hay invasión de ganglios regionales

N1 Hay invasión de 1 a 3 ganglios perirectales o pericólicos

N2 Hay invasión de 4 o más ganglios periintestinales

\section{M- METÁSTASIS}

Mx No se completaron estudios para descartar metástasis a distancia

M0 No se demostró metástasis a distancia con estudios adecuados 
M1 Se demostró metástasis a distancia con estudios adecuados

Figura 9: ESTADIOS PRONÓSTICOS en el CÁNCER COLORRECTAL

\begin{tabular}{|c|c|c|c|c|c|}
\hline & & $\mathbf{T}$ & $\mathbf{N}$ & $\mathbf{M}$ & Dukes * \\
\hline \multicolumn{2}{|l|}{ Estadio 0} & Tis & No & M 0 & No \\
\hline \multirow{2}{*}{\multicolumn{2}{|c|}{ Estadio I }} & $\mathrm{T} 1$ & No & M 0 & $A$ \\
\hline & & T 2 & No & M 0 & B 1 \\
\hline \multirow{2}{*}{ Estadio II } & A & T 3 & No & M 0 & B 2 \\
\hline & B & T 4 & No & M 0 & B 3 \\
\hline \multirow{3}{*}{ Estadio III } & A & T 1-2 & N 1 & M 0 & C 1 \\
\hline & B & Т 3-4 & N 1 & M 0 & C 2 \\
\hline & C & cualquier $\mathrm{T}$ & $\mathrm{N} 2$ & M 0 & C 3 \\
\hline \multicolumn{2}{|l|}{ Estadio IV } & cualquier T & cualquier $\mathrm{N}$ & M 1 & $\mathrm{D}$ \\
\hline
\end{tabular}

* Equivalencia con clasificación de Dukes, sus modificaciones y la modificación de Astler y Coller (47) y (48)

Tomado de la 6 a $^{\mathbf{a}}$ edición de los Estadios Pronósticos del American Joint Committee on Cancer

Para establecer el pronóstico interesan además:

- el tipo histológico

- el grado de diferenciación celular 
- la ploidía del DNA.

Respecto del primero, la inmensa mayoría son adenocarcinomas, y solo cobra interés cuando sean del tipo histológico mucinoso o coloide, pues estas variedades tienen peor pronóstico. (44)

En cuanto a los grados de diferenciación celular se observan a continuación:

Figura 10: GRADOS de DIFERENCIACIÓN CELULAR (45)

G1- Bien diferenciados: conservan la estructura glandular y sólo son malignos porque infiltran la muscularis mucosae)

G2- Moderadamente bien diferenciados: las células tumorales son más numerosas pero todavía forman 1 o 2 hileras alrededor de los espacios glandulares, hay mitosis irregulares y anomalías nucleares

G3- Pobremente diferenciados: hay aún más células tumorales y las estructuras son discontínuas, hay más alteraciones nucleares que en el grado anterior)

G4- Indiferenciados: no hay estructuras glandulares y los grupos celulares son sólidos.

La presencia peritumoral de linfocitos sugiere reacción del huésped y se asocia a mejor pronóstico. Y finalmente, la ploidía del DNA medida por citometría de flujo permite detectar tumores aneuploides, que tienen peor pronóstico. (43) y (49) 
Con respecto al tumor residual luego del tratamiento quirúrgico del tumor primitivo o de las metástasis, a pesar de sus deficiencias aún se utiliza la siguiente clasificación:

Figura 11: TIPO de RESECCIÓN en la CIRUGÍA de EXÉRESIS (44)

R0- Resección completa: con márgenes histológicamente negativos en las 3 dimensiones. Sin tumor residual después de la resección

R1- Resección incompleta con márgenes histopatológicamente comprometidos, con tumor microscópico remanente luego de la resección de gran parte de la enfermedad.

R2- Resección incompleta con márgenes comprometidos o gran parte de la enfermedad remanente luego de la resección. 


\section{2-G- Técnicas de Mapeo Linfático y Ganglio Centinela}

Dado el éxito observado en la aplicación del concepto de Ganglio Centinela para el tratamiento del melanoma y del cáncer de mama, su aplicación a otras neoplasias, se ha hecho extensivo especialmente a las del aparato digestivo. Sin embargo, la factibilidad y el grado de certeza en el aparato digestivo,y muy especialmente en el Cáncer Colorrectal, se encuentra en sus comienzos y es todavía un tema de controversia.

Las técnicas para la identificación del Ganglio Centinela pueden describirse según el momento en que sean efectuados, y de acuerdo al marcador biológico utilizado.(50)

1- Preoperatorio: Esta técnica se efectúa con la inyección de Sulfuro Coloidal con Tecnesio 99 y Solución Coloidal de Estaño con Tecnesio 99, 2 a 8 horas antes de la cirugía. A través del colonoscopio se efectúa una inyección submucosa del radio coloide $(0.15$ a $4 \mathrm{mCi}$ ) TC99Sn, en un volumen de 1 a 2 ml., distribuido en 4 cuadrantes. La lectura se hace durante la cirugía con una sonda para gama cámara portátil (tipo Navigator, Autosuture, Tokio, Japan), en busca de ganglios radiomarcados (50)

2- Postoperatoria: Sobre la pieza operatoria (ex-vivo), se hace una inyección submucosa peritumoral de 0,25 ml. de Isosuflan blue (Lymphazurin 1\% en solución acuosa) en los 4 cuadrantes. La inyección comienza en el cuadrante proximal, luego sigue el distal, y finalmente se inyecta a a ambos lados del tumor. Se masajea la región por un período de 
2 a 5 minutos, y luego se identifican los canales linfáticos teñidos de azul, que se siguen hasta encontrar ganglios teñidos. Todos los ganglios teñidos, se consideran ganglios centinelas y se envían para examen histopatológico. (51)

3- Intraoperatoria: Una vez identificado del tumor, se inyectan 1 a $2 \mathrm{ml}$. de Isosulfam blue (Lynphazurin) en el plano subseroso, utilizando una jeringa de insulina con una aguja calibre 25, 0,25 ml. en cada cuadrante, comenzando en el proximal. Luego se observa el mesenterio cuidadosamente a fin de identificar el egreso del colorante por los linfáticos y se los sigue hasta encontrar uno o más ganglios coloreados; los ganglios linfáticos pueden tardar de 2 a 5 minutos en colorearse. Tan pronto son visualizados, se marcan con suturas (algunos autores prefieren extirparlos y enviarlos por separado). Los primeros ganglios en captar el colorante (de 1 a 4) son considerados como ganglios centinelas. (52)

4- Intraoperatoria por vía videolaparoscópica: se marcan los tumores previamente con carbón por colonoscopía, para poder identificarlos por videolaparoscopía, y luego se procede de la misma manera que en la cirugía "abierta", inyectando el colorante y la sustancia radioisotópica en la subserosa de la periferia del tumor, sobre las marcas de carbón.(53)

\section{Análisis de los ganglios seleccionados}

Técnicas histopatológicas 
Los métodos que se usan actualemente para el examen anatomopatológico de la pieza operatoria en el cáncer colorrectal tiene numerosas fallas, tanto en lo que respecta a la identificación de los ganglios, como al estudio histopatológico de los mismos, lo cual puede producir serios errores de subestadificación. (54)

Esser, describe tres patrones de error que se producen con mayor frecuencia:

$1^{\mathrm{o}}$ - Encontrar insuficiente número de ganglios. Hay autores que sugieren tener al menos 15 ganglios estudiados, para evitar falsos negativos y obtener certeza diagnóstica (55)

$2^{\circ}$ - El insuficiente estudio histológico de cada ganglio, ya que con sólo 1 o 2 cortes por ganglio, fácilmente pueden fallar detectar metástasis.

$3^{\circ}$ - El examen histológico corriente con Hematoxilina-Eosina puede ser insuficiente para detectar micrometástasis, requiriendo la utilización de métodos mas sofisticados. Las técnicas histopatológicas recomendadas para el análisis de los ganglios centinelas incluyen:

A- Estudios seriados completos con Hematoxilina - Eosina, por lo menos con 5 niveles de cortes cada uno.

B- Análisis inmunohistoquímicos. 
C- Análisis genéticos por PCR (Polimerase Chain Reaction) o sea análisis por amplificación y detección de ADN específico para mutaciones tumorales varias.

D- Amplificación del ARN m (mensajero) para CEA (Antígeno Carcino Embrionario) o RT-PCR-CEA.(56)

\section{Focalización}

El uso del mapeo linfático con la identificación de los ganglios centinela permitiría reducir el número de ganglios a estudiar, y focalizar el esfuerzo histopatológico para aplicar estudios más complejos sólo a los ganglios identificados con ésta técnica, haciendo posible encontrar enfermedad metastásica oculta (micrometástasis).

\section{Contraindicaciones para su utilización}

1. Presencia de metástasis ganglionares evidentes.

2. Pacientes con tumores de gran tamaño que invaden el mesenterio.

\section{Resultados:}

Las razones por las cuales algunos autores han obtenido una baja incidencia de identificación de los Ganglios Centinela pueden obedecer varios motivos: 
1. Realización de una técnica inadecuada. A pesar de que no es una técnica difícil de aprender, se estima que es necesario efectuar de 10 a 15 casos para adquirir la experiencia necesaria.

2. Selección equivocada de los casos. Inclusión de pacientes con metástasis ganglionares evidentes o tumores que invaden el mesenterio, en los que hay una alta tasa de falsos negativos debido al bloqueo linfático tumoral.

3. Desconocimiento de la posibilidad de drenaje aberrante. De un 2 al 14\% de los casos los linfáticos que drenan el tumor no lo hacen en forma ordenada, afectando ganglios fuera del territorio anatómico correspondiente.

El análisis de las evidencias científicas proporcionadas por la investigación clínica, muestra que utilizando el método del Ganglio Centinela, un $14 \%$ de los casos sufrieron una "reestadificación", con migración de un estadio I-II a un estadio superior, el estadio III de la clasificación del AJCC. (57)y (58)

\section{Conclusiones:}

Los aspectos controversiales en el uso de la detección del Ganglio Centinela, incluyen:

1. Los resultados obtenidos, por ahora, carecen de impacto en el tratamiento quirúrgico a realizar, a diferencia de lo que ocurre con el Melanoma y el Cáncer de Mama, 
donde la linfadenectomía depende de su resultado, en Cáncer Colorrectal el mesenterio con el territorio linfático correspondiente debe ser siempre extirpado.

Sin embargo, el uso de la cirugía mininvasiva y del tratamiento local de las neoplasias tempranas puede fácilmente apoyarse en el concepto de Ganglio Centinela, una vez logrado un alto grado de identificación positiva y de predicción del estado de la cadena ganglionar cercano al 100\%. (60)

2. Aún existen dudas acerca del significado biológico de la presencia de micrometástasis, lo que aún no permite la inclusión de estos casos en los programas de adyuvancia.

Los aspectos positivos incluyen:

1. La simplicidad de la técnica y la posibilidad de realizarla, aunque más no sea con colorantes en casi cualquier medio hospitalario.

2. La posibilidad de mejorar la estadificación oncológica, en aquellos hospitales que tienen un porcentaje de ganglios por pieza operatoria que no alcanza los estándares necesarios (entre 10 y 15 ganglios por pieza operatoria) para una buena estadificación. Su uso podría asegurar que aquellos pacientes con ganglios positivos sean correctamente identificados.(58) (61)

El grupo oncológico del American College of Surgeons, se encuentra efectuando estudios multicéntricos de mapeo linfático en el Cáncer Colorrectal, con la finalidad de confirmar el grado de certeza de identificación del Ganglio Centinela, y la sensibilidad del mismo para predecir el estadio correctamente en pacientes con TI y TII.(59), (60),(61) 
También deberá analizarse en futuros estudios prospectivos, la sobrevida y las recidivas en los casos en que se hallen micrometástasis, lo que determinará el pronóstico y el tratamiento a realizar en esos casos.

\section{2-H- Diagnóstico de metástasis hepáticas del Cáncer Colorrectal}

\section{2-H-I- Introducción}

Debido a su ubicación en el sistema venoso portal, el hígado es el órgano en el que con mayor frecuencia se alojan metástasis del Cáncer Colorrectal (62)

El doble flujo sanguíneo que tiene el órgano y las características de su microcirculación contribuyen al implante de metástasis, ya que si los émbolos tumorales son grandes quedan alojados en las ramas finas de la vena Porta, y si son lo suficientemente pequeños como para pasar a los sinusoides, son atrapadas por las células de Kupffer, que obstruyen su paso.

Además, el endotelio de los sinusoides que es normalmente fenestrado, permite el pasaje de "colgajos celulares atípicos" a los espacios de Disse, donde quedan en íntimo contacto con los nutrientes, y con el colágeno allí presente, que les sirve de anclaje para su implante; a diferencia del endotelio normal, continuo y no fenestrado, que impide la adhesión tumoral. También debemos tener en cuenta que los sinusoides suelen estar dañados por la detención del flujo sanguíneo que provocan localmente los émbolos tumorales, lo que los hace aún más propicios para el implante. 
Varios autores han estudiado los aspectos ultra estructurales de la invasión tumoral, y hallaron diferentes patrones de invasión hepática para los diferentes tipos de células neoplásicas, aunque el implante inicial ya descrito es similar para todas ellas.(62) y (63)

Los principales factores que condicionan el modo en que las células tumorales invaden el hígado, son: 1- su tendencia a mantener la forma esférica, 2- su adhesividad entre ellas y a los hepatocitos, 3- la habilidad de las células tumorales para sobrevivir y proliferar en la corriente sanguínea por largos períodos, 4- la presión de los tejidos circundantes, 5- la formación de uniones entre las células tumorales y los hepatocitos, 6- la movilidad de las células tumorales y 7- la destrucción de tejido hepático por las enzimas elaborada por el tumor (62)

\section{2-H-II- Características anatomo-patológicas de las metástasis}

La histología de las metástasis remeda la del tumor primitivo, y con frecuencia muestran el mismo grado de vascularización que aquél. La mayoría son hipovasculares, pero las metástasis de tumores carcinoides, leiomiosarcomas, carcinomas renales, y tumores neuroendocrinos son claramente hipervascularizadas. (62), (64)

Sin embargo, el flujo sanguíneo de las metástasis es siempre mayor que el del parénquima normal en que asientan, y sólo en las metástasis muy grandes puede haber isquemia y hasta necrosis central de la lesión, debido a su rápido crecimiento.

El patrón de vascularización de las metástasis hepáticas tiene un considerable valor clínico, ya que la utilidad de numerosos métodos diagnósticos y terapéuticos dependen precisamente del grado de su neo-vascularización, y del tipo y origen de su flujo sanguíneo. 
$(64),(65)$ y (66)

\section{2-H-III Diagnóstico:}

\section{a- $\quad$ Ecotomografía (ECT)}

Detecta con facilidad masas intrahepáticas, pero la apariencia ecográfica de las metástasis no es específica y es necesario confirmarlas mediante una biopsia dirigida por ecotomografía. La punción debe evitarse en caso de duda que la lesión sea un hemangioma, o bien si las características de la misma hicieran presumir que se tratase de una metástasis rescable con intención curativa La ecotomografía además permite, ante la detección de la imagen de una lesión con forma de "coliflor", probable metástasis hepática de cáncer colorrrectal, buscar la masa intrabdominal en el marco colónico correspondiente al tumor primitivo, confirmando de ese modo el hallazgo intrahepático.(67)

La ecogenicidad de la lesión depende de la vascularización del tumor, de la composición tisular del mismo, de la presencia o ausencia de necrosis, hemorragia o infección en su interior.

Las metástasis isoecoicas son las más difíciles de detectar, y se las sospecha por la presencia de signos indirectos como compresiones de los vasos intrahepáticos, la aparición de linfopatías hiliares o la presencia de ascitis libre en el abdomen. En cambio, las metástasis hiperecoicas o ecogénicas son lesiones hipervascularizadas, en las cuales los ecos dependen de las interfases provocadas por la sangre, más que por las paredes de los vasos que la contienen, tal es el caso de las metástasis del cáncer colorrectal. Las metástasis hipoecoicas son generalmente hipovascularizadas y de un tejido más uniforme, como ocurre 
habitualmente con las metástasis de linfoma, melanoma y carcinoma de páncreas o pulmón, entre otros. (67)

En ocasiones se observan imágenes de forma muy definida, como ocurre con las lesiones "en ojo de buey", que muestran un halo producido por la compresión del parénquima hepático normal alrededor de la zona tumoral proliferativa. Esta forma sugiere un comportamiento agresivo del tumor y aparece regularmente en las metástasis del carcinoma broncogénico, aunque puede ser encontrada en metástasis de otros tipos de tumores, como el cáncer de colon o los tumores primitivos del hígado. (67)

\section{Técnicas especiales de ecotomografías}

\section{i- Doppler}

Se han hecho intentos de utilizar Doppler doble y color, con la finalidad de definir los patrones arteriales de flujo sanguíneo alrededor de las lesiones hepáticas, pero los resultados no han sido satisfactorios en cuanto a la especificidad del método. Actualmente hay experiencias con contrastes ecogénicos a base de microburbujas. (68)

\section{ii- $\quad$ Ecografía intraabdominal por laparoscopía:}

Desde los años '70 la ecotomografía se ha usado en cirugía hepática y específicamente de las metástasis hepáticas, utilizando los transductores convencionales para estudios percutáneos cubiertos con aislantes estériles de polivinilo.

Sin embargo, su uso laparoscópico es el gran avance para la detección de metástasis hepáticas en portadores de tumores primitivos colorrectales y la determinación de sus características y relaciones, sobre todo en pacientes pasibles de ser tratados con resecciones quirúrgicas. Se utiliza un transductor de alta frecuencia miniaturizado para su inserción en 
el abdomen a través de los trócares laparoscópicos y un equipo que permita generar imágenes de flujo en Doppler color, con los que se recorre toda la superficie libre del hígado. Con ésta técnica diversos autores han detectado un 25 a 30\% más de metástasis, sobre el total de lesiones detectadas por ecografía preoperatoria, y lo que es aún más importante, un 40\% de esas lesiones no se veían en la superficie de la glándula ni se palpaban manualmente durante la laparotomía. (69), (70)

Se trata de una técnica versátil que permite también realizar otros tratamientos alternativos a la resección, como la ablación por radiofrecuencia. Bajo visión laparoscópica se colocan las “agujas” guiadas ecográficamente con precisión sobre las lesiones. (67)

\section{b- Tomografía axial computarizada (TAC)}

Es el método de elección para la detección de metástasis hepáticas, debido a que el doble flujo hepático condiciona una respuesta diferente a la inyección de contraste de las metástasis con respecto al parénquima normal. Para evitar errores, la TAC debe ser obtenida no más de un mes antes de la operación. El advenimiento reciente de la TAC helicoidal, y más recientemente la TAC multisección han revolucionado el uso del método para esa finalidad y han hecho mucho más cortos los estudios. La tomografía axial computarizada de secciones múltiples (“multisección”), utiliza detectores múltiples (MDCT -Multidetector row $\mathrm{CT}$ ) que permiten adquirir 64 cortes superpuestos de $0,6 \mathrm{~mm}$ por cada rotación, en lugar de los 16 cortes que adquieren los aparatos corrientes en la actualidad, con lo que mejora sustancialmente la definición de sus imágenes, tanto en las reconstrucciones tridimensionales como en las de planos múltiples. Sin embargo, la sensibilidad no varía sólo por el 
método de exploración utilizado, pues también difiere de acuerdo con el tipo de lesión primaria y el grado de vascularización de las metástasis. (71), (72)

La mayoría de las metástasis son hipovascularizadas, poco atenuantes de los rayos X ("hipo-atenuantes") en comparación con el parénquima circundante, lo que permitiría verlas en estudios de TAC no contrastada cuando tienen tamaño suficiente, cuando están calcificadas o cuando tienen hemorragias en su interior. Mientras que los estudios con TAC contrastada, al intensificar la respuesta de la metástasis, las diferencian del hígado normal, y además permiten detectar imágenes más pequeñas que hubieran permanecido ocultas sin contraste. (67)

La sensibilidad de ésta técnica depende de la dinámica temporal con que se realiza, siendo preferible la técnica dinámica de doble fase; una fase venosa portal y otra fase arterial, la cual sólo se puede lograr utilizando TAC helicoidal o multisección.

La fase venosa portal, con la que logran las mejores imágenes, se obtiene adquiriendo las imágenes 60 segundos después de inyectar el contraste. Durante esta fase, la capacidad de atenuación de los rayos $\mathrm{X}$ del parénquima hepático normal aumenta, lo que revela una relativa "hipo-atenuancia" de las metástasis, que algunas veces se acompaña de una vaga intensificación de su periferia, que se corresponde con la zona más activa del tumor. En la fase arterial, con imágenes tomadas entre 20 y 30 segundos después de inyectar el contraste, las metástasis se muestran homogéneamente "hiper-atenuantes" comparadas con el hígado circundante, y en algunos casos muestran un halo periférico "hipo-atenuante". La importancia de hacer ambas fases reside en que muchas de las metástasis puestas en evidencia en la Fase Arterial, aparecían como"iso-atenuantes" en la Fase Venosa Portal. (67) y 


\section{Otras técnicas de TAC}

i- TAC demorada intensificada con alta dosis de contraste: Es una técnica poco usada, que tiene indicación sólo con la finalidad de "aclarar" imágenes dudosas obtenidas con la TAC Doble Fase. Dicho estudio previo ha determinado la anatomía normal de la vascularización hepática, y 4 a 6 horas más tarde se toma otra TAC, aprovechando que el contraste iodado se concentra en el hepatocito normal y no lo hace en las lesiones focales. (67),(73)

ii- Arteriografía por TAC: Es una técnica útil para definir la extensión necesaria de futuras resecciones hepáticas cuando no se ha logrado la información por TAC con contraste endovenoso, evidencia mejor las lesiones "hiper-atenuantes". Para lograrla, colocamos en forma percutánea (vía femoral) un catéter en la Arteria Hepática e inyectamos contraste mientras realizamos una TAC helicoidal. (67), (73)

iii- Arterioportografía por TAC: Su utilidad es similar a la de la arteriografía por TAC, pero evidencia mejor las lesiones "hipo-atenuantes". Se hace colocando un catéter percutáneo en la Arteria Mesentérica Superior o en la Arteria Esplénica (67), (73) 
La sensibilidad de la TAC helicoidal con contraste intravenoso en la detección de metástasis hepáticas es de aproximadamente un 80 a 90\%, y su especificidad aún mayor para lesiones mayores de $7 \mathrm{~mm}$. La arteriografía y la arterioportografía por TAC son más sensibles que la anterior en lesiones más pequeñas. (67)

Los estudios de TAC puede tener falsos positivos, y existen situaciones que lo favorecen, como en el caso de la presencia de hemangiomas, que pueden mostrarse como lesiones hipo-atenuantes simulando metástasis muy vascularizadas en la TAC sin contraste, pero cuando se les administra contraste, se diferencian porque tardan más en llenarse que las metástasis, si bien también suelen presentar el halo periférico. En los hígados grasos, puede producirse un enmascaramiento de las metástasis por el estado del resto del parénquima (falso negativo), tanto como la confusión de una infiltración grasa focal con metástasis (falso positivo). (66), (67)

\section{c- $\quad$ Resonancia magnética $(\mathrm{RM})$}

Cuando se coloca un tejido dentro de un fuerte campo magnético, algunos de los isótopos naturales (átomos) que lo componen se "alinean" con dicho campo, orientándose en dirección longitudinal (aunque, para ser precisos, no se alinean exactamente con el eje del mismo y se bambolean un poco fuera de él). Éste fenómeno ocurre con muchos isótopos presentes en los tejidos, pero la RM usa las señales producidas por el hidrógeno $(\mathrm{H})$, el isótopo endógeno más potente. Ante la aplicación transitoria de un pulso de radiofrecuencia perpendicular al eje del campo magnético, se reorienta la magnetización del tejido con el plano transverso, incrementando de esa forma el nivel de energía en el tejido. Una vez que el pulso de radiofrecuencia cesa, la magnetización del tejido vuelve a su estado previo (eje 
longitudinal), resultando en una señal de "resonancia magnética" que puede ser recibida por detectores adecuados, resultando en una imagen clara del tejido estudiado. La observación de la secuencia conocida como T1, T2, protón (densidad) y eco, mejoran la utilidad de la RM. (67), (74)

Sus ventajas son: - la ausencia de radiación ionizante, - exquisita sensibilidad al flujo sanguíneo, - produce imágenes en planos de cualquier orientación, - sensibilidad a la acumulación de hierro en los tejidos, y - buena visualización de tejidos blandos.

La resonancia magnética raramente es utilizada como un estudio primario para realizar el diagnóstico en el Cáncer Colorrectal, pero en cambio se la usa para resolver problemas diagnósticos no aclarados por la tomografía axial computarizada, la ecotomografía u otros estudios, o en caso que dichos estudios estén contraindicados. (76), (75)

Las mayores limitaciones del método son: los artificios producidos por el movimiento respiratorio, cardíaco, vascular e intestinal, y el costo elevado del procedimiento. $(67)$

El uso de gadolinio unido al ácido dietilen-triamino-penta-acético (gadolinioDTPA) como contraste por inyección endovenosa altera la susceptibilidad magnética de los tejidos, proveyendo valiosa información de ellos, lo que se traduce en imágenes, que ponen en evidencia sus alteraciones (por ejemplo: tejidos neoplásicos dentro de una víscera homogénea) (67) y (74)

En la resonancia magnética la mayoría de las metástasis hepáticas son "hipointensas" en T1, e "hiper-intensas" en T2. En T2 las imágenes de lesiones benignas, como el hemangioma o los quistes hepáticos, pueden diferenciarse de las producidas por metástasis, porque las benignas provocan una intensidad más alta de resonancia magnética. En 
cuanto a la morfología de las imágenes de las metástasis en T2, se ve una heterogenicidad de la intensidad de la señal, con márgenes externos irregulares y poco distinguibles, y con un área central de alta intensidad rodeada por un anillo periférico de más baja densidad que el centro, pero más alta que el resto del hígado adyacente.

La resonancia magnética puede mejorar su sensibilidad con la utilización de medios de contraste. La RM Dinámica intensificada con gadolinio-DTPA mejora mucho la detección de masas intrahepáticas, y también permite la diferenciación entre lesiones benignas y malignas, ya que éstas últimas se muestran heterogéneas y ocasionalmente tienen zonas centrales que no intensifican debido a la necrosis tumoral. Las metástasis hipervascularizadas intensifican más que el resto del hígado en la Fase Arterial del estudio dinámico, mientras que las hipovascularizadas producen el fenómeno inverso. (67)

El gadolinio como contraste extracelular, logra imágenes hepáticas por un tiempo muy corto, si necesitamos lograr tiempos más largos debemos usar compuestos como el bencilopropionictetraacetato de Gadolinio (Gd-BOPTA), desarrollado como un contraste extracelular hepatobiliar para Resonancia Magnética con la finalidad de producir una más selectiva intensificación hepática por un tiempo más prolongado; o el manganeso dipiridoxal difosfato (Mn-DPDP), que produce una intensificación hepática 5 veces mayor que el Gadolinio, logrando un pico a los 30 minutos de haber inyectado el contraste.

También se usa el óxido de hierro, en forme de: partículas de óxido de hierro superparamagnéticas (SPIOs), y partículas de óxido de hierro superparamagnéticas ultrapequeñas (USPIOs) que disminuyen la intensidad de la señal del hígado normal por acortamiento del T2. Por ese motivo, en la captación de imágenes retardadas a los 60 minutos nos muestra la "actividad fagocítica" del hígado normal, pero como las metástasis no tienen células de Kaupffer, no captan las partículas de hierro y se ponen así en evidencia pues siguen con "brillo" intenso. 
La sensibilidad del estudio con Mn-DPDP para diferenciar metástasis de otras lesiones hepáticas fue del 90\% en estudios controlados, con una especificidad del 92\%. Las imágenes obtenidas con SPIO y USPIO, permitieron detectar lesiones no intensificadas (metástasis) más pequeñas, de hasta $3 \mathrm{~mm}$ de diámetro mínimo. (el Gadolinio sólo permite detectar lesiones de hasta $10 \mathrm{~mm}) .(67)$

En la actualidad se ha desarrollado la resonancia nuclear magnética de alta resolución (HRMRI - High-Resolution Magnetic Resonance Imaging), que utiliza la recepción a través de 24 canales independientes, que "adquieren" la resonancia magnética en paralelo, para mejorar la "nitidez" de las imágenes obtenidas, (74)

\section{d- Imágenes Radionucleares}

Son técnicas que usan compuestos biológicos radiactivos (trazadores radio-ligados) para describir los procesos biológicos en que participan, y de ese modo poner en evidencia ciertas entidades patológicas.

\section{i- La tomografía por emisión de positrones con fluoro-deoxi-glucosa (FDG-PET) re-} quiere la inyección intravenosa del trazador marcado con un isótopo emisor de positrones hacia el tejido circundante, durante el tiempo de declinación radiactiva. Debido a que los positrones son los equivalentes en la antimateria de los electrones, la colisión de un electrón con un positrón aniquila ambas partículas, convirtiendo sus masas en energía en forma de dos protones, emisores de rayos gamma, que abandonan los tejidos en un ángulo de $180^{\circ}$ entre ambos, y ésta energía puede ser detectada . El trazador más frecuente usado es la fluoro-deoxi-glucosa, para medir las modificaciones del metabolismo 
glúcido en los tejidos observados. El fenómeno es muy útil para diferenciar tejidos neoplásicos de otros que no lo son, ya que los tejidos neoplásicos malignos tienen un metabolismo de la glucosa mucho más elevado que el de llos tejidos hepáticos normales circundantes. (67), (77)

La mayor limitación del método consiste en su alto costo, debido a la necesidad de contar con un ciclotrón para producir los trazadores; y que la resolución de ellos es muy restringida espacial y temporalmente. Es por ello que el PET, hasta tanto se abaraten sus costos, se usa sólo en los casos en que otros métodos por imágenes dejen dudas, a pesar de su alta sensibilidad. En un estudio reciente. Johnson y cols. hallaron que su sensibilidad fue del 100\% para detectar metástasis hepáticas, contra el 69\% que obtuvieron con la TAC en el mismo grupo de pacientes; y de un 90\% para la detección de enfermedad extrahepática, para la cual la sensibilidad de la TAC sólo fue del 52\%. En ambos casos la especifidad de los dos métodos fue similar. (77)

Debido a su escasa definición anatómica, en ocasiones su uso se combina con una TAC helicoidal dinámica, con lo que se obtiene aún más información. (78), (79), (80)

ii- Tomografía computarizada por emisión de un único fotón (SPECT): el fenómeno producido es similar al observado en la Tomografía por Emisión de Positrones, pero la diferencia reside en que en la SPECT el trazador emite sólo un fotón único (SinglePhoton-Emission.Computed Tomography). Básicamente se utilizan trazadores para medir flujos como el Xenon-133 y el Tecnesio 99 m-hexametil-propanilamina-oxime. Casi no se usa para detectar metástasis hepáticas del cáncer colorrectal. (67) 


\section{2-I- Tratamiento del Cáncer Colorrectal:}

\section{2-I- i Introducción}

El tratamiento con intención curativa del cáncer colorrectal sólo se logra mediante la resección quirúrgica total de la lesión. La terapia con radiaciones y la quimioterapia no han demostrado ser eficaces para la curación, aunque la combinación de ambas ha permitido mejorar los resultados de la cirugía. (81), (82), (83)

Los tratamientos complementarios pueden usarse como: adyuvancia, en el postoperatorio de resecciones $\mathrm{R} 0$, con la finalidad de completar el tratamiento realizado con la cirugía y para limitar las recidivas locales, o bien como neoadyuvancia, en el preoperatorio, con la finalidad de disminuir la masa tumoral para facilitar o hacer posible la resección ulterior, o para limitar las recidivas locales postoperatorias como ocurre en algunos estadios del cáncer rectal. También pueden utilizarse como tratamiento paliativo, en tumores más avanzados o irresecables. (81), (82)

\section{1- Radioterapia}

Su objetivo es prevenir la diseminación neoplásica local y regional, y así limitar la aparición de recidivas y/o metástasis a distancia. En el Cáncer Colorrectal está indicada en el post-operatorio de aquellos tumores que infiltran la serosa del órgano, o más allá de la 
misma con invasión de órganos vecinos. En esos casos se efectúa radioterapia sobre la zona, para lo que habituamente se usa una dosis de $5.000 \mathrm{cGg} .$.

\section{1-a- Neoadyuvancia:}

Existen evidencias científicas producidas por autores suecos y estadounidenses, que han tenido éxito para controlar la enfermedad en la pelvis y para conservar los esfínteres con neoadyuvancia simultánea con quimio y radioterapia en tumores avanzados del recto bajo (Estadio III), sobre todo en aquellos muy próximos o invasores del esfínter, que obligarían a realizar una resección abdominoperineal que sacrifique el aparato esfinteriano (84) y (85). Se debe considerar cada caso en particular, y si la respuesta es satisfactoria, evaluar siempre la posibilidad de conservar el esfínter anal.

\section{1-b- Adyuvancia:}

En nuestro medio generalmente se la indica como tratamiento complementario en los tumores de recto:

1- resecados con intención curativa, que invaden o sobrepasan la capa muscular del recto y/o más allá de la misma (Estadio II), y se la combina con quimioterapia en aquellos tumores que además presentan adenopatías metastásicas (Estadio III)

2- en los tumores no resecables, en forma paliativa, para disminuír el tamaño tumoral

3- como procedimiento hemostático en los tumores que ocasionan hemorragias en forma de radioterapia paliativa exclusiva. 
Con la técnica más habitual, en tumores resecados con intención curativa, se irradia la pelvis anterior y posterior $(4.500 \mathrm{cGg})$ en 3 ó 4 campos (posterior, laterales con o sin campo anterior). Eventualmente se les agrega una "sobredosis" en campos reducidos de 1000 a $1.500 \mathrm{cGg}$, si estuviera indicado.

En los tumores tempranos, menores de $3 \mathrm{~cm}$, ubicados a menos de $10 \mathrm{~cm}$ del margen anal el tratamiento indicado varía, de acuerdo con el estadio T del tumor: (81)

T1- Resección local

T2- Resección local + radioterapia post-operatoria

T3- Resección local + radioterapia + quimioterapia post-operatorias.

En tumores avanzados, irresecables (T4 N0/N1) con invasión de la vejiga y/o uréteres y/o vesículas seminales, etc.; se aplica radioterapia $5.000 \mathrm{cCg}$ en fraccionamiento convencional con o sin boost, más quimioterapia (5FU y Platino ó 5FU y Mitomicina C (81), $(82)$

\section{2- Quimioterapia}

\section{2-a- Adyuvancia:}

Tiene indicación en los tumores de colon en estadios C de la clasificación de Dukes modificada (AJCC: E III) y en los tumores de recto estadios de Dukes B y C (AJCC: E II con T3/4 y E III ). 
El esquema clásico consiste en la administración endovenosa de 5-Fluorouracilo (5 FU) y Leucovorina en los días 1 a 5 desde el comienzo del tratamiento, repitiendo 6 ciclos de 28 días.

Actualmente para pacientes sin tratamiento quimioterápico previo, se prefiere administrar una asociación de 3 drogas: Oxalilplatino + Fluorouracilo (5FU)+ Leucovorina, pues en varios estudios randomizados estos esquemas han probado ser más eficaces que la asociación de 5FU y leucovorina solas, tanto en términos del número de respuestas, como en calidad de vida (81), (82), (83)

En el caso de los tumores de recto situados por debajo de la plica peritoneal el tratamiento adyuvante consiste siempre en asociar al esquema propuesto de quimioterapia, la radioterapia, que se aplica en forma simultánea. Las dosis de la quimioterapia pueden ser reducidas en caso de toxicidad. (82), (83)

El tratamiento de la enfermedad rectal avanzada, consistirá en la asociación de 2 ó 3 drogas, y el mismo se determina de acuerdo a si tuvo o no tratamiento adyuvante previo. Si lo hubiera tenido y el período libre de enfermedad fuera mayor de 1 año, a los ciclos con la asociación más conocida de 5FU y Leucovorina, se le puede agregar el Irinotecan en forma semanal o cada 21 días, o el Oxalilplatino en forma quincenal o cada 21 días Las asociaciones más utilizadas para éste propósito son: (82)

- Oxalilplatino día 1 + 5 FU + Leucovorina Cálcica día 1 a 5 cada 28 días.

- Oxalilplatino + Fluorouracilo + Leucovorina Ca día 8, 15, 21 cada 21 días.

- Irinotecan día 1, 8, 15, 21 + 5FU día 1, 8, 15, 21 + Leucovorina día 1, 8, 15, 21 cada 6 semanas 


\section{3- Cirugía}

\section{Consideraciones generales}

Los pacientes portadores de Cáncer Colorrectal pueden ser operables o inoperables, y a su vez los pacientes operables pueden presentar tumores resecables o irresecables de acuerdo con la extensión local, regional o a distancia, y finalmente los tumores resecables pueden serlo con intención curativa o paliativa. (81)

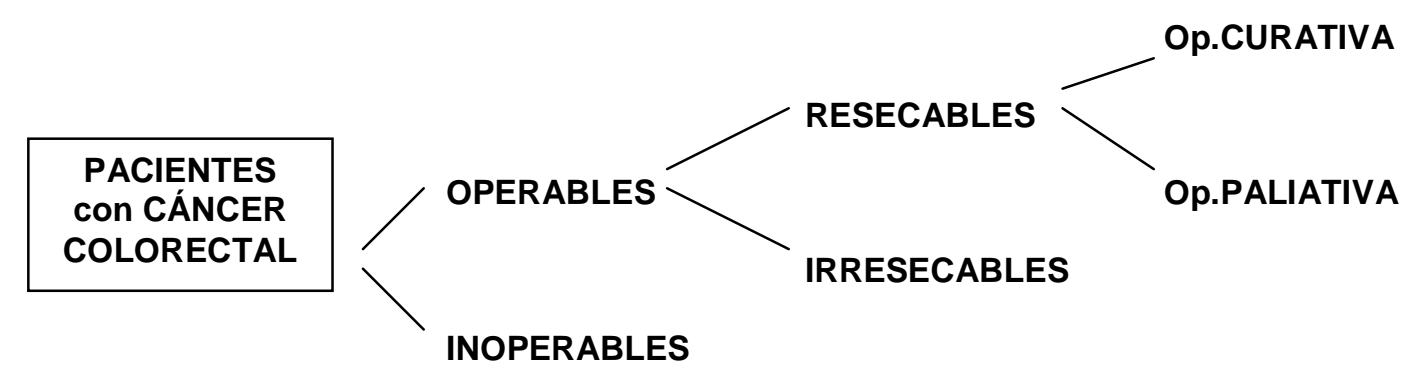

Cuando la exéresis se realiza con intención curativa su objetivo es lograr, con márgenes oncológicos de seguridad, la exéresis del tumor y su territorio linfático correspondiente. Cuando se lo hace con intención paliativa, la resección no incluye linfadenectomía.

El tratamiento paliativo no se propone prolongar el tiempo de sobrevida, pero sí mejorar su calidad. Se realiza para prevenir y/o tratar la oclusión, el dolor y/o la hemorragia. El mejor tratamiento paliativo, en cualquier caso, es la resección del tumor. 
Condiciones de inoperabilidad del paciente: (81)

- Metástasis pulmonares con gran disminución de la capacidad respiratoria.

- Carcinomatosis peritoneal diagnosticada en el preoperatorio (TAC, videolap)

- Ascitis (traducción clínica de carcinomatosis peritoneal).

- Insuficiencia funcional orgánica y/o metabólica no corregibles con tratamiento.

Condiciones de irresecabilidad del tumor(81)

- Carcinomatosis peritoneal no diagnosticada en el preoperatorio

- Fijación por adherencias neoplásicas firmes a estómago, duodeno, páncreas, riñones, vías urinarias y/o retroperitoneo (siempre que la exéresis en block no resulte factible).

- Fijación por adherencias neoplásicas firmes a tejidos retroperitoneales, a órganos pelvianos y/o elementos óseos de la pelvis (pelvis congelada).

- Presencia de metástasis hepáticas múltiples o muy voluminosas, cuando su tratamiento condicione la exéresis de los 2/3 o más del parénquima hepático, ya que estos casos la expectativa de vida no supera unos pocos meses. 
En los tumores colorrectales la táctica quirúrgica empleada se adecua a las caraterísticas y a la localización del tumor primario y sus eventuales diseminaciones, como asimismo a la condición de cirugía electiva o de urgencia de la operación a realizar.(90)

La cirugía de urgencia del colon se indica con frecuencia por la obstrucción del mismo, y menos frecuentemente por hemorragia o perforación de la víscera. El calibre del recto, condiciona que la causa mencionada en primer término sea excepcional, y predominen las operaciones de urgencia debidas a hemorragias. (91)

Aunque se prefiere no hacer ostomas derivativos, las operaciones efectuadas para tratamiento de tumores que asientan en el colon izquierdo o el recto, en ciertas circunstancias de falta de preparación colónica o mal estado de la víscera a anastomosar pueden requerir la derivación digestiva mediante la confección de ileostomía o colostomía de descarga, aún en condiciones de cirugía electiva.

La preparación para la cirugía electiva incluye dietas sin residuos, limpieza mecánica del colon, y la prescripción de Neomicina y Metronidazol vía oral 5 días previos al acto quirúrgico, y por vía intravenosa durante la inducción anestésica y durante las primeros 48 hs del post-operatorio.(92)

Las técnicas de limpieza mecánica del colon han ido cambiando en los últimos tiempos, y en nuestro medio se prefiere la forma ambulatoria en pacientes sin comorbilidades y menores de 65 años, por lo que los internamos el mismo día de la cirugía. La preparación consiste en (86) 


\section{Día 1}

- Neomicina: 0,50 g. 2 comp. cada 6 horas.

- Metronidazol: 1 cápsula cada 8 horas.

- Dieta: evitar frutas, verduras y lácteos. Pueden ingerirse carnes blancas o rojas condimentadas,

- Gelatina, jalea de membrillo y líquidos claros (agua mineral sin gas, caldos colados, jugos colados y mate, té o café azucarados).

\section{Día 2}

- Neomicina, Metronidazol y dieta igual que en el día 1.

- 17,00 hs.: diluir 1 frasco de $45 \mathrm{ml}$ de fosfato disódico (18 g) y monosódico (48 g) en 1/2 vaso de agua fría. A continuación, ingerir otros 2 vasos de agua fría.

- 22,00 hs.: diluir 1 frasco de $45 \mathrm{ml}$ de fosfato disódico (18 g) y monosódico (48 g) en 1/2 vaso de agua fría. A continuación ingerir otros 2 vasos de agua fría.

- Controlar hasta que aparezca diarrea "clara", si así no ocurriera, repetir la dosis

\section{Día operatorio}

- Ayuno completo desde 8hs antes de la Cirugía (no ingerir ni agua). 
- En Quirófano: Metronidazol 500 mg (EV lento) + Gentamicina 80 mg (EV) antes de la inducción anestésica y otra dosis cada 2 hs de cirugía.

- Postoperatorio: Metronidazol 500 mg (EV lento) + Gentamicina 80 mg (EV) cada 8 hs si no hay alteración de la función renal (en caso contrario, dosificar según Creatinina) (83), (86)

\section{2-I- ii Guía para el tratamiento del Cáncer Colorrectal}

\section{1- Adenocarcinoma del Colon}

Estadio 0 : a- Si el tumor ha sido Completamente resecado con la biopsia (Tis,N0M0) endoscópica, sólo debe hacerse el seguimiento mediante una Fibrocolonoscopía de todo el colon (ETC) a los 6 meses (82)

b- Si en cambio quedó Tumor residual, se practicará una polipectomía endoscópica con disección hidráulica de la mucosa por inyección submucosa de suero, para elevar la lesión residual y permitir su resección con el asa de termocauterio. Si su estudio histopatológico demuestra un tumor muy anaplásico, o si tenemos la posibilidad de hacer citometría de flujo de la pieza tumoral fresca y el resultado nos muestra que es aneuploide, se aconseja ampliar el tratamiento quirúrgico a una resección segmentaria del colon, que incluya todo el meso correspondiente al territorio de drenaje linfático del tumor. (82) 
Estadio I: a- Cuando se trate de un tumor T1, N0, M0 resecado endoscópicamente (T1-2,N0,M0) con márgenes libres (siempre que el adenocarcinoma esté a más de $3 \mathrm{~mm}$ del borde de sección) y su diferenciación sea del tipo GI o GII, sólo se le hará seguimiento con ETC a los 3 meses.(82)

b-Si en cambio, se taratase de un T1, N0, M0 resecado endoscópicamente con margenes invadidos (tumor residual), y/o una muestra fragmentada, y/o diferenciación del tipo GIII o GIV, y/o se trata de un T2, N0, M0, se debe preferir realizar una resección segmentaria del colon, que incluya todo el meso correspondiente al territorio de drenaje linfático del tumor.(81)

Estadio II : 1- Se trata con una resección segmentaria del colon, que incluya todo el (T3-4, N0, M0) meso correspondiente al territorio de drenaje linfático del tumor.(en colon derecho se practica la hemicolectomía derecha).(81), (82), (83)

2- En cuanto a la adyuvancia, hay evidencias que sugieren no hacer terapias complementarias en los tumores en estadio II. Sin embargo, se haría una excepción con aquellos tumores (T4) adheridos a órganos vecinos, perforados u obstruídos, y con aquellos que resulten histológicamente muy indiferenciados o que sean aneuploides. El tratamiento preferido en la actualidad, para aquellos casos en que se decide hacer tratamiento adyuvante, consiste en la administración de Oxalilplatino el día 1 de cada ciclo, y 5-Fluorouracilo más Leucovorina Cálcica diariamente, durante los días 1 a 5 de cada ciclo que dura 28 días. (82), (83) 
Estadio III : 1- Su tratamiento es la resección colónica segmentaria con exéresis total (T1-4, N1-2, M0) del meso correspondiente al territorio de drenaje linfático del tumor. La disección debe realizar la ligadura precoz de los vasos, para luego recién realizar el decolamiento colónico, con lo que se impide la migración de células neoplásicas por vía venosa. En el tratamiento del Cáncer de Colon, el diagnóstico de invasión de los ganglios linfáticos regionales (estadio III), en la mayoría de los casos se hace durante la cirugía, y en no pocas ocasiones lo hace el patólogo en el estudio macroscópico de la pieza operatoria. (84),(85)

\section{(ver Fotos 1 y 2$)$}

Cuando contemos con los medios necesarios, podremos realizar una Cirugía Radioinmunoguiada. Para lo cual, se inyectan compuestos radioactivos (generalmente se usa Tecnesio-99 (TC99) en Sulfuro coloidal o Estaño coloidal) en la pared del colon en cercanías del tumor primitivo, para luego rastrear los tejidos correspondientes al drenaje linfático regional mediante un sensor de radiactividad estéril (Probe), conectado a un contador de radiactividad, que para hacer más fácil la maniobra, emite una señal sonora ante el aumento de la captación, lo que va guiando nuestra búsqueda . De ese modo se detectan los ganglios regionales "hipercaptantes" y con su exéresis, se logra una resección más completa de ganglios microscópicamente invadidos por el tumor.(57), (58)

2- Adyuvancia: Luego de la estabilización de las heridas operatorias, aproximadamente un mes o dos después de la operación, se comienza el tra- 
tamiento con agentes citostáticos, que generalmente consta de seis ciclos de: Oxalilplatino el día 1 de cada ciclo, y 5-Fluorouracilo más Leucovorina Cálcica durante los días 1 a 5 de cada ciclo de 28 días de duración.(82)

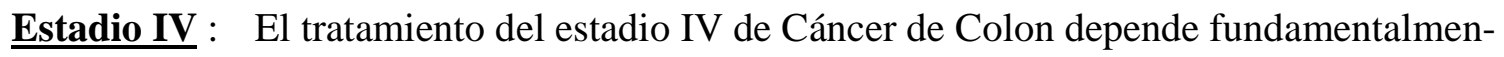
(T1-4, N1-2, M1) te del tipo de metástasis a distancia y de las posibilidades de tratamiento que ellas tengan.

a- Las Metástasis hepáticas resecables son las que luego de ser resecadas completamente, nos permiten conservar más del $25 \%$ del parénquima (volúmen mínimo capaz de mantener la función en un hígado previamente sano) y no se acompañan de metástasis extra-hepáticas (carcinomatosis peritoenal, metastasis pulmonares, en hueso, etc). ()Generalmente asientan en pacientes con buen estado general, capaces de soportar una operación muy agresiva. Su tamaño y localización intrahepática nos permiten inferir si serán resecadas completamente sin dejar metástasis "macroscópica". Para evaluar la factibilidad de intentar el tratamiento quirúrgico, evaluamos los parámetros de función hepática clínicos y de laboratorio que sugiriera Child (bilirrubina, albúmina, ascitis, encefalopatía, nutrición y concentración de protrombina), y sólo si fueran aceptables procedemos a la resección de todas las metástasis o metastasectomías. A pesar de ser la mejor terapia disponible para la obtención de buenos resultados, la resección de las metástasis hepáticas del CCR sólo es posible aproximadamente un $20 \%$ de los portadores, por ese motivo W.Jarnagin del Memorial Sloan-Kettering Cancer Center de Nueva 
York, genero una categorización predictiva de la potencial resectividad de las metástasis hepáticas, tomando en consideración el número de metástasis y su ubicación en un solo lóbulo del hígado o en ambos, de acuerdo con los resultados de una investigación clínica que hicieron en 416 pacientes portadores de metástasis hepáticas, sobre los cuales practicaron una análisis de regresión logística multivariable con la finalidad de determinar el "peso relativo" de cada parámetro en los resultados. En el estudio, fueron resecados el 95\% de los casos con "score 0" y sólo 62\% con score 3 .

Tabla 2: Categorización Predictiva de Resecabilidad (88)

\begin{tabular}{|c|c|}
\hline № METÁSTASIS & PUNTAJE \\
\hline 1 & $\mathbf{0}$ \\
\hline 2 & $\mathbf{1}$ \\
\hline$>2$ & $\mathbf{2}$ \\
\hline EXTENSIÓN & \\
\hline Unilobar & $\mathbf{0}$ \\
\hline Bilobar & $\mathbf{1}$ \\
\hline
\end{tabular}

Tomado de Jarnagin W et al. J 1999

Al resecarlas, es necesario dejar un margen de seguridad sano de $1 \mathrm{~cm}$ alrededor de cada una de ellas, para lo cual es conveniente usar ecografía intraoperatoria, que nos permite ver en tiempo real imágenes de metástasis más pequeñas y localizar dentro del parénquima los elementos vasculobiliares para evitar su lesión. Y para seccionar el parénquima, 
la utilización del disector ultrasónico (Cavitron Ultrasonic Surgical Aspirator: CUSA) nos permite realizar una disección segura, ya que "elimina" el tejido hepático y va "esqueletizando" los vasos y los conductos biliares, lo que permite una fácil individualización para ser ligados. (89), (90),(91)

En los casos en que existieran varias metástasis vecinas, es más conveniente realizar resecciones hepáticas regladas (lobectomía, sectorectomía, segmentectomía) que las eliminen a todas, ya que se evitan complicaciones postoperatorias (hemorragias), y disminuye la frecuencia de las recidivas. (91)

En cuanto a la morbilidad por hepatectomías, los pacientes con ASA 3 y 4 , como único predictor independiente y las resecciones hepáticas realizadas en hígados patológicos, fueron las que se asociaron al riesgo de desarrollar complicaciones y/o muerte.(91), (92)

Hoy, gracias a los avances del "ultrasonido", ha quedado en desuso el límite de 3 o a lo sumo 4 metástasis como máximo para ser resecables, o el impedimento de la cercanía con los vasos o conductos importantes; ya que en manos de cirujanos entrenados y contando con la ecografía intraoperatoria y el CUSA, son candidatos a técnicas puramente resectivas, o combinadas con métodos de ablación local: crioablación o aplicación de radiofrecuencia con agujas insertas en su seno.(93),(94)

La contraindicación actual para la resección hepática en las metástasis del CCR está determinada únicamente por la conservación de la función de la glándula, por la existencia de metástasis extra-hepáticas y por el es- 
tado general del paciente. La resección completa de todas las metástasis hepáticas en centros especializados, eleva la sobrevida a los 5 años, de un $3 \%$ observado en pacientes no resecados, al 30 a $40 \%$. En esos centros, la mortalidad no llega al 5\%, y la morbilidad tratables ocurre en menos del $30 \%$ de los pacientes, (95),(96),(97) (ver Fotos 3 y 4)

b- Se consideran Metástasis hepáticas no resecables, las que no puedan serlo“completamente", dejando al hígado sin enfermedad residual macroscópica, ya sea porque: - tienen gran volumen, o - una localización en íntima relación con los vasos y conductos biliares troncales (por ejemplo las localizadas en segmento III ), o - porque son multinodulares. (92) Como tratamiento complementario, las evidencias científicas disponibles, nos autorizan a utilizar neoadyuvancia para disminuir el tamaño o la cantidad de metástasis, y transformarlas en resecables (Downstaging). En ese sentido H. Bismuth ha hecho una experiencia interesante con la quimioterapia sistémica crono-modulada con 5-fuorouracilo, ácido folínico y oxalilplatino, en el cual el triple esquema se aplica en una secuencia fija diaria ("cronomodulada"), mediante el uso de una bomba portátil multicanal que permite programar las dosis en el tiempo.(98)

\section{Figura 12: Quimioterapia sistémica cronomodulada}




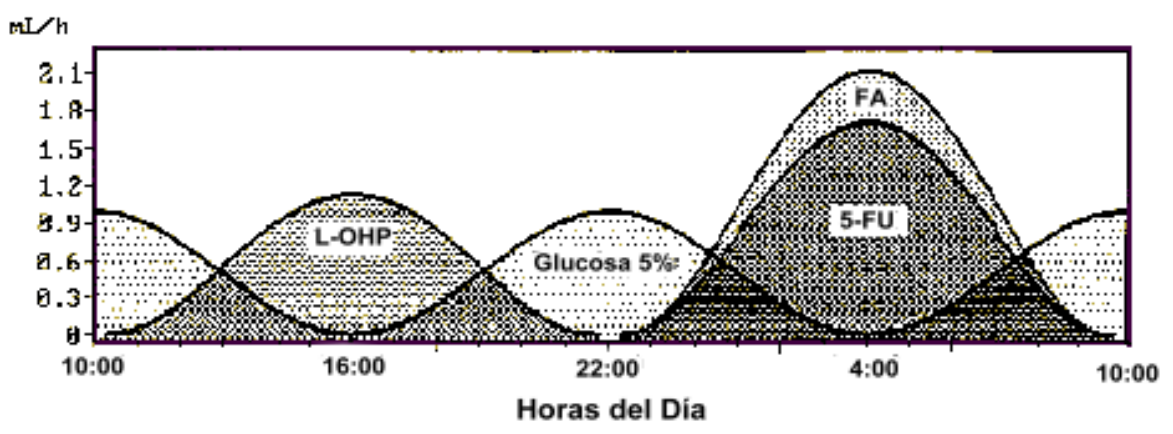

Plan diario de aplicación del triple esquema de quimioterapia "cronomodulada" con: $\quad$ 5-FU $=5$-fluorouracilo; $\quad$ FA. $=$ ácido folinico $; \quad \mathbf{L - O H P}=$ Oxaliplatino

\section{Tomado de Bismuth $\mathrm{H}$ et al, Oct 1996 (98)}

Los ciclos duran entre 4 y 5 días y se repiten cada 2 a 3 semanas, realizando evaluaciones mediante TAC helicoidal dinámica del abdomen cada 3 ciclos. La resección se indica cuando entre 2 evaluaciones sucesivas hay poca o ninguna diferencia de imágenes, siempre que hagan presumir resecabilidad, y el nivel de marcadores tumorales se haya estabilizado.

En la investigación clínica realizada por Bismuth, la media de duración del tratamiento con quimioterapia fue de 8 meses.

Si las metástasis se hubieran "estabilizado" en su respuesta a la quimioterapia en un tamaño aún inconveniente para la resección, se puede utilizar la embolización portal selectiva del sector o sectores hepáticos involucrados, para provocar la atrofia de los sectores a resecar con la con- 
secuente hipertrofia compensadora del parénquima remanente. (99), (100)

Si en cambio, luego del tratamiento quedaran metástasis en localizaciones que dificulten o hagan muy riesgosa su resección, o bien metástasis múltiples de las cuales sólo algunas fueran "resecables", se las puede someter a termoablación local, mediante el uso de frío, como en la crioablación, o de calor, como en la ablación por radiofrecuencia (101), (102)

Los electrocauterios de radiofrecuencia (RF) se usan desde hace más de 70 años en cirugía, y su principio físico consiste en que el paso de una corriente genera calor en los tejidos que atraviesa, dependiendo de la potencia de la corriente y la impedancia del tejido.

Cuando el calor supera $\operatorname{los} 50^{\circ} \mathrm{C}$ se produce la desnaturalización de las proteínas intracelulares y la destrucción de las membranas celulares, pues se derriten de las capas lipídicas de la misma, provocando necrosis tisular. Para tratar metástasis hepáticas de CCR, se colocan electrodos que transmiten la RF al interior de la lesión, uno de los más conocidos es la aguja-electrodo de LeVeen, un trócar de $15 \mathrm{~cm}$ de longitud que contiene 10 electrodos con forma de gancho que se separan en un circunferencia de $3 \mathrm{~cm}$ de diámetro.(102)

Figura 13: Aguja de Le Veen y sus 10 electrodos expandidos 


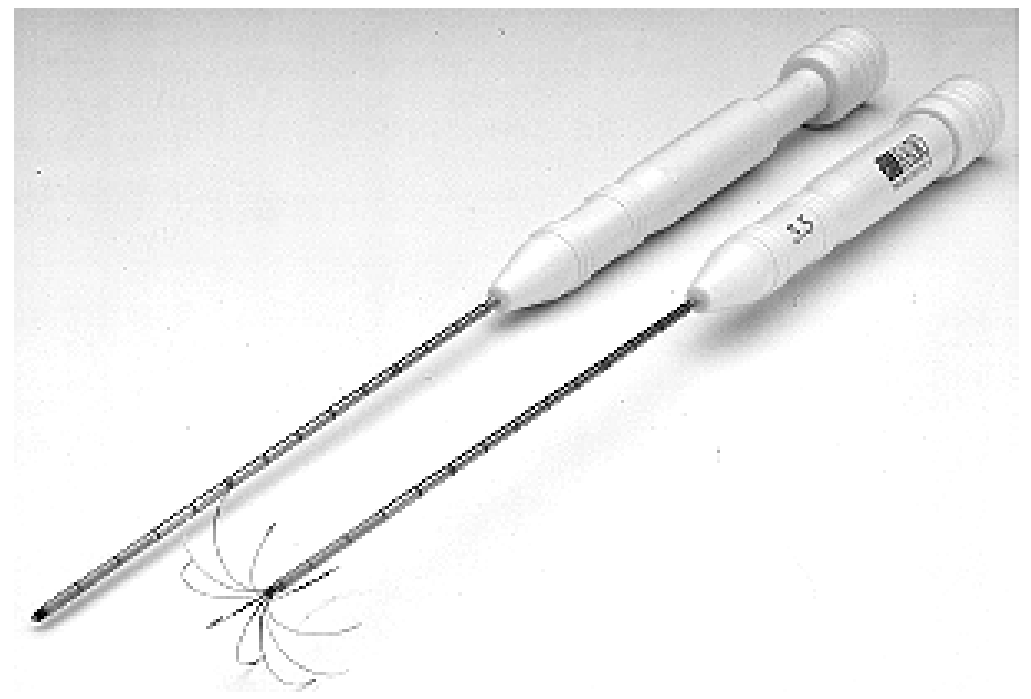

Tomado de Curley, S et al 1999 (102)

Los electrodos se colocan bajo control ecográfico o de TAC en el centro del tumor, si tiene hasta $3 \mathrm{~cm}$ de diámetro, si fuera mayor hay que tomar sectores de $3 \mathrm{~cm}$ de diámetro hasta cubrir totalmente al tumor, más un margen de $1 \mathrm{~cm}$ de parénquima sano. Los electrodos se pueden colocar muy próximos a los vasos sanguíneos, pero no de los conductos biliares, ya que éstos podrían resultar lesionados por la RF. La complicación más frecuente es la hemorragia, siendo particularmente riesgosas, las que se producen en el sitio del tumor a los 5 días de la ablación. Menos frecuentemente se generan abscesos en el sitio de la necrosis. (101), (102)

c- Las metástasis extrahepáticas más frecuentes son la carcinomatosis peritoneal que se ve en el 10 a $15 \%$ de los pacientes con CCR), y las metástasis pulmonares que se ven en otro 9 a $10 \%$ (más frecuentemente en el cáncer de recto, por su irrigación doble, que en el de colon). En 
cuanto a la carcinomatosis peritoneal, tradicionalmente fue considerada como un estadio terminal del CCR, y sólo se la trataba con quimioterapia con malos resultados. Fue recién hace una década, que comenzó a tratar mediante la combinación de peritonectomías y cirugía citorreductora con quimioterapia peritoneal intraoperatoria y postoperatoria temprana, con o sin hipertermia con el sorprendente resultado de una sobrevida a los 3 años de 25 a $47 \%$ de los pacientes tratados. (103)

Sugarbaker y colaboradores, para facilitar la evaluación de los resultados del tratamiento, propusieron un índice de severidad de la carcinomatosis peritoneal, para lo cual dividieron la cavidad abdominal en 13 regiones, y valoraron los implantes según su tamaño de 0 a 3, con lo que la suma numérica tiene un rango de 1 a 39.(103),(104),(105),(106) 
Figura 14: Indice de Carcinomatosis Peritoneal de Sugarbaker

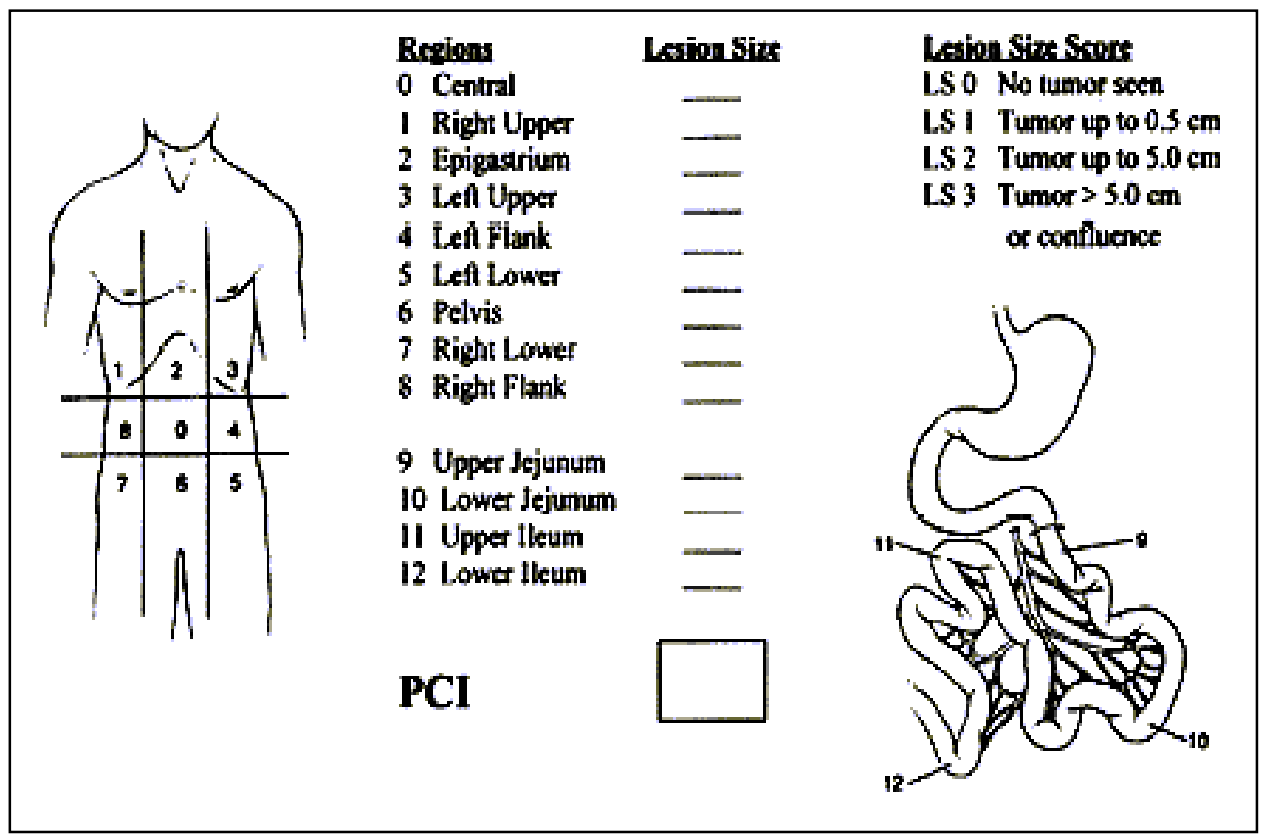

Tomado de Glehen O., et al 2004 (103)

d- En ocasiones la imitación para el tratamiento proviene de tumores que por estar localmente muy avanzados ocluyen totalmente o casi totalmente la luz intestinal, en estos casos ha sido tradicional el tratamiento mediante una colostomía proximal a la obstrucción; y si bien esta metodología de tratamiento se mantiene vigente, en los tumores oclusivos de los últimos $40 \mathrm{~cm}$ del colon y recto, existe la posibilidad de colocar con el fibrocolonoscopio una guía atravesando el tumor, y sobre ella deslizar una prótesis expandible metálica, que restablezca el tránsito colónico de forma similar a lo que se hace con el cáncer de esófago. Este tratamiento evita una cirugía en tumores resecables y/o brinda una paliación poco invasiva en pacientes con lesiones irresecables. (107), 108) 


\section{2- Adenocarcinoma del Recto}

Estadio 0 Si el tumor se encuentra a menos de $7 \mathrm{~cm}$ del margen anal, se puede tratar (Tis, No, M0) con una exéresis local transanal de la lesión sospechosa (biopsia total), incluyendo todo el espesor de la pared y un margen circunferencial de seguridad de $1 \mathrm{~cm}$. , y suturar la brecha rectal a puntos separados. (109), (110), (111), (112),(113), (114), (115)

O bien, mediante la exéresis por microcirugía endoscópica transanal (TEM: Transanal Endoscopic Microsurgery), con la que se realiza la misma biopsia total de la lesión y la sutura de la brecha, pero utilizando un resectoscopio especial de 12 a $20 \mathrm{~cm}$ de largo, que cuenta con un estéreotelescopio que permite, bajo insuflación de aire, una visión panorámica tridimensional del recto con un aumento de 6 veces la imagen normal, lo que facilita mucho las maniobras. (116), (117), (118).

Si en cambio, la lesión estuviese a más de $7 \mathrm{~cm}$ del margen anal, debe intentarse la polipectomía endoscópica, con disección hidráulica de la mucosa por inyección de suero submucoso, para elevar la lesión y permitir su resección total con el asa de termocauterio. Si se confirma el diagnóstico de Tis, no se hace ningún tratamiento complementario y sólo se lo somete a seguimiento con rectosigmoidoscopía periódica.(109), (111), (112)

Estadio I: En éste estadio, cuando el tumor tiene ciertas características: Localizado a 
(T1-2,N0,M0) menos de $7 \mathrm{~cm}$ del margen anal, ubicado en cara posterior, con menos de 3 cm de diámetro, no ulcerado, con baja penetración parietal (T1-T2, móviles), bien diferenciado o semidiferenciado, y sin diseminación linfática, determinada por Ecografía Endoanal; se hace posible realizar la exéresis local transanal de la lesión sospechosa (biopsia total) o la microcirugía endoscópica transanal (TEM), y del estudio de la pieza se pueden dar dos circunstancias: (81), (82),(115), (116), (117).

a-Cuando el T1, N0, M0 ha sido resecado localmente con margenes libres (el adenocarcinoma está más de $3 \mathrm{~mm}$ del borde de sección) y la diferenciación es de tipo GI o GII, sólo se hace el seguimiento con rectosigmoidoscopía periódica (cada 3 meses el primer año, cada 6 meses el $2^{\circ}$ año y 1 por año hasta los 5 años) (82), (117).

b-Cuando el T1,N0, M0 ha sido resecado localmente con margenes invadidos (tumor residual), o la muestra está fragmentada, o la diferenciación es del tipo GIII o GIV, o se trata de un T2, N0, M0 debe tratarse con una resección rectal, cuya magnitud depende de la localización. Si se trata de un tumor del recto medio y alto, desde los $7 \mathrm{~cm}$ hasta $\operatorname{los} 15 \mathrm{~cm}$ del margen anal, la operación de elección es la resección anterior del recto (RA) (operación de Dixon). (81), (82), (83)

Si estuviera por debajo de los $7 \mathrm{~cm}$ y hasta $\operatorname{los} 3$ a $4 \mathrm{~cm}$ por encima del margen anal, siempre que se pueda resecar con un margen distal de $2 \mathrm{~cm}$ y el paciente tenga una función esfinteriana aceptable, está indicado realizar la 
resección anterior con anastomosis ultrabaja (RA-UB) o coloanal, ya que sus resultados oncológicos son análogos a los de la amputación abdominoperineal, y nos permite conservar el aparato esfinteriano. (81), (82)

Finalmente, si el tumor fuera tan bajo que no nos permitiera hacer la resección con un margen de $2 \mathrm{~cm}$ o el paciente no tuviera una aceptable función esfinteriana estaría indicado hacer la amputación abdomino- perineal (AAP) (operación de Miles) en la que se reseca todo el recto y el ano, junto a los elevadores, aparato esfinteriano y la grasa pelvi-rectal e isquio-rectal. (118), (119), (120), (121), (122)

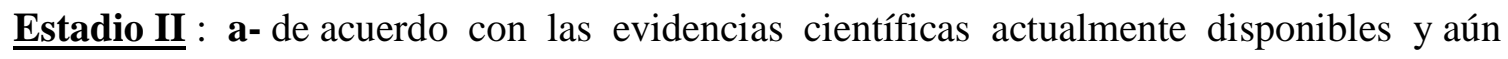
(T3-4, N0, M0) considerando que los que más se favorecen son los estadios III de la enfermedad, estamos autorizados a realizar neoadyuvancia con la finalidad de disminuir el tamaño del tumor y lograr el "control pélvico" de la enfermedad, lo cual aumenta la probabilidad de lograr un tratamiento quirúrgico con conservación del aparato esfinteriano, disminuye el riesgo de recidivas locales y aumenta la sobrevida libre de enfermedad de los pacientes. (123), (124), (125), (126), (127), (128), (129)

La modalidad utilizada en el MD Anderson Cancer Center, uno de los centros con más experiencia en neoadyuvancia en CCR incluye:

Radioterapia: Se aplican 45 Gy, en dosis iguales de 1.8 Gy de lunes a viernes durante 5 semanas (25 aplicaciones en total), y durante la última semana se agrega un refuerzo diario de $1.5 \mathrm{~Gy}$, que se aplica separado por unas $6 \mathrm{hs}$ 
del tratamiento diario, sobre la masa tumoral según una simulación tridimensional, con lo que se llega; a una dosis total de 52.5 Gy.(130)

Quimioterapia: se hace una infusión endovenosa diaria de lunes a viernes con $300 \mathrm{mg} / \mathrm{m} 2 / \mathrm{d}$ de 5 -Fluorouracilo y Levamisol durante las 5 semanas de tratamiento radiante. (81), (82)

Como la neoadyuvancia completa descripta dura 5 semanas y luego hay que esperar otras 4 a 8 semanas antes de operar, algunos grupos en Suecia, tratando de abreviar, han utilizado 5 sesiones diarias de $5 \mathrm{~Gy}$ cada una hasta totalizar 25 Gy con buenos resultados. (123), (124), (125)

b- En la cirugía de resección rectal, no importa que ésta se trate de una resección anterior común, o de una con anastomosis ultrabaja o coloanal, o de una amputación abdominoperineal, hay algunas cuestiones que conviene remarcar, pues han demostrado tener un rol relevante en la disminución de las recidivas locales, la prolongación de la sobrevida y el mejoramiento de la calidad de vida de los pacientes. Ellas son:

1- La conservación del aparato esfinteriano en la exéresis rectal, aún en tumores del recto bajo, siempre que sea posible conservar un margen de seguridad de $2 \mathrm{~cm}$ y el paciente tenga buena función esfinteriana. Su realización ha sido factible debido a los conocimientos actuales de fisiología del piso pélvico, en parte debido al desarrollo de los suturadores mecánicos que han hecho más seguras las anastomosis ultrabajas, y a la posibilidad técnica de realizar anastomosis coloanales, con o sin el reservorio colónico en "J", que mejora mucho la cantidad de deposiciones y los escapes involuntarios de materia fecal. (131) 
2- La resección total del "mesorrecto", que fuera preconizada a finales de los años 80 por Richard Helad, quien llamó mesorrecto a la grasa que rodea al recto adentro de su fascia visceral. Había demostrado "focos de adenocarcinoma en el mesorrecto varios centímetros distal al límite inferior aparente del tumor, muchos de los cuales no tenían otro indicio de invasión linfática", lo que lo llevó a programar la resección completa de ese tejido graso con el cáncer de recto, siguiendo lo que denominó "the holy plane of rectal surgery", y fue grande su sorpresa cuando la tasa de recidivas locales disminuyó de alrededor del $20 \%$ con los procedimientos anteriores, a un 3\% a 5 años y $4 \%$ a 10 años con la resección total del mesorrecto; con una sobervida global libre de enfermedad .

A partir de entonces, su procedimiento de resección total del mesorrecto con conservación de los nervios autónomos pelvianos se convirtió en el estándar de tratamiento para los tumores rectales (131), (132), (133), (134), (135), (136)

Figura 15: "the holy plane of rectal surgery"

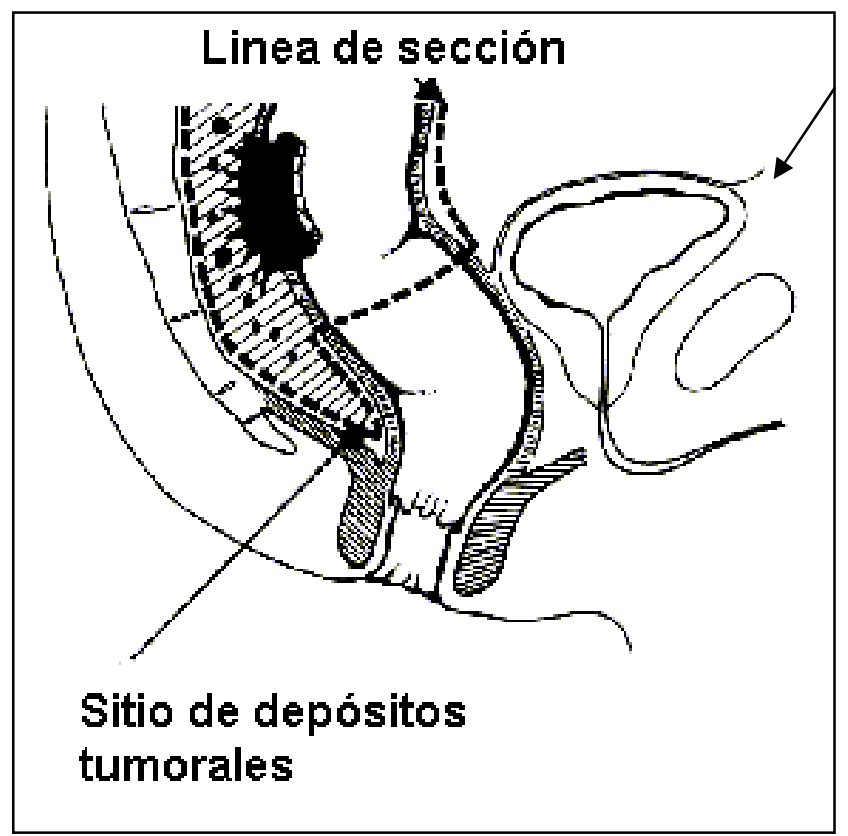


Figura 16: Anatomía de los nervios autónomos pelvianos

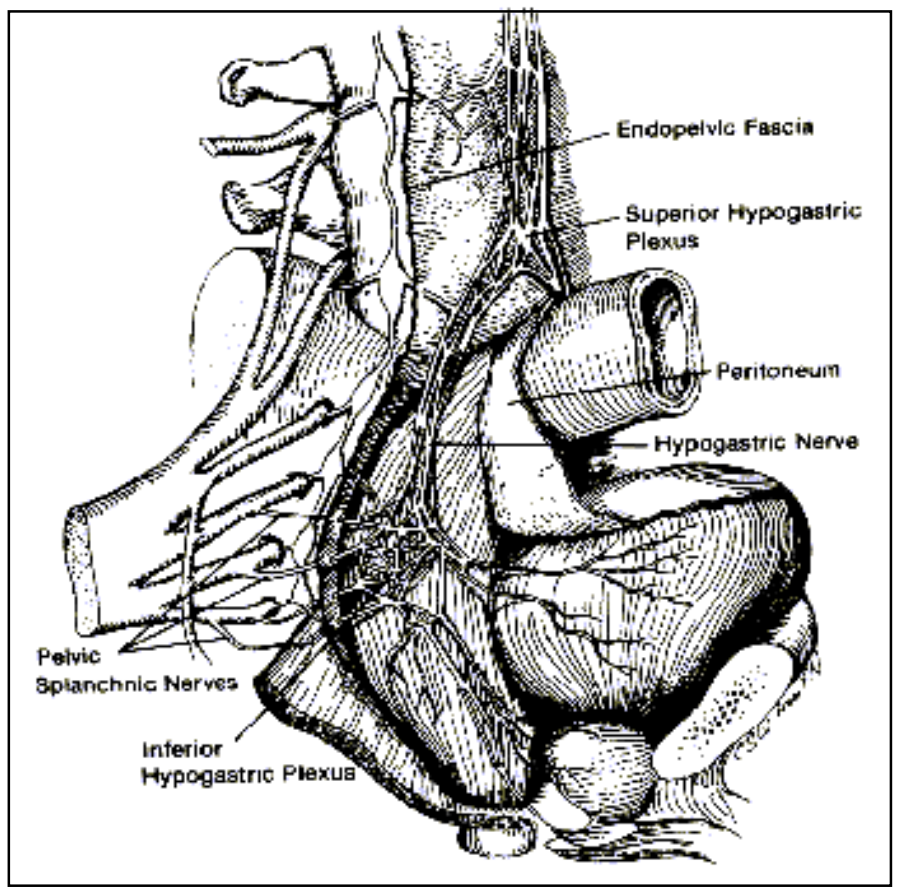

Lee JF. Maurer VM. Block GE. 1973 (137).

e- Aquellos pacientes que no hubiesen hecho neoadyuvancia, podrán hacer adyuvancia, para lo cual luego de estabilizadas las heridas operatorias, aproximadamente un mes después de la operación, se comienza el tratamiento con quimioradiante, que generalmente consta de seis ciclos de: Oxalilplatino el día 1 de cada ciclo, y 5-Fluorouracilo más Leucovorina Cálcica durante los días 1 a 5 de cada ciclo de 28 días de duración. (138), (139)

f- Para la irradiación postoperatoria los principales grupos emplean dosis que varían entre 45 y 50,4 Gy, la aplican con un fraccionamiento de 1,8 
Gy/día y los volúmenes de irradiación con frecuencia comprenden a toda la pelvis.(82)

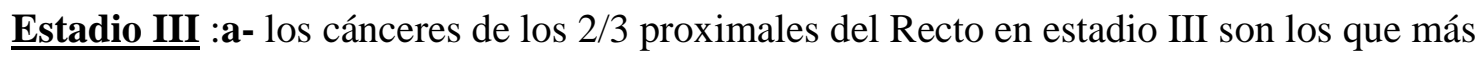
(T1-4,N1-2,M0) se beneficia de con la neoadyuvancia, por lo que está indicado utilizarla en ellos con la técnica ya descrita (50 Gy en 5 semanas + 5-FU y Levamisol).Las ventajas que ofrece la RT preoperatoria sobre la postoperatoria son varias: a) una mejor respuesta al efecto biológico debido a la oxigenación tisular (mayor que en tejido cicatrizal), mejor respuesta con dosis menores; b) una disminución y esterilización de las lesiones vegetantes con una menor siembra intraoperatoria de células neoplásicas viables; c) una mayor preservación de esfínteres cuando se utilizan dosis elevadas en lesiones del recto inferior, y d) una menor morbilidad entérica actínica al disminuir la dosis que recibe el intestino delgado cuando se trata una pelvis no intervenida y en la que la reflexión peritoneal impide al intestino delgado situarse en el campo de la irradiación. Al momento de decidir si hacer neoadyuvancia o adyuvancia en el Cáncer de Recto, debemos tener en cuenta que ya hay varios ensayos clínicos que las comparan y afirman que la neoadyuvancia es más eficaz en el control local de la enfermedad con menor toxicidad, aunque, como la adyuvancia no mejora la sobrevida actuarial de los pacientes.(130)

b- En los tumores del recto superior, con su límite distal a más de $11 \mathrm{~cm}$ del margen anal, la operación de elección es la resección anterior del Recto convencional (operación de Dixon) con resección total del mesorrecto y conservación de los 
nervios autónomos pelvianos; en los del recto medio, con límite distal entre los 7 y $10 \mathrm{~cm}$ del margen anal la resección anterior con un margen de seguridad de 2 a 4 $\mathrm{cm}$ obliga a una anastomosis baja o menos frecuentemente a una ultrabaja (a menos de $5 \mathrm{~cm}$ del margen anal), en la que son más frecuentes las complicaciones. En el recto bajo, con límite inferior del tumor a $7 \mathrm{~cm}$ o menos del margen anal, la única forma de reconstruír el tránsito digestivo es mediante una anastomosis ultrabaja o coloanal. En todos los casos se respetan las premisas "oncológicas" de: -resecar 20 $\mathrm{cm}$ proximales al recto y no menos de $2 \mathrm{~cm}$ de recto sano distales al tumor, - extirpar todo el mesorrecto, junto al recto dentro de su fascia visceral (continuar resecando la grasa retrorectal por dentro de la fascia visceral del recto hasta los elevadores), y - evitar que el recto se abra y contamine la pelvis durante la disección. (131), (132), (133), (134), (135), (136)

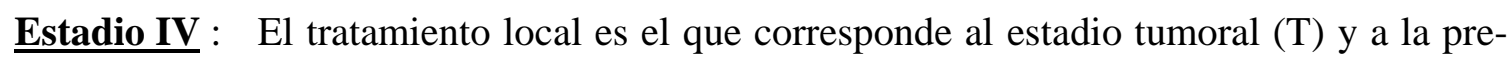
sencia o ausencia de adenopatías positivas (N). En tanto, el tratamiento de las metástasis a distancia es el mismo que fuera explicitado para el Cáncer de Colon . (88), (91), (93), (98), (140)

\section{I- Seguimiento postoperatorio del Cáncer Colorrectal:}


Una vez realizado el tratamiento indicado para cada estadio del CCR, se debe hacer un seguimiento planificado que permita la detección precoz de recidivas o nuevos tumores asociados a la susceptibilidad que tienen estos pacientes para producir CCR metacrónico.

La entrevista con una minuciosa anamnesis y el examen físico se realizará cada 3 meses durante los 2 primeros años y semestralmente hasta los 5 años de realizado el tratamiento. Asimismo, se indicarán determinaciones de laboratorio y de antígenos: Carcinoembrionario (CEA) y CA-19-9 cada 3 meses el primer año, cada 6 meses el segundo año y una vez por año por lo menos hasta los 5 años. Un ecotomografía hepática está indicada anualmente para detectar metástasis y una TAC de abdomen y pelvis se indicará a los 18 meses. (141)

El seguimiento se podría esquematizar como sigue, en la tabla 3 :

Tabla 3: Esquema de seguimiento postoperatorio del CáncerColorrectal

\begin{tabular}{|c|c|c|c|c|c|}
\cline { 2 - 6 } \multicolumn{1}{c|}{} & Ex F & Lab & ECT & TAC & Ag \\
\hline 3 m & $x$ & no & & & $x$ \\
\hline $12 \mathrm{~m}$ & $\mathrm{x}$ & $\mathrm{x}$ & $\mathrm{x}$ & & $\mathrm{x}$ \\
\hline $18 \mathrm{~m}$ & $\mathrm{x}$ & $\mathrm{x}$ & & $\mathrm{x}$ & $\mathrm{x}$ \\
\hline $24 \mathrm{~m}$ & $\mathrm{x}$ & $\mathrm{x}$ & $\mathrm{x}$ & & $\mathrm{x}$ \\
\hline 1 /año & $\mathrm{x}$ & $\mathrm{x}$ & $\mathrm{x}$ & & $\mathrm{x}$ \\
\hline
\end{tabular}




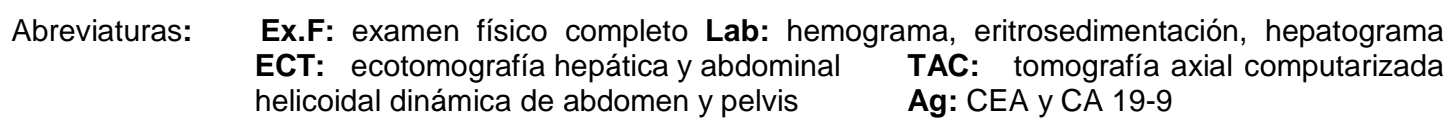

\section{J- Recidivas pelvianas del cáncer de recto:}

Definimos como recidiva pelviana, aquella recidiva que se presenta a nivel de la pelvis luego de efectuada una cirugía con intención curativa por cáncer de recto.

Cuando la recidiva compromete órganos intrapélvicos (vejiga, colon descendido, recto remanente y mesos), se considera que se trata de una recidiva pelviana central. Dentro de este grupo estarían incluidas la recidivas anastomóticas. (142), (143)

En los casos en que la invasión se extiende a la pared de la pelvis ( músculo, huesos, vasos y nervios), se considera que se trata de una recidiva pelviana parietal. De acuerdo con el sector de la pared de la pelvis que estuviera comprometido, podrá ser además lateral y/o posterior. (ver Fotos 5 y 6 )

La recidiva pelviana, luego de una cirugía con intención curativa por cáncer de recto, se observa con una frecuencia del 4 a $30 \%$ de los pacientes. En el $66 \%$ de los casos, la recurrencia se presenta dentro de los dos primeros años de la cirugía, con una mayor frecuencia promedio a los 18 meses para su aparición. De ellas, solamente un 14 a $38 \%$ podrán ser operados y resecadas con intención curativa. (142)

Como ha sido señalado las diferentes formas de presentación de la enfermedad, obligan a la utilización de diversas modalidades terapéuticas. De las cuales, la quirúrgica es la que ofrece los mejores resultados, especialmente en los casos de recidivas centrales.(143)

Desafortunadamente, la forma de presentación mas frecuente es la recidiva parietal en sus diferentes variantes, lo que ha llevado al desarrollo de técnicas quirúrgicas complejas como la resección sacropélvica, pelvectomía inferior, etc. Sin embargo, la elevada morbi- 
mortalidad de estos procedimientos, que no pueden ser aplicados a todos los pacientes, y la obtención de márgenes quirúrgicos escasos o insuficientes, aún en cirugías de gran envergadura, obligan a la utilización de otros procedimientos terapéuticos como la radioterapia intraoperatoria y la braquiterapia intra o postoperatoria. (142), (143), (144).

\section{Radioterapia intraoperatoria:}

Los enfoque agresivos multimodales empleando la irradiación intraoperatoria, han logrado un control local de la enfermedad en el $25 \%$ de los casos, con tasas de sobrevida del $20 \%$. Gunderson y Cols (145), (146) han definido los criterios para su utilización cuando:

1) La cirugía sola no pudiera lograr un control efectivo de la enfermedad y los requerimientos de radioterapia externa para un intento curativo fueran de 60-70 Gy o más.

3) El tumor se encontrare localizado y que su masa estuviera comprendida dentro del campo a irradiar.

4) No se comprobaran metástasis a distancia

5) El tratamiento fuera de intención curativa.

Suzuki y cols en un estudio sobre 106 recidivas de cáncer de recto operados, y que recibieron radioterapia intraoperatoria., observaron una sobrevida global de $28 \%$ y $12 \%$ a 3 y 5 años respectivamente y una sobrevida libre de tumor de $16 \%$ y $9 \%$ en los mismos períodos. En aquellos pacientes que tuvieron resecciones R1 (márgen quirúrgico con invasión tumoral microscópico), la sobrevida libre de tumor fue de $27 \%$ a 3 años, en tanto que en las R2 (márgen quirúrgico con invasión tumoral macroscópica), esta fue del $15 \%$. Este hecho señala la necesidad de realizar el máximo esfuerzo quirúrgico para lograr la resec- 
ción completa de la lesión o al menos dejar un margen quirúrgico sin invasión tumoral macroscópico. (147)

\section{Braquiterapia}

El término braquiterapia proviene del griego Brachys que significa:"breve", y en este caso indica la proximidad de las fuentes radiactivas con la región que debe ser tratada.

Es la forma mas antigua de tratamiento radiante y consiste en la aplicación local de fuentes de material radiactivo, que al liberar energía en un área determinada, destruyen del tejido neoplásico con menos daño para las estructuras adyacentes. Cuando las fuentes radiantes han sido correctamente colocadas, la dispersión de la radiación resulta homogénea.

Éstas fuentes radioactivas, pueden ser insertadas directamente en forma de agujas o semillas, o pueden ser aplicadas por medio de la técnica del "afterloading" (retrocarga o carga diferida). Para lo cual es necesario colocar quirurgicamente un vector (aguja o tubo de nylon) próximo al área a irradiar. (148), (149)

Este procedimiento solo ó asociado a radioterapia externa desde hace tiempo es utilizado con éxito para el tratamiento de neoplasias de: cabeza y cuello, próstata, cuello uterino, cerebro, páncreas, etc. En el caso de las recidivas pelvianas del cáncer rectal, la experiencia con esta modalidad terapéutica es limitada. En el año 1986 Edington et al, comunican un reporte preliminar con la utilización de cirugía mas braquiterapia, con Ir192 introducidos a través de catéteres. Minsky et al, usaron braquiterapia en pacientes que habían recibido previamente radioterapia y con tumores irresecables o sometidos a resecciones parciales. Sus resultados demostraron un aceptable control local de la enfermedad cuando: el volumen del tumor era inferior a los $40 \mathrm{~cm} 3$. En años más recientes, la braquiterapia ha 
encontrado un espacio en el tratamiento multimodal de la recidiva del cáncer del recto. (143), (148)

La mejor indicación es para tratar pacientes con recidivas tumorales, sin metástasis a distancia y sometidos a "re-resecciones" R0 con margen mínimo o dudoso y las re-resecciones R1 y R2, que ya han recibido altas dosis de radiación, o en los cuales no es posible realizar radioterapia intraoperatoria, por ubicación inconveniente de la zona a irradiar o por no contar con un equipo adecuado.

Las fuentes de material radioactivo, como son las semillas de I125 pueden ser colocadas directamente sobre el lecho de la resección tumoral o mediante la colocación intraoperatoria de catéteres plásticos de polietileno, denominados: vectores, que se aplican cubriendo totalmente el área a irradia, separados uno de otro por una distancia de $1 \mathrm{~cm}$.

Esta técnica tiene la desventaja de ser muy dependiente del operador, ya que demanda una cierta habilidad por parte del cirujano para la colocación de los vectores, especialmente en aquellas áreas de difícil acceso o donde no se encuentren estructuras parietales aptas para la fijación de los catéteres (hueso, elementos vasculares y nerviosos). Debido a ello, muchas veces la fijación de los vectores resulta inestable, pudiendo desplazarse provocando áreas "frías," al quedar separados, o áreas "calientes" cuando se superponen. Por este motivo es preferible fijar previamente los vectores a una plancha de material de reabsorción lenta como es una malla de hebras de Poliglactina (Vycril®) (143) 


\section{3- Determinación de la sensibilidad de la Estadificación Videolapa- roscópica del Cáncer Colorrectal para detectar circunstancias desfa- vorables que obliguen a realizar una laparotomía no terapéutica}

\section{3-1- Introducción}

Al planificar el diseño de nuestro trabajo tomamos en cuenta que el texto de la declaración de Helsinski (18th World Medical Assambly Helsinski 1964, 29th World Medical Assambly Tokio 1975, y 35th World Medical Assambly Venice 1983) en su artículo II inciso B, acerca de la investigación médica con atención de pacientes dice: "en los estudios con pacientes, se debe asegurar que cada uno de ellos reciba la mejor prueba diagnóstica y el mejor método terapéutico disponible, incluyendo también al grupo control.", circunstancia que nos enfrentó con la imposibilidad de hacer un estudio prospectivo randomizado seleccionando un grupo de pacientes para estadificación videolaparoscópica y otro grupo para seguir haciendo la estadificación por laparotomía exploradora, ya que incumpliríamos la norma en aquellos pacientes que fueran objeto de una laparotomía no terapéutica, o en aquellos otros en que se realizara tratamiento sólo derivativo por laparotomía, exponiéndolos a complicaciones y sufrimientos evitables. (150), (151)

Ante esta eventualidad, consideramos la posibilidad de utilizar como "control" a un grupo de pacientes que habían sido tratados usando la información obtenida de la estadificación por laparotomía exploradora, durante los 2 años anteriores al comienzo de nuestro estudio (1998 y 1999). Los procedimientos estaban bien documentados y habían sido realizados por el mismo grupo de cirujanos que ahora emprendíamos la estadificación viedola- 
paroscópica; por lo que decidimos comparar sus resultados con una muestra prospectiva de pacientes de la consulta espontánea del Servicio de Cirugía del Hospital "Prof. Dr. Rodolfo Rossi” de La Plata entre los años 2000 y 2004 con diagnóstico de Cáncer Colorrectal

\section{3-2- Objetivos:}

A-Objetivo General: Determinar la sensibilidad de la estadificación videolaparoscópica (EVL) en pacientes con Cáncer Colorrectal (CCR), para determinar circunstancias desfavorables que obliguen a realizar laparotomías no terapéuticas.

B-Objetivos Específicos: - Evaluar la utilidad de la EVL en pacientes con CCR, para detectar carcinomatosis peritoneal

- Evaluar la utilidad de la EVL en pacientes con CCR, para determinar la presencia de ascitis, y para la obtención de muestras para Citología

- Evaluar la utilidad de la EVL en pacientes con CCR, para detectar metástasis hepáticas visibles en superficie, que impidan la exéresis quirúrgica (pequeñas múltiples, confluentes ubicadas en zonas muy riesgosas, etc)

- Determinar la tasa de laparotomías no terapéuticas en los pacientes con CCR estudiados mediante EVL en el preoperatorio y los que se sometieron a estadificación durante la laparotomía. 
- Determinar la diferencia entre las medias de días de estadía hospitalaria entre ambos grupos

\section{3-3- Material y Procedimientos:}

\section{A- Población:}

Como ya hemos expresado, comparamos un grupo de pacientes a los que se le realizó la Estadificación Videolaparoscópica (grupo A), con otro grupo histórico que fue tratado con los datos obtenidos de la estadificación durante la laparotomía (grupo B), las características de los grupos se describen a continuación:

Grupo A: Cincuenta y seis $(n=56)$ pacientes incluidos en un estudio retrospectivo portadores de Cáncer Colorrectal no complicado (sin obstrucción ni sangrado), provenientes de la consulta espontánea y de derivación del Servicio de Cirugía del Hospital Interzonal General de Agudos "Profesor Dr. Rodolfo ROSSI” de La Plata, provincia de Buenos Aires, que fueron tratados entre el $1^{\circ}$ de enero de 1998 y el 31 de diciembre de 1999, usando la información obtenida mediante la estadificación convencional realizada durante la Laparotomía Exploradora practicada con la finalidad de resecar el tumor primitivo.

Grupo B: Setenta y cuatro $(\mathrm{n}=74)$ pacientes de la consulta espontánea y de la derivación del Servicio de Cirugía del Hospital Interzonal General de Agudos "Profesor Dr. Rodolfo ROSSI” de La Plata, provincia de Buenos Aires, portadores de Cáncer Colorrectal no complicado (sin obstrucción ni sangrado),que fueron tratados entre el $1^{\circ}$ de enero de 2000 y el 31 de diciembre de 2001, incluidos en un estudio prospectivo para 
determinar la sensibilidad de la Estadificación Videolaparoscópica (EVL) de pacientes con Cáncer Colorrectal, en la detección de situaciones de inoperabilidad (Carcinomatosis Peritoneal y Metástasis Hepáticas irresecables), que permitan evitar laparotomías no terapéuticas.

B- Equipamiento: Para la Estadificación Videolaparoscópica utilizamos:

1. Mesa de operaciones articulada con movimientos axiales y laterales.

2. Laparoscopio STORZ modelo Hopkins II (10 mm x $31 \mathrm{~cm})$ óptica a $30^{\circ}$

3. Laparoscopio STORZ modelo Hopkins II $(10 \mathrm{~mm} \times 31 \mathrm{~cm})$ óptica a $0^{\circ}$

4. Sistema de Video STORZ Dx Cam CCU (NTSC) modelo 20230120

5. Fuente de luz STORZ Halogen 250 Twin modelo 20113320

6. Monitor SONY Tinitron modelo PVM-14N1E

7. Insuflador STORZ modelo 26410020 (1-10 L/min, 30mmHg max)

8. Stereo Videocassette Recorder SONY modelo SVO-1500P

9. 1 Trócar STORZ $11 \mathrm{~mm}$ modelo $30103 \mathrm{C}(10,5 \mathrm{~cm})$

10. 2 Trócares STORZ 5mm modelo 30101 MC (10,5 cm)

11. Trócar Optiview (introductor bajo visión) descartable

12. Pinza tipo "Grasper" de $30 \mathrm{~cm}$

13. Electrobisturi “Hook"STORZ monopolar Autocon 200 modelo 20522520

14. Separador plástico insuflable para laparoscopia

15. Trócar $n^{\circ} 10$ (punción subclavia)

16. Aguja Trucut descartable no 19 (Wilson-Cook Medical Inc., Winston-Salem, N.C.).

C-Análisis Estadístico: fue necesario comparar porcentajes y conocer su significación, por lo que se utilizó el test de Chi Cuadrado; con excepción de la comparación de la razón de masculinidad en que se usó un test de T. Elprocesamiento se hizo con el Programa de Estadísticas para Ciencias Médicas versión 1.1 de los Dres. Borracci y Arribalzaga de la Facultad de Medicina de la Universidad de Buenos Aires. 


\section{C- Procedimientos Operativos:}

Preferimos realizar la Estadificación Videolaparoscópica en pacientes portadores de Cáncer Colorrectal inmediatamente antes de realizar la laparotomía para la exéresis del tumor primitivo.

Colocamos al paciente sobre la camilla operatoria en decúbito supino, sin realces posteriores, y lo sujetamos firmemente por ambos miembros superiores e inferiores. Consideramos a éste procedimiento muy importante, ya que durante la exploración tendremos que cambiar la camilla de posición en varias oportunidades para permitir la "separación" de los órganos abdominales móviles por gravedad, ayudando así a despejar los órganos del área en exploración, sin que por ello se deslice el paciente, y pueda caerse de la camilla.

El médico anestesiólogo le practica una anestesia general inhalatoria, con buena relajación de la pared anterior del abdomen, como se estila en los procedimientos laparoscópicos con insuflación.

A continuación, el equipo quirúrgico toma posiciones y coloca el instrumental y los aparatos de la siguiente forma: - el cirujano operador se coloca a la izquierda del paciente, inmediatamente bajo el brazo extendido del paciente, quedando libres ambas manos para el manejo del instrumental, - el cirujano ayudante, se coloca a la izquierda del paciente y a la izquierda del cirujano operador, su misión principal será guiar la cámara, la instrumentadora se coloca a la derecha del paciente, y - el anestesiólogo en la cabecera. El monitor, si es 
único, se coloca a la derecha del paciente frente al cirujano y la torre del laparoscopio detrás del cirujano y el ayudante.

Figura 17: Posición del equipo quirúrgico en la sala de operaciones

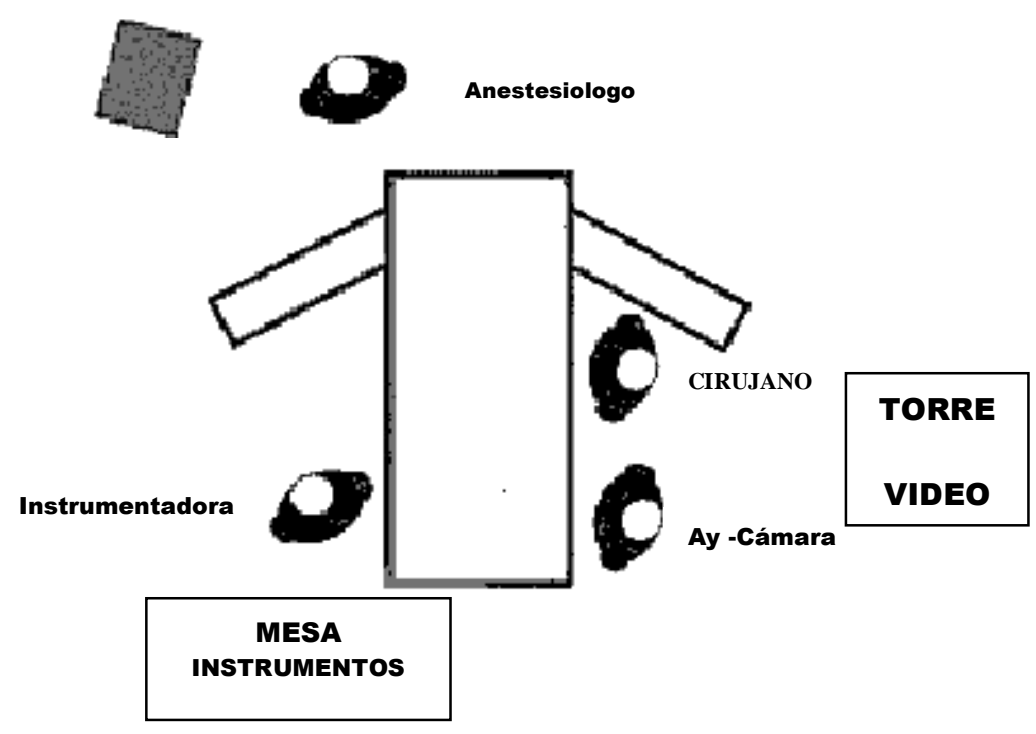

\section{OPERACIÓN de ESTADIFICACIÓN:}

1- Antisepsia de piel y campos como para la laparotomía planeada para la exéresis del tumor primitivo, y se cubren con compresas las zonas más alejadas del área a utilizar para la estadifiacción videolaparoscópica.

2- Pequeña incisión de $1,5 \mathrm{~cm}$ en un borde lateral del ombligo con la finalidad de introducir el Trócar $\mathrm{n}^{\circ} 1$ (celíaco), un trócar de punta traslúcida de 10 mm (del tipo Optiview ®), que permite colocar el Laparoscopio con la cámara ya acoplada en su interior, y ver los planos abdominales mientras los se van divulsionando con la punta aguda del instrumento. Al pasar el Peritoneo y llegar a la cavidad abdominal, se retira el mandril del trócar que contiene el laparoscopio. 
3- Insuflación con Dióxido de Carbono $\left(\mathrm{CO}_{2}\right)$ a través del $\mathrm{T} 1$ ya colocado, hasta lograr unos $10 \mathrm{mmHg}$ de presión intraabdominal. Se solicita al anestesiólogo que a partir de éste momento nos informe de los cambios en el medio interno que pudiera detectar en el Oxicapnografo, instrumento imprescindible para realizar la anestesia de pacientes que están siendo operados con insuflación de Dióxido de Carbono.

4- Se Introduce el Laparoscopio dentro de la cavidad peritoneal por el acceso umbilical, y bajo visión se coloca el Trócar $\mathrm{n}^{\circ}$ 2, un trócar metálico reutilizable de $5 \mathrm{~mm}$, en el flanco derecho a la altura de la línea medio-clavicular, y a mitad de camino entre el reborde costal y la región inguinal. Finalmente, se coloca el Trócar n³, un trócar metálico reutilizable de $5 \mathrm{~mm}$, a la derecha de la línea media en un punto a mitad de distancia entre el ombligo y el reborde costal.

Figura 18: Sitio de colocación de los trócares

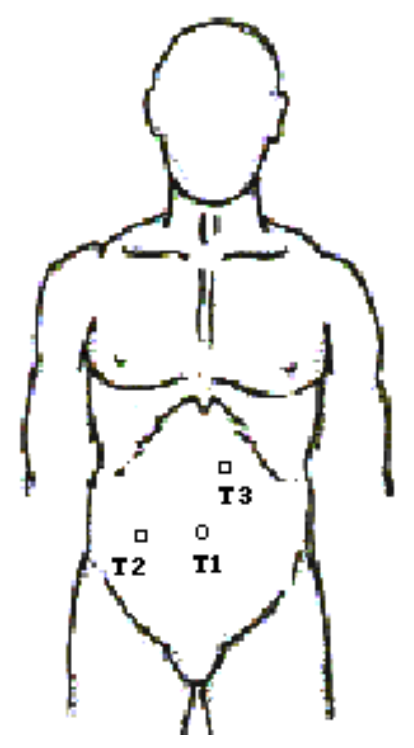

Tomado de The SAGES Manual, 1999 
Para realizar la exploración propiamente dicha preferimos utilizar un laparoscopio de visión a $30^{\circ}$, lo que nos permite "tomar distancia" para explorar el hígado desde los espacios subfrénicos y no dificulta el resto de la operación, pero tambien hemos utilizado la óptica de $0^{\circ}$ con la misma finalidad y obtuvimos buenos resultados.

El primer paso es la Exploración Hepática, para lo cual es necesario colocar al paciente en posición de Trendelenburg invertida pronunciada, con la mesa operatoria colocada de forma que la cabeza del paciente quede a unos $40^{\circ}$ por encima de la horizontal. La posición provoca la caída del Epiplón Mayor, el Colon Transverso, y la masa de Intestino Delgado hacia el abdomen inferior, dejando libre los espacios subfrénicos supra e infrahepáticos, que son ocupados por el $\mathrm{CO}_{2}$, lo que permite una buena visualización del Hígado, la cara inferior del diafragma y las paredes laterales del abdomen superior; que exploramos visualmente y "palpamos instrumentalmente" con una pinza tipo "grasper" cerrada, que avanza deprimiendo el hígado. (Ver Foto 7)

Se comienza la exploración por la cara superior del hígado a la derecha del ligamento Suspensorio (Lóbulo Derecho del Hígado), más precisamente donde éste se une con el fondo de saco posterior formado por el adosamiento hepático ("pars fija" del ligamento Coronario del Hígado) visualizándolo meticulosamente para descartar la presencia de Carcinomatosis Peritoneal o Ascitis, para luego ir deprimiendo por sectores la cara superior de la glándula con la pinza roma, con la finalidad de conocer la consistencia del parenquima y "palpar" instrumentalmente masas en su interior, que no se evidencien en la superficie. (Ver Fotos 7, 8,9 y 10) 
Posteriormente, para ver la cara inferior del hígado derecho, más fijo que el hígado izquierdo, con una pinza tipo "grasper" introducida en el abdomen por T2, se tracciona del Epiplón Mayor hacia abajo, y con otra pinza introducida por T3 se retrae el ligamento redondo hacia arriba (proximal). Con ésta simple maniobra, habitualmente nos queda expuesta la vesícula biliar y la parte medial de la cara inferior del lóbulo derecho del hígado, pero si no fuera suficiente, con un separador inflable, o bien con otra pinza tipo "grasper" de punta roma introducida por T3, se procede a levantar directamente el hígado derecho, exponiendo su cara inferior ampliamente en toda su extensión. En éste punto, es muy importante fijarse si hay Ascitis en la unión del espacio de Morrison (subhepático) con el espacio Parieto-Cólico derecho, donde se la ha encontrado con mayor frecuencia, si la se encuentra se deben tomar muestras para citología con un catéter, que se habrá introducido en el abdomen a través de un trócar $\mathrm{n}^{\mathrm{o}} 10$ (de los utilizados para introducir un catéter $\mathrm{n}^{\mathrm{o}} 9$ en la vena Subclavia). ( Ver Fotos 11 y 12 )

A continuación, para la exploración de la cara superior del hígado izquierdo, se retira el laparoscopio hasta ver el ligamento redondo y se reintroduce a su izquierda, realizando las mismas maniobras que hiciéramos en el hígado derecho. La luxación del hígado izquierdo es más fácil que la del derecho, y se lleva a cabo con la pinza tipo "grasper" de punta roma o con un separador inflable introducidos por T3, exponiendo dicha cara en toda su extensión hasta la inserción del ligamento triangular.

Si se ve en la superficie del hígado o en del peritoneo una imagen sospechosa, se procede a tomar una muestra de tejido para practicarle una biopsia. Para ello se introduce un trócar $\mathrm{n}^{\mathrm{o}} 10$ (subclavia) y por su interior una aguja de tipo Trucut de $25 \mathrm{~cm}$ de largo 
(Biocore II ® de Histo, calibre 18 largo $25 \mathrm{~cm}$ ), es muy importante luego de la toma de tejido, realizar un meticuloso control de la hemostasia. Si el sangrado lo justifica, se procede a electrofulgurar su superficie con un Electrobisturí laparoscópico tipo Hook, hasta que cese totalmente.

El paso siguiente es ver el resto de la cavidad abdominal, para lo cual se inclina la camilla hacia la izquierda del paciente, de modo que su miembro superior derecho quede a unos $45^{\circ}$ de la horizontal, lo que hace caer las vísceras hacia la derecha y nos permite recorrer el espacio Parieto-Cólico derecho visualizando el ángulo esplénico del Colon, el Colon Ascendente y el Ciego con el apéndice cecal; hasta llegar a ver caudalmente, el fondo de saco de Douglas, donde habitualmente se pone de manifiesto la presencia de ascitis cuando hay escasa cantidad, ya que es el lugar más declive del abdomen en el decúbito supino.

Si existiera ascitis, se procederá a tomar muestras mediante un catéter tipo K30, introducido en el abdomen inmediatamente por encima del acúmulo de ascitis, a través de un trócar $\mathrm{n}^{\mathrm{0}} 10$ de los utilizados para colocar catéteres para infusión endovenosa en la vena Subclavia..

Una vez finalizada la exploración del fondo de saco peritoneal, se asciende hacia proximal viendo el Colon Sigmoides, el Colon Ascendente y el ángulo esplénico del Colon sucesivamente, mientras con una pinza tipo grásper roma cerrada vamos movilizando y "palpando" instrumentalmente cada una de las vísceras. 
Para poner fin a la exploración, se visualiza la masa central intestinal constituída por el Yeyuno-Ileon, el Colon Transverso y el Epiplón Mayor, luego de lo cual se procede a retirar los trócares 2 y 3 bajo visión laparoscopica para comprobar que no haya hemorragias, y a continuación desinsuflamos el abdomen haciendo presión sobre los flancos con la válvula de T1 abierta, hecho lo cual procedemos a retirar el trócar 1 y se cierran las heridas con puntos de nylon monofilamento. (en caso de realizar la laparotomía, se repasan las heridas desde el abdomen antes de cerrar).

Todo el procedimiento dura sólo 20 minutos, el mismo tiempo que nos tomaría practicar la exploración del abdomen "a cielo abierto", y a diferencia de aquél, nos permite una visualización magnificada (x 6), de mucho mejor calidad, con mucha menor destrucción de tejidos y estrés perioperatorio.

\section{3-4- Resultados:}

En primer término analizamos estadísticamente ambos grupos poblacionales con la finalidad de determinar si eran equivalentes respecto de las variables independientes (condiciones que a priori suponemos que modifican a la variable dependiente que estamos estudiando, en éste caso, la sensibilidad de la estadificación videolaparoscópica para detectar carcinomatosis peritoneal y/o metástasis irresecables). 
Estudiamos su composición por edades, sexo y localización de los tumores primitivos, y encontramos que no había diferencia significativa entre las proporciones de dichas variables de ambos grupos.

Tabla 4: Comparación de ambos grupos en edades, género y localización

\section{Abreviaturas:}
CR= cá.recto,
CCT= cá.colon transverso,
CCS= cá.colon sigmoides,
$\mathbf{C C l}=$ cá.colon izquierdo,
$\mathrm{CCD}=$ cá.colon derecho

\begin{tabular}{|c|c|c|cr|}
\cline { 2 - 3 } \multicolumn{1}{c|}{} & $\begin{array}{c}\text { Grupo A } \\
\text { LAPAROTOMíA } \\
1998-99\end{array}$ & $\begin{array}{c}\text { Grupo B } \\
\text { EST.VIDEOLAP } \\
2000-04\end{array}$ & & \multicolumn{1}{c}{} \\
\hline $\mathbf{N}$ & 56 & 74 & & \\
\cline { 1 - 3 } Media Edad & 65,4 & 66,9 & Test $\mathbf{t}=0.68 \quad$ No Significativo \\
\hline Razón V/M & .93 & 1,55 & $\mathbf{X}^{\mathbf{2} / \mathbf{T}}=0.60 \quad$ No Significativo \\
\hline
\end{tabular}

\begin{tabular}{|l|c|c|cc|}
\hline CR & 26 & 23 & $\mathbf{X}^{2}=1.43$ & No Significativo \\
\hline CCT & 5 & 6 & $\mathbf{X}^{2}=0.02$ & No Significativo \\
\hline CCS & 16 & 24 & $\mathbf{X}^{2}=0.12$ & No Significativo \\
\hline CCI & 2 & 2 & $\mathbf{X}^{2}=0.056$ & No Significativo \\
\hline CCD & 7 & 19 & $\mathbf{X}^{2}=2.35$ & No Significativo \\
\hline
\end{tabular}

Posteriormente, comprobamos la frecuencia con que se presentaron en nuestros grupos A (estadificación por laparotomía) y B (estadificación videolaparoscópica) las circunstancias habitualmente condicionantes de Laparotomías No Terapéuticas, como son: 1- el hallazgo de Carcinomatosis Peritoneal, y/o 2- la presencia de Metástasis Hepáticas muy 
extensas y cercanas a los elementos nobles intrahepáticos ó Múltiples en ambos lóbulos hepáticos, que no habían sido diagnosticadas por los estudios por imágenes preoperatorios, o bien otros elementos hallados durante la estadificación que impidan la resección en pacientes portadores de metástasis hepáticas avanzadas. (cuando coexistieron ambas circunstancias, se las computó sólo como carcinomatosis peritoneal )

Tabla 5: Comparación de causas de irresecabilidad

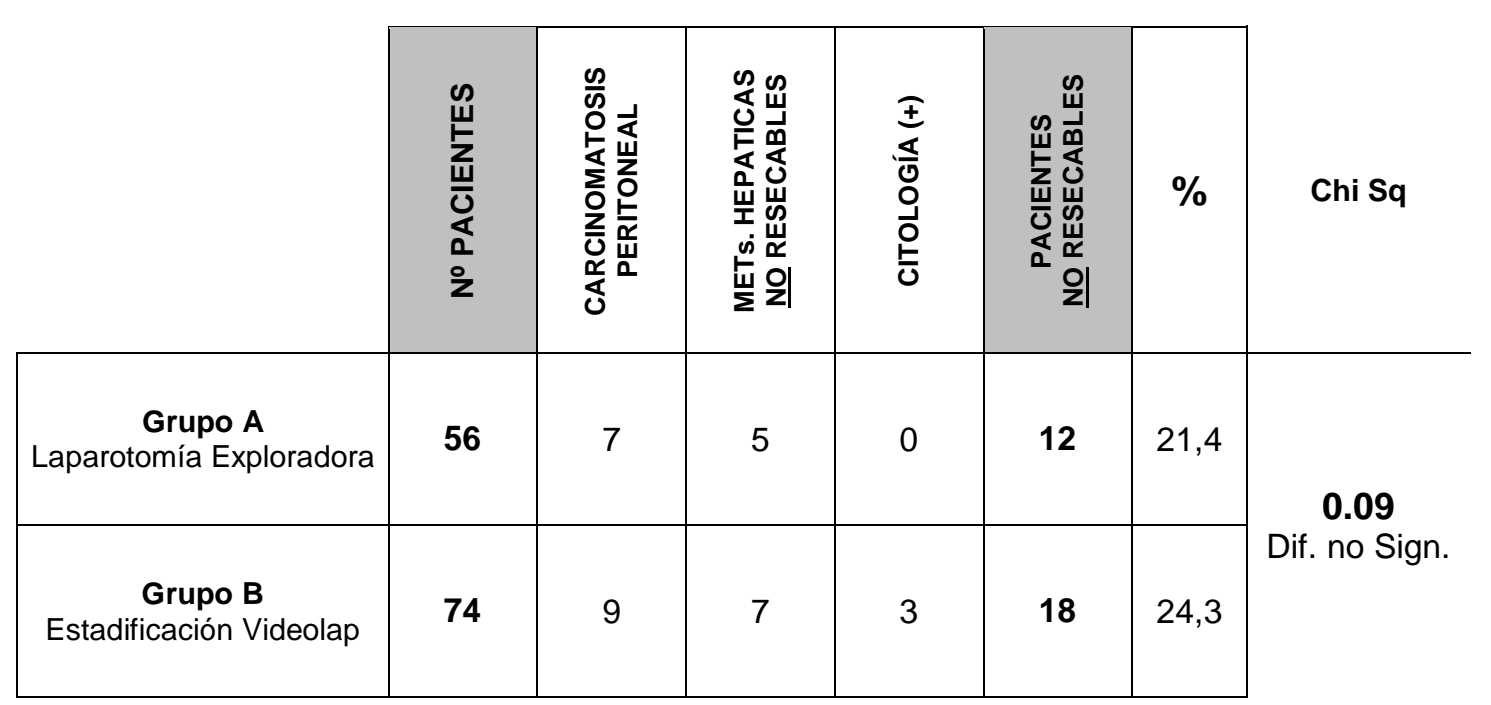

La frecuencia fue de alrededor del $20 \%$ en ambos grupos y la diferencia entre ellos no fue estadísticamente significativa, lo cual hace a los grupos comparables para la determinación de la variable "en estudio”, cantidad de Laparotomías No Terapéuticas. 
Tabla 6: Comparación de Laparotomías no terapéuticas

\begin{tabular}{|l|c|c|c|c}
\cline { 2 - 4 } \multicolumn{1}{c|}{} & $\mathbf{n}$ & $\begin{array}{r}\text { Laparot } \\
\text { No Terap }\end{array}$ & $\%$ & \multirow{2}{*}{$\mathbf{X}^{\mathbf{2}}$} \\
\hline Laparotomía Exploradora & 56 & $\mathbf{1 2}$ & 21,43 & \multirow{2}{*}{7.36} \\
\hline Estadificación Videolap & 74 & $\mathbf{3}$ & 4,05 & $\mathbf{p}<\mathbf{0 . 0 1}$ \\
\hline
\end{tabular}

En sólo $3(4,05 \%)$ de nuestros casos estadificados videolaparoscópicamente, no encontramos razones para proceder a la resección tumoral y/o de una metástasis única accesible, y cuando realizamos la laparotomía no los pudimos llevar a cabo, y sólo pudimos hacer un procedimiento paliativo, usualmente una derivación colostómica del tránsito, que podríamos haber realizado con videoasistencia y sin necesidad de llegar a una laparotomía. Sin embargo cuando comparamos esa cifra con las $12(21,43 \%)$ de los casos del grupo A, estadificados por laparoscopia, la diferencia resulta estadísticamente significativa.

En cuanto a la determinación de la sensibilidad de la Estadificación Videolaparoscópica para detectar condiciones de irresecabilidad en pacientes con Cáncer Colorrectal avanzado, hemos decidido no sólo determinar la sensibilidad como parámetro del comportamiento del test, sino también las tasas de errores $\alpha$ y $\beta$ y el valor predictivo positivo y negativo del test, referido ,más al potencial portador de metástasis y/o carcinomatosis que al test. 
Tabla 7: Determinación de la Sensibilidad, Especificidad, Tasas de Error $\alpha$ y $\beta$ y Valor Predictivo de la Estadificación Videolaparoscópica para detectar condiciones de irresecabilidad en pacientes con Cáncer Colorrectal avanzado

\begin{tabular}{|c|c|c|}
\hline & NO Resecables & Resecables \\
\hline EVL (+) & $\begin{array}{ll}(+) \vee & \\
& 15\end{array}$ & $\begin{array}{lll}F(+) & & \\
& 1\end{array}$ \\
\hline EVL (+) & $\mathrm{F}(-)$ & $\begin{array}{ll}(-) \mathrm{V} & \\
& 55\end{array}$ \\
\hline
\end{tabular}

1- SENSIBILIDAD: $\frac{(+) V}{(+) V+F(-)}=\frac{15}{15+3}=0,83$

2- ESPECIFICIDAD : $\frac{(-) \mathrm{V}}{(-) \mathrm{V}+\mathrm{F}(+)}=\frac{55}{55+1}=\mathbf{0 , 9 8}$

3- Tasa ERROR $\beta$ : $\frac{F(+)}{F(+)+(-) V}=\frac{3}{3+15}=\mathbf{0 , 1 7}$

4- Tasa ERROR $\alpha$ : $\frac{F(-)}{F(-)+(+) V}=\frac{1}{1+55}=\mathbf{0 , 0 2}$

5- VALOR PRedictivo (+): $\frac{(+) \mathrm{V}}{(+) \mathrm{V}+\mathrm{F}(+)}=\frac{15}{15+1}=\mathbf{0 , 9 4}$

6- VAlOR PRedictivo (-): $\frac{(-) \mathrm{V}}{(-) \mathrm{V}+\mathrm{F}(-)}=\frac{55}{55+3}=\mathbf{0 , 9 5}$ 
Lo que podría expresarse diciendo que la Sensibilidad de la Estadificación Videolaparoscópica para detectar condiciones de irresecabilidad en pacientes con Cáncer Colorrectal avanzado es del $83 \%$, con una Especificidad del 98\%, Tasa de Error $\alpha$ del 2\%, Tasa de Error $\beta$ del 17\%. Siendo el Valor Predictivo Positivo del $94 \%$ y el Valor Predictivo Negativo del $95 \%$

Para finalizar, y con la finalidad de tener una idea global de las ventajas del método para ser utilizado en éstos pacientes, comparamos los días de estada promedio de cada uno de los grupos.

Tabla 8: Comparación de la duración de las internaciones

\begin{tabular}{|l|c|c|c|}
\hline & $\begin{array}{c}\text { No } \\
\text { Resecados }\end{array}$ & D.Estada & X D.E. \\
\hline Laparotomía Exploradora & 12 & 77 & 6,4 \\
\hline Estadificación Videolap & 18 & 38 & 2,1 \\
\hline
\end{tabular}

Y comprobamos que existe una diferencia de más de 4 días de internación en el promedio de días de estada entre ambos grupos, a favor de aquellos en los que se evitó la laparotomía. 


\section{2-J-4 - Conclusiones:}

1- La sensibilidad de la Estadificación Videolaparoscópica para detectar condiciones de irresecabilidad en pacientes con Cáncer Colorrectal avanzado en nuestro estudio fue del 83\%, con una Especificidad del 98\%.

2- Con los estudios convencionales para estadificar el CCR que se practican en nuestro medio: - radiografía contrastada de colon, - ecotomografía de hígado y abdomen, y tomografía axial computarizada helicoidal dinámica del abdomen y pelvis; el diagnóstico de carcinomatosis peritoneal se hizo, en todos los casos, bajo visión directa del peritoneo en la operación. Por lo que podemos afirmar que: la utilización de la videolaparoscopía para explorar la cavidad, evitó la realización de una laparotomía no terapéutica en los pacientes portadores de carcinomatosis peritoneal.

3- Además, la videolaparoscopía fue útil para determinar la presencia de metástasis superficiales en las caras expuestas del hígado, no detectadas por los métodos convencionales por imágenes en el preoperatorio, y permitió realizar tratamientos videoasistidos, como la colocación de agujas para aplicar radiofrecuencia sobre lesiones ubicadas en los sitios más inaccesibles y peligrosos para la resección, transformando en operable un hígado con metastasis irresecables. También, demostró ser útil en pacientes portadores de metastasis hepáticas aparentemente resecables de acuerdo con los estudios por imágenes preoperatorios. 
4- Cuando encontramos ascitis, aunque sea una pequeña cantidad, nos permite tomar muestras por aspiración mediante un catéter para hacer su análisis citológico en busca de células neoplásicas, con lo cual obtenemos un muy valioso parámetro pronóstico.

5- La estadificación videolaparoscópica en pacientes con Cáncer Colorrectal disminuyó críticamente la tasa de laparotomías no terapéuticas en los pacientes con carcinomatosis peritoneal y con metástasis hepáticas irresecables. Consecuentemente se notó una recuperación postoperatoria más rápida y una estadía hospitalaria significativamente más baja en dicho grupo $B$ de pacientes.

6- Lo dicho precedentemente, hace muy recomendable el uso sistemático de la Estadificación Videolaparoscópica previo a la realización de la laparotomía con fines resectivos en el tratamiento de los Cánceres Colorrectales.

Medico Alberto H.CARIELLO

Doctorando
Profesor. Dr. Juan A. BASUELDO FARJAT

Co- Director de la Carrera
Profesor Dr. Jorge R. DEFELITTO

Director de la Carrera 


\section{4- Bibliografía:}

1. Koea J, Rodgers M, Thompson P, Woodfield J, Holden A \& Mc Call J Laparoscopy in the management of colorectal cancer metastatic to the liver, ANZ Journal of Surgery Dec 2004, 74 (12):1056-59,

2. Jarnagin WR, Fong Y, Ky A, Schwartz LH, Paty PB, Cohen AM, Blumgart LH., Liver Resection for Metastatic Colorectal Cancer: assessing the Risk of Ocult Irresecable Disease, J.Am.Coll.Surg. Jan 1999, 188(1):33-42,

3. Milsom JW, Kim SH.,\& Seon-Hahn K, Laparoscopic versus open surgery for colorectal cancer.World J Surg. 1997, 21(7):702-5.

4. Marchesa P, Milsom J, Hale JC, O’Malley CM, \& Fazio VW Intraoperative laparoscopic liver ultrasonography for Staging of Colorectal Cancer.Initial experience. Di.Colon Rectum 1996, 39:S73-8,

5. Hartley JE \& Monson JR., The Role of Laparoscopy in the Multimodality Treatment of Colorectal Cancer, Surg.Clin.N.Am. 2002, 82:1019-1034,

6. Viola R, y Santángelo H, Cáncer de Recto: cirugía videoscópica. Pren. Méd. Argent. 1997, $84: 785-9$,

7. Torres R, Orban R, Beltrame O, y Serra E, Amputación abdominoperineal asistida por laparoscopia Rev.Argent.Cirug. 2000, 79:102-7,

8. Foroutani A, Garland AM, Berber E, String A, Engle K, Ryan TL, et al Laparoscopic Ultrasound vs. Trifasic Computed Tomographyfor Detecting Liver Tumors, Arch.Surg Aug 2000, 135(8):933-38,

9. Metcalfe MS, Close JS, Iswariah H, Morrison C, Wemyss-Holden SA, Maddern GJ., The Value of Laparoscopic Staging for Patients with Colorectal Cancer, Arch.Surg 2003, 138:770-2

10. Velanovich V. Staging Laparoscopy in the Management of Intra-Abdominal malignancies, Surgery 1998, 124:773-81

11. Schima W, Kulinna C, Ba-Ssalamah A, Grunberger T., Multidetector computed tomography of the liver, Radiologe. 2005 Jan;45(1):15-23.

12. Awai K, Imuta M, Utsunomiya D, Nakaura T, Shamima S, Kawanaka K, et al., Contrast enhancement for whole-body screening using multidetector row helical CT: comparison between uniphasic and biphasic injection protocols. Radiat Med. 2004 Sep-Oct; 22(5):303-9

13. Ellsmere J, Mortele K, Sahani D, Maher M, Cantisani V, Wells W, Brooks D, Rattner D, Does multidetector-row CT eliminate the role of diagnostic laparoscopy in assessing the resectability of pancreatic head adenocarcinoma?, Surg Endosc. 2005 Mar;19(3):369-73.

14. Schlemmer HP, Schafer J, Pfannenberg C, Radny P, Korchidi S, Muller-Horvat C, et al., Fast whole-body assessment of metastatic disease using a novel magnetic resonance imaging system: initial experiences, Invest Radiol. 2005 Feb;40(2):64-71.

15. Selzner M, Hany T, Wildbrett P, McCormack L, Kadry $\mathbf{Z}$ and Clavien $\mathbf{P}$, Does the Novel PET/CT Imaging Modality Impact on the Treatment of Patients With Metastatic Colorectal Cancer of the Liver? , Annals of Surgery • Dec 2004, Vol240 6:1037-36 
16. N.Amato, E.Sternberg, P.Pertierra, C.Muhlemberg, M.Clérici, Reconstrucción de la continuidad intestinal por laparoscopía luego de operación de Hartmann . Rev.Arg.Cirugía 2002, 83:3 y 4,

17. Actas del Congreso Argentino de Gastroenterología y Endoscopía Digestiva 2000 (FAGE SAGE - AAED), Guía de recomendaciones para el tratamiento del Cáncer Colorrectal, Buenos Aires, Argentina, del 8 al 12 de octubre de 2000

18. M.Salomón, E. Donnelly, C.Tyrrell, J.Patrón Uriburu, F. Bugallo, E. Podestá, ¿Es segura y efectiva la cirugía colorrectal laparoscópica en pacientes mayores de 75 años? Rev. Argent. Cirug 2004, 87 (3-4): 137-143

19. The Clinical Outcomes of Surgical Therapy (COST) Study Group, A Comparison of laparoscopically Assisted and Open Colectomy for Colon Cancer, N Engl J Med;350:2050-2059, 2004

20. Hazebroek EJ; COLOR Study Group. COLOR: a randomized clinical trial comparing laparoscopic and open resection for colon cancer.Surg Endosc. 2002 Jun;16(6):949-53. Epub 2002 Mar 18.

21. Pappas T. N., Jacobs D. O. Laparoscopic Resection for Colon Cancer - The End of the Beginning? N Engl J Med 2004; 350:2091-2092, May 13, 2004

22. Weeks J; Nelson H.; Gelber S; Sargent D,; Schroeder, G; for the Clinical Outcomes of Surgical Therapy (COST) Study Group, Short-term Quality-of-Life Outcomes Following LaparoscopicAssisted Colectomy vs Open Colectomy for Colon Cancer A Randomized Trial JAMA. 2002;287:321-328

23. Vogel P, Ruschoff J, Kummel S, Zirngibl H, Hofstadter F, Hohenberger W, et al., Prognostic value of microscopic peritoneal dissemination: comparison between colon and gastric cancer. Dis Colon Rectum. 2000 Jan;43(1):92-100

24. www.nci.nih.gov . National Cancer Institutte, American Cancer Society, Surveillance Reserch 2002-Cancer Facts and Figures: Colorectal cancer and Early Detection - (Updated jan 05, consultado mayo 2005)

25. Fundación FUNDONAR - Compendio del Registro del Cáncer de la Provincia de Buenos Aires, Ed.CATA, 1999 - Coordinadora: Dra. Silvia Bonicato

26. http://web.facs.org/ncdbbmr/sas6/surv/GRAPHS/OY96S14XaT00000B.htm - NCDB, Commis sion on Cancer, ACoS/ACS. Survival Reports, $l$, (Updated May 05, consultado 9 septiembre 2005)

27. Hawk ET, Limburg PJ, Viner JL., Epidemiology and prevention of colorectal cancer, Surg Clin North Am. 2002 Oct;82(5):905-41

28. Nivatvongs,S.; Surgery for Early Colon Cancer. World J. Surg 2000, 24: 1052-55

29. Park Y, Kim W, Paeng S \& Park J.; Histoclinical Analisis of Colorectal Cancer. World J. Surg 2000, 24: 1030-35

30. Schlemper RJ, Itabashi M, Kato Y, Lewin KJ, Riddell RH, Shimoda T, et al Differences in the diagnostic criteria used by Japanese and Western pathologists to diagnose colorectal carcinoma. Cancer. 1998 Jan 1;82(1):60-9

31. Watanabe, T \& Muto T Colorectal Carcinogenesis Based on the Molecular Biology of Early Colorectal Cancer, with Special reference to Nonpolypoid (Superficial) Lesions. World J. Surg.2000, 24: 1091-97 
32. Matsui, T, Yao T \& Iwashita A ; Natural History of Colorectal Cancer. World J. Surg 2000, 24:1022-28

33. Japanese Research Society for Cancer of the Colon and Rectum, General rules for clinical and pathological studies on cancer on the colon, rectum and anus. Histological Clasification. (Jpn.J. Surg. 13:574, 1983) Repr. World J. Surg 2000, 24:1023

34. Haggitt RC. Glotzbach RE. Soffer EE. Wruble LD. Prognostic factors in colorectal carcinomas arising in adenomas: implications for lesions removed by endoscopic polypectomy. Gastroenterology 1985 Aug., 89(2):328-36

35. Maruyama M, Koizumi K, Kai S, Kazami A \& Handa T.; Radiografic Diagnosis of Colorectal Cancer, with Special Reference to the Superficial Type of Invasive Carcinoma. World J. Surg 2000,

36. Fearon ER, A genetic basis for the multi-step pathway of colorectal tumorigenesis Pr. Takamatsu Symp.;22:37-48, 1991

37. Luebeck EG, Moolgavkar SH. - Multistage carcinogenesis and the incidence of colorectal cancer. Proc Natl Acad Sci U S A.; 99(23), Nov 122002

38. Jass JR. Pathogenesis of colorectal cancer. Surg Clin North Am. 2002 Oct; 82(5):891-904

39. Baker S, Markowitz S, Fearon ER, Willson JK, Volgelstein B., Cell growth by wild-type p53 Science 249:912-5, Aug 1990

40. Fearon ER, Vogelstein B. A genetic model for colorectal tumorigenesis, Cell. 1;61(5):759-67, 1990 Jun

41. Trowbridge B, Burt RW. Colorectal cancer screening. Surg Clin North Am. 2002 Oct;82(5):943$5724: 1036$

42. Pickhardt PJ, Choi JR, Hwang I, Butler JA. Puckett ML, Hildebrandt H. et al, Computed tomographic virtual colonoscopy to screen for colorectal neoplasia in asymptomatic adults $\mathrm{N}$ Engl $\mathrm{J}$ Med 2003; 349:2191-2200

43. Northover J., Staging and management of colorectal cancer, World J.Surg. 1997, 21,672-677

44. Hermanek P, Wittekind $\mathbf{C}$. The pathologist and the residual tumor $(R)$ classification. Pathol Res Pract. 1994 Feb;190(2):115-23

45. Greene F, Stewart A, and Norton HJ A new TNM staging strategy for node-positive (stage III) colon cancer, Ann.Surg 2002, Vol.232 4:416

46. American Joint Committee on Cancer, Page D. (editor), Cancer Staging Manual. 6th ed. - disponible en http:// www. cancerstaging.org/education/tnmschema /colonandrectum.ppt

47. Dukes CE \& Bussey HJ, The spread of rectal cancer and its effect on prognosis , Br.J.Cancer 1958; 12:309-12, On Line Data Base on the Internet [cited Sept 2005] Available at: http:// www.ovid.com/site/index.jsp

48. Astler Vb \& Coller FA, The prognostic significance of direct extension of carcinoma of the colon and rectum, Ann.Surg. 1954; 139846-52

49. Jass J, Role of Pathologist in Reporting Colorectal Cancer, World J.Surg 1997, 21:688-93 
50. Kitagawa Y, Fujii H, Mukai M, Kubota T, Ando N, Watanabe $M$ et al. The role of sentinel lymph node in Gastrointestinal Cancer. Surg.Clin.N.Am. 2000, 80:6, 1799 - 1809,

51. Veronesi V, Paganelli G, Galimberti V, Viale G, Zurrida S, Bedoni M, et al Sentinel node biopsy to avoid axillary disection in breast cancer with clinically negative lymph-nodes. Lancet 1997 , 349:1864-67

52. Saha S., Nora D., Wong JH., Wise D. Sentinel node mapping in Colorrectal Cancer a review. SCNA 2000, 80: 1811-19

53. Wong JH. A Historical perspective on the development of intraoperative lymphatic mapping and selective lymphadenectomy. SCNA 2000, 80: 1675 - 82

54. Esser S, Reilly WT, Riley LB, Eyvazzadeh C, Arcona S.. The role of Sentinel node mapping in staging of Colorectal Cancer. Dis Colon Rectum 2001, 44:850-56

55. Ratto C, Sofo L, Ippoliti M, Merico M, Bossola M, Vecchio FM, et al. Accurate lymph node detection in colorrectal specimens resected for cancer is of Prognostic significance. Discolon Rectum 1999,$42 ; 143 ; 58$

56. Treseler P.A., Tauchi P.S.. Pathologic Analysis of the sentinel lymph node. SCNA 2000, 80:16951719

57. Saha S, Bilchik A, Wiese D, Espinosa M, Badin J, Ganatra BK et al Ultrastreging of Collorrectal Cancer by Sentinel Lymph node mapping technique. A multicentric Trial Ann Surg Oncol. 2001, 8(95) 94-98

58. Wood TF, Saha S, Morton DL, Tsioulias GJ, Rangel D, Hutchinson W et al. Validation of lymphatic mapping in colorectal cancer: in vivo, ex vivo, and laparoscopic techniques. Ann Surg Oncol. 2001, 8(2):150-7

59. Wood TF, Spirt M, Rangel D, Shen P, Tsioulias GJ, Morton DL et al. Lymphatic mapping improves Staging During Laparoscopic Colectomy for Cancer. Surg Endosc 2001, 15: 715 - 19

60. Rotholz N y cols, Factibilidad técnica del mapeo linfático en el cáncer colorrectal. Rev.Argent. Cirug. 2002, 83 (1-2):42-50

61. Bilchik AJ, Nora DT., Lymphatic Mapping of Nodal Micrometastases in Colon Cancer: Putting the Cart Before the Horse?. Ann.Surgic.Oncol 2002 Jul, 9(6):529-31

62. Dingemans KP, Roos E, van den Bergh Weerman MA, van de Pavert IV Invasion of liver tissue by tumor cells and leukocytes: comparative ultrastructure, .J Natl Cancer Inst. 1978;60(3):583-98

63. Roos E, Dingemans KP. Mechanisms of metastasis, Biochim Biophys Acta. 1979 Feb 4;560(1):135-66

64. Strauli P, Weiss L. Cell locomation and tumor penetration. Report on a workshop of the EORTC cell surface project group, Eur J Cancer. 1977 Jan;13(1):1-12.

65. Penna C \& Nordlinger B, .Colorectal metastasis (liver and lung).[review] Surg Clin North Am. 2002 Oct;82(5):1075-90

66. Nakamura S, Suzuki S \& Baba S., Resection of liver metastases of colorectal carcinoma. World J Surg. 1997, 21(7):741-7. 
67. Khan AN, Macdonald S \& Amin Z (editor), Liver Metastases,[monography on the Internet], emedicine, Radiology (updated Nov.21,2003) (cited Set.13,2005) Available at: http://www.emedicine.com/radio/topic394.htm

68. Hotta N, Tagaya T, Maeno T, Ayada M, Sato K, Ishikawa T et al , Advanced dynamic flow imaging with contrast-enhanced ultrasonography for the evaluation of tumor vascularity in liver tumors, Clin Imaging. 2005 Jan-Feb;29(1):34-41.

69. Hartley JE, Kumar H, Drew PJ, Heer K, Avery GR, Duthie GS, Monson JR. Laparoscopic ultrasound for the detection of hepatic metastases during laparoscopic colorectal cancer surgery.Dis Colon Rectum. 2000 Mar;43(3):320-4

70. Callery MP, Strasberg SM, Doherty GM, Soper NJ, Norton JA. Staging laparoscopy with laparoscopic ultrasonography: optimizing resectability in hepatobiliary and pancreatic malignancy, .J Am Coll Surg. 1997 Jul;185(1):33-9

71. Atasoy C, Akyar S. Multidetector CT: contributions in liver imaging., Eur J Radiol. 2004 Oct;52(1):2-17.

72. Ellsmere J, Mortele K, Sahani D, Maher M, Cantisani V, Wells W et al, Does multidetector-row CT eliminate the role of diagnostic laparoscopy in assessing the resectability of pancreatic head adenocarcinoma? Surg Endosc. 2005 Mar;19(3):369-73

73. Nelson R. Radiological evaluation of metastases to the liver:The Emory Experience. In Sugarbaker P (editor), Hepatobiliary Cancer, Boston, Kluwer Acad.Publishers 1994, p 129-46

74. Schlemmer,H, Schafer J, Pfannenberg C, Radny P, Korchidi S, Muller-Horvat C et al . Fast whole body assesment of metastatic disease using a novel Magnetic Resonance Imaging system: initial experience, Investigative Radiology 40(2):64-71 Feb.2005)

75. Jardine VL, Sala E, Lomas DJ, MR colonography: baseline appearance of the unprepared rectosigmoid., Br J Radiol. 78(927):202-6, 2005

76. Ajaj W, Lauenstein TC, Pelster G, Holtmann G, Ruehm SG, Debatin JF, et al MR colonography in patients with incomplete conventional colonoscopy. Radiology. 2005 Feb;234(2):452-9

77. Johnson K, Bakhsh A, Young D, Martin TE Jr Correlating computed tomography and positron emission tomography scan with operative findings in metastatic colorectal cancer. Dis Colon Rectum. 2001 Mar;44(3):354-7.

78. Roman C, Martin W, and Delbeke D, Incremental Value of Fusion Imaging With Integrated PETCT in Oncology, Clin Nucl Med 2005;30: 470-477

79. Selzner M, Hany T, Wildbrett P, McCormack L, Kadry Z, Clavien PA Does the Novel PET/CT Imaging Modality Impact on the Treatment of Patients With Metastatic Colorectal Cancer of the Liver? Ann Surg 2004;240: 1027-36

80. Gorospea L, Ramanb S, Echevestea J, Avrilb N,Herreroa Y \& Hernandeza S, Whole-body PET/CT: Spectrum of physiological variants, artifacts and interpretative pitfalls in cancer patients Nucl. Med. Comm. 2005, 26:671-687

81. Pradier R, García salas C, Kirchuk R y Loria D, Pautas en Oncología Hospital "Angel Roffo" UBA - ISBN 987-97055-9-9 Ed.Médicas SA, Bs As, 2000, pag. 68-78 
82. Abbruzzese J, Curley S, Janjan N, Lee J, Sinicope F \& Skibber J - Practice Guidelines of the U. of Texas MD Anderson Cancer Center- University of Texas, MD Anderson CC (posted 9/2/05) Available at http://utm-ext01a.mdacc.tmc.edu/mda/cm/cwtguide.nsf/LuHTML/SideBar1

83. Tjandra JJ, Kilkenny JW, Buie WD, Hyman N, Simmang C, Anthony T et al Practice Parameters for the Management of Rectal Cancer (Revised by The Standards Practice Task Force of The American Society of Colon and Rectal Surgeons) Dis.Colon Rectum 2005, 48:411-23 - Available at: http://www.fascrs.org/associations/1843/files/rectal_cancer_0605.pdf

84. Schlegel R y Parc R, La técnica quirúrgica de la anastomosis coloanal con reservorio colónico en "J". Rev.Argent.Cirug. 72:198-202, 1997

85. Ojea Quintana G, Benati M, Bonadeo Lasalle F, Vaccaro C, Resección primaria con anstomosis en el cáncer oclusivo de colon izquierdo. Rev.Argent.Cirug. 79:102-7, 2000

86. Vaccaro C, Bonadeo Lasalle F, Benati M y cols, Limpieza colónica mecánica: polietilenglicol vs. una nueva preparación de bajo volumen. Rev.Argent.Cirug. 73:115-23, 1997

87. Vaccaro C, Bonadeo Lasalle F, Benati M y cols, Preparación preoperatoria en cirugía colorrectal electiva : una evaluación prospectiva. Rev.Argent.Coloproct 7:14-9, 1996

88. Jarnagin WR, Fong Y, Ky A, Schwartz LH, Paty PB, Cohen AM, Blumgart LH Liver resection for metastatic colorectal cancer: assessing the risk of occult irresectable disease. J Am Coll Surg. 1999 Jan;188(1):33-42.

89. Andreani $\mathbf{O}$ y cols, Rev. Argent. Análisis de la morbi-mortalidad en 225 resecciones hepáticas, Cirug., 85 (3-4): 156-168, 2003

90. Asbun H, Tsao J \& Huges K, Resection of Hepatic Metastases from Colorectal Carcinoma, In: Sugarbaker P (editor), Hepatobiliary Cancer., Boston, Kluwer Academic Publishers 1994, pag.3342, ISBN 0-7923-2501

91. Penna C, Nordlinger B - Colorectal metastasis (liver and lung) - Surg.Clin.N.Am 82:1075-90, 2002

92. Nordlinger B, Surgical Management of Hepatic Metastases from Large Bowel Cancer, In: Sugarbaker P (editor), Hepatobiliary Cancer., Boston, Kluwer Academic Publishers 1994, pag.43-52, ISBN 0-7923-2501

93. Grobmyer SR, Fong Y, D'Angelica M, Dematteo RP, Blumgart LH, Jarnagin WR. Diagnostic laparoscopy prior to planned hepatic resection for colorectal metastases. Arch Surg. 2004 Dec; 139 (12):1326-30.

94. Berber E, Senagore A, Remzi F, Rogers S, Herceg N, Casto K, Siperstein A. Laparoscopic radiofrequency ablation of liver tumors combined with colorectal procedures. Surg Laparosc Endosc Percutan Tech. 2004 Aug;14(4):186-90

95. E.de Santibañes, F. Bonofiglio, J.Acuña Barrios, M.Ciardullo, J.Pekolj, J.Sívori, O.Mazza, G.Arbues, F.Maceda, M.López , M.Moro, Resecciones hepáticas.importancia de la técnica quirúrgica y anestésica en el consumo de sangre y hemocomponentes, Rev. Argent. Cirug., 84 (1-2): $62-70,2003$ 
96. M.Secchi, L.Quadrelli, G.Raimundo, L.Rossi, A.Ramadán, J.Bandeo, D.Castellini, Resecciones hepáticas. nueva terminología y nuestra experiencia en el Hospital Italiano de Rosario Rev. Argent. Cirug., 84 (1-2): 79-90, 2003

97. O.Andriani, D.Beltramino, M.Fauda, V.Descalzi, C.Luque, G.Orce, F.Klein, M.Silva, F.Villamil, L.Podestá, Análisis de la morbi-mortalidad en 225 resecciones hepáticas, Rev. Argent. Cirug., 85 (3-4): 156-168, 2003

98. Bismuth H, Adam R, Levi F, Farabos C, Waechter F, Castaing D, et al Resection of nonresectable liver metastases from colorectal cancer after neoadjuvant chemotherapy. Ann Surg. 1996 Oct ;224 (4):509-20; discussion 520-2.

99. Madoff DC, Abdalla EK, Vauthey JN. Portal vein embolization in preparation for major hepatic resection: evolution of a new standard of care. J Vasc Interv Radiol. 2005 Jun;16(6):779-90.

100.E. de Santibañes, R. García Mónaco, M. Ciardullo, J. Pekolj, J. Acuña Barrios, G. Arbúes, O. Mazza, O. Peralta, J.A. Sívori, Oclusión portal previa a la resección hepática. indicaciones y resultados. Rev.Arg.Cirugía 83:3 y 4, Set/Oct 2002

101.Berber E, Senagore A, Remzi F, Rogers S, Herceg N, Casto K, Siperstein A Laparoscopic radiofrequency ablation of liver tumors combined with colorectal procedures. Surg Laparosc Endosc Percutan Tech. 2004 Aug;14(4):186-90

102. Curley SA, Izzo F, Delrio P, Ellis LM, Granchi J, Vallone P, et al Radiofrequency ablation of unresectable primary and metastatic hepatic malignancies: results in 123 patients. Ann Surg. 1999 Jul;230(1):1-8

103.Glehen O, Kwiatkowski F, Sugarbaker PH, Elias D, Levine EA, De Simone M, Cytoreductive surgery combined with perioperative intraperitoneal chemotherapy for the management of peritoneal carcinomatosis from colorectal cancer: a multi-institutional study. J Clin Oncol. 2004 Aug 15;22 (16):3284-92

104.Jacquet P, Sugarbaker PH: Clinical research methodologies in diagnosis and staging of patients with peritoneal carcinomatosis. Cancer Treat Res 82:359-374, 1996

105.Sugarbaker PH. Colorectal carcinomatosis: a new oncologic frontier. Curr Opin Oncol. 2005 Jul; 17(4):397-9.

106.Sugarbaker PH. Carcinomatosis--is cure an option? J Clin Oncol. 2003 Mar 1;21(5):762-4.

107.Miyayama S.et al., Malignant Colonic Obstruction due to Extrinsic Tumor:Palliative Treatment with a Self-Expanding Nitinol Stent. Am.J.Roentgenol. 175:1631-7, 2000

108. Gimenez M., Suarez Anzorena F. y cols, Empleo de prótesis expandibles metálicas en el tubo digestivo, Rev.Argent.Cirug.,73:41-8, 1997

109.Sengupta S, Tjandra J - Local Excision of Rectal Cancer, What is the evidence? - Dis.Colon Rectum $2001 ; 44: 1345-61$ -

110.Bleday R.Local excision of rectal cancer.World J Surg.;21(7):706-14. 1997

111.Paty P, Nash GM, Baron P, Zakowski M, Minsky B, Blumberg D et al, Long-Term Results of Local Excision for Rectal Cancer. Ann. Surg. 2002, 236 (4): 522-30. 
112.Lev-Chelouche D, Margel D, Goldman G \& Rabau, M, Transanal Endoscopic Microsurgery: Experience with 75 Rectal Neoplasms Dis.Colon Rectum 2000 May, 43: (5) 662-8

113.E. Donnelly, M. Salomón, F. Bugallo y col Adenoma velloso de colon y recto. su relación con el cáncer. nuestra experiencia. Rev.Arg.Cirugía 81:3 y 4, Set/Oct 2001

114.O. Bosisio, A.Graziano, P. Ramírez Rojas y C. Gómez, Resección transanal de los adenomas vellosos del recto. análisis retrospectivo. Rev.Arg.Cirugía 81:3 y 4, Set/Oct 2001

115.Buess G, Kipfmuller K, Hack D, Grussner R, Heintz A, Junginger T. Technique of transanal endoscopic microsurgery. Surg Endosc. 1988;2(2):71-5

116.Buess GF, Raestrup H. Transanal endoscopic microsurgery. urg Oncol Clin N Am. 2001 Jul;10(3):709-31

117.Mentges B, Buess G, Schafer D, Manncke K, Becker HD, Local therapy of rectum carcinoma. A prospective follow-up study, Dis Colon Rectum. 1996 Aug;39(8):886-92.

118.F.Bonadeo, C.Vaccaro, G. Ojea Quintana, M.Benati, G.Castellano Eglof, A.Debat Cortés, R. Bosio Cáncer de recto - análisis de nuestra experiencia en los últimos 14 años, Rev. Argent. Cirug., 87 (3-4): 155-168, 2004

119.M.Benati, F.Bonadeo, C.Vaccaro, G. Ojea Quintana, Telenta M, Tratamiento radical del adenocarcinoma de recto inferior. Análisis de su estado actual Rev. Argent. Cirug., 71: 144-58, 1996

120.Benati M, Relato al $62^{\circ}$ Congreso Argentino de Cirugía: Adelantos en el diagnóstico y tratamiento del cáncer del recto y del ano, Rev. Argent. Cirug. 1991, Nº Extraordinario, Relatos.

121.R.Rijana, C.Rosales, A. Marmo y col, Anastomosis coloanal en el tratamiento del cáncer de recto inferior. indicaciones y resultados. Rev.Arg.Cirugía 82:1 y 2, Ene/Feb 2002

122.Donnelly E, Tyrrell C, Salomón M y cols, Relación del lavado preanastomótico y las células exfoliadas en el tratamiento del cáncer de Recto. Experiencia prospectiva. Rev. Argent. Cirug., 73:17984, 1997

123.Graf W, Dahlberg M, Osman MM, Holmberg L, Pahlman L, Glimelius B. Short-term preoperative radiotherapy results in down-staging of rectal cancer: a study of 1316 patients. Radiother Oncol. 1997 May;43(2):133-7

124.Dahlberg M, Glimelius B, Pahlman L. Improved survival and reduction in local failure rates after preoperative radiotherapy: evidence for the generalizability of the results of Swedish Rectal Cancer Trial.Ann Surg. 1999 Apr;229(4):493-7.

125.Folkesson J, Birgisson H, Pahlman L, Cedermark B, Glimelius B, Gunnarsson U Swedish Rectal Cancer Trial: long lasting benefits from radiotherapy on survival and local recurrence rate.J Clin Oncol. 2005 Aug 20;23(24):5644-50.

126.Sauer R, Becker H, Hohenberger W, Rödel K, Wittekind C, Rainer F, et al, for the German Rectal Cancer Study Group Preoperative versus Postoperative Chemoradiotherapy for Rectal Cancer N Engl J Med 2004;351:1731-40.

127.Bosset JF, Calais G, Mineur L, Maingon P, Radosevic-Jelic L, Daban A et al, Enhanced Tumorocidal Effect of Chemotherapy With Preoperative Radiotherapy for Rectal Cancer: Preliminary Results-EORTC 22921 J Clin Oncol 2005, 23:5620-5627. 
128.Kodner IJ, Myerson RJ Preoperative Radiation Therapy for Rectal Cancer In J.A.Reis Neto New Trends in Coloproctology [Book on the Internet] Livraria e Editora Revinter Ltda. ISBN 85-7309457-5 Available at: http://www.proctosite.com/library/books/livro_jreis_neto/index_new_trends.htm

129. Reis Neto JA, Quilici FA, Cordeiro F, Ciquini S, dos Reis JA Jr, Kagohara O,et al, Long-Term Results of Preoperative Radiotherapy for Cancer of the Lower Rectum In J.A.Reis Neto New Trends in Coloproctology [Book on the Internet] Livraria e Edit. Revinter Ltda., ISBN 85-7309-457-5, Available at: http://www.proctosite.com/library/books/livro_jreis_neto/index_new_trends.htm

130. Crane CH, Janjan NA, Mason K, Milas L. Preoperative chemoradiation for locally advanced rectal cancer: emerging treatment strategies. Review MD Anderson, U of Texas Oncology 2002 May; 16(5 Suppl 5):39-44.

131.Heald RJ, Husband EM, Ryall RD. The mesorectum in rectal cancer surgery--the clue to pelvic recurrence? Br J Surg. 1982 Oct;69(10):613-6

132.Salerno G, Daniels I, Heald RJ, Brown G, Moran BJ. Management and imaging of low rectal carcinoma.Review Surg Oncol. 2004 Aug-Nov;13(2-3):55-61.

133.Heald RJ, Smedh RK, Kald A, Sexton R, Moran BJ. Abdominoperineal excision of the rectum-an endangered operation. Norman Nigro Lectureship. Dis Colon Rectum. 1997 Jul;40(7):747-51

134. Wibe A, Moller B, Norstein J, Carlsen E, Wiig JN, Heald RJ, Langmark F, Myrvold HE, Soreide O; Norwegian Rectal Cancer Group. A national strategic change in treatment policy for rectal cancer--implementation of total mesorectal excision as routine treatment in Norway. A national audit. Dis Colon Rectum. 2002 Jul;45(7):857-66.

135.M. Barrionuevo, O. Cervini, J. Taullard, J. Valmaggia y A. Fernández, Investigación anatómica de los plexos autónomos génito-vesicales; su importancia en la cirugía del cáncer del recto .Rev.Arg.Cirugía 81:1 y 2, Jul/Ago 2001

136.Enker WE, Havenga K, Polyak T, Thaler H, Cranor M. Abdominoperineal resection via total mesorectal excision and autonomic nerve preservation for low rectal cancer. World J Surg. 1997 Sep;21(7):715-20

137.Lee JF. Maurer VM. Block GE. Anatomic relations of pelvic autonomic nerves to pelvic operations. Archives of Surgery. 107(2):324-8, 1973. Cited by: Ruo, L et al , Major 20th-Century Advancements in the Management of Rectal Cancer, Dis.Colon Rectum 42(5) 563-578, May 1999

138. Isacoff WH, Borud K, Chemotherapy for the treatment of patients with metastatic colorectal cancer: an overview. World J Surg.;21(7):748-62. 1997

139.Figueras J, Valls C, Rafecas A, Fabregat J, Ramos E, Jaurrieta E. Resection rate and effect of postoperative chemotherapy on survival after surgery for colorectal liver metastases. Br J Surg. $2001 \mathrm{Jul} ; 88(7): 980-5$.

140.Buell JF, Rosen S, Yoshida A, Labow D, Limsrichamrern S, Cronin DC, et al Hepatic resection: effective treatment for primary and secondary tumors. Surgery. 2000 Oct;128(4):686-93.

141.David G. Pfister, et al, Surveillance Strategies after Curative Treatment of Colorectal Cancer, N Engl J Med 350;2375-82, 2004

142.Donnely E.,Dávila M., Salomon M. Y cols, La recidiva neoplásica y los factores de pronóstico en el cáncer colorrectal.Investigación retrospectiva. Rev.Argent.Cirug. 77:27-34, 1999 
143.Ojea Quintana G M. Recidiva pelviana: Lugar de la braquiterapia, Actas IX Curso Internacional de Coloproctología - Hosp..Italiano Bs.As. - 9-10 Agosto 2002

144.Minetti M y cols, Tratamiento quirúrgico de la recurrencia del cáncer colorrectal Rev. Argent. Coloproct 7:20-3, 1996

145.Gunderson LL, y cols. External beam and intraoperative electron irradiation for locally advanced colorectal cancer. Ann Surg. 207:52-60,1988.

146.Gunderson L L,O'Connel M J, Dozois $\mathbf{R}$ R. The role of intraoperative irradiation in locally advanced primary and recurrent rectal adenocarcinoma. World J Surg 16: 495-501,1992.

147.Suzuki K, Gunderson L L, Devine R M, Weaver A L, Dozois R R, Ilstrup D M, Martenson J A, $\mathbf{O}^{\prime}$ Connell $\mathbf{M}$.Intraoperative radiation after palliative surgery for locally recurrent rectal cancer. Cancer 75: 939-952,1995.

148.Goes RN, Beart RW, Simmons AJ, Gunderson LL, Grado G, Streeter O. Use of brachitherapy in the management of locally recurrent rectal cancer. Dis Colon Rectum. Vol: 40, 1177-1179,1997.

149.Temple WJ, Saettler EB. Locally recurrent rectal cancer: role of composite resection of extensive pelvic tumors with strategies for minimizing risk of recurrence. J. Surg. Oncol. 73:47-59,2000.

150.World Medical Association General Assembly. World Medical Association Declaration of Helsinki: ethical principles for medical research involving human subjects. J Int Bioethique. 2004 Mar;15(1):124-9. Available at: http://www.wma.net/e/

151.World Medical Association. World Medical Association Declaration of Helsinki: ethical principles for medical research involving human subjects. J Postgrad Med. 2002 Jul-Sep;48(3):206-8 


\section{Anexo (imágenes)}




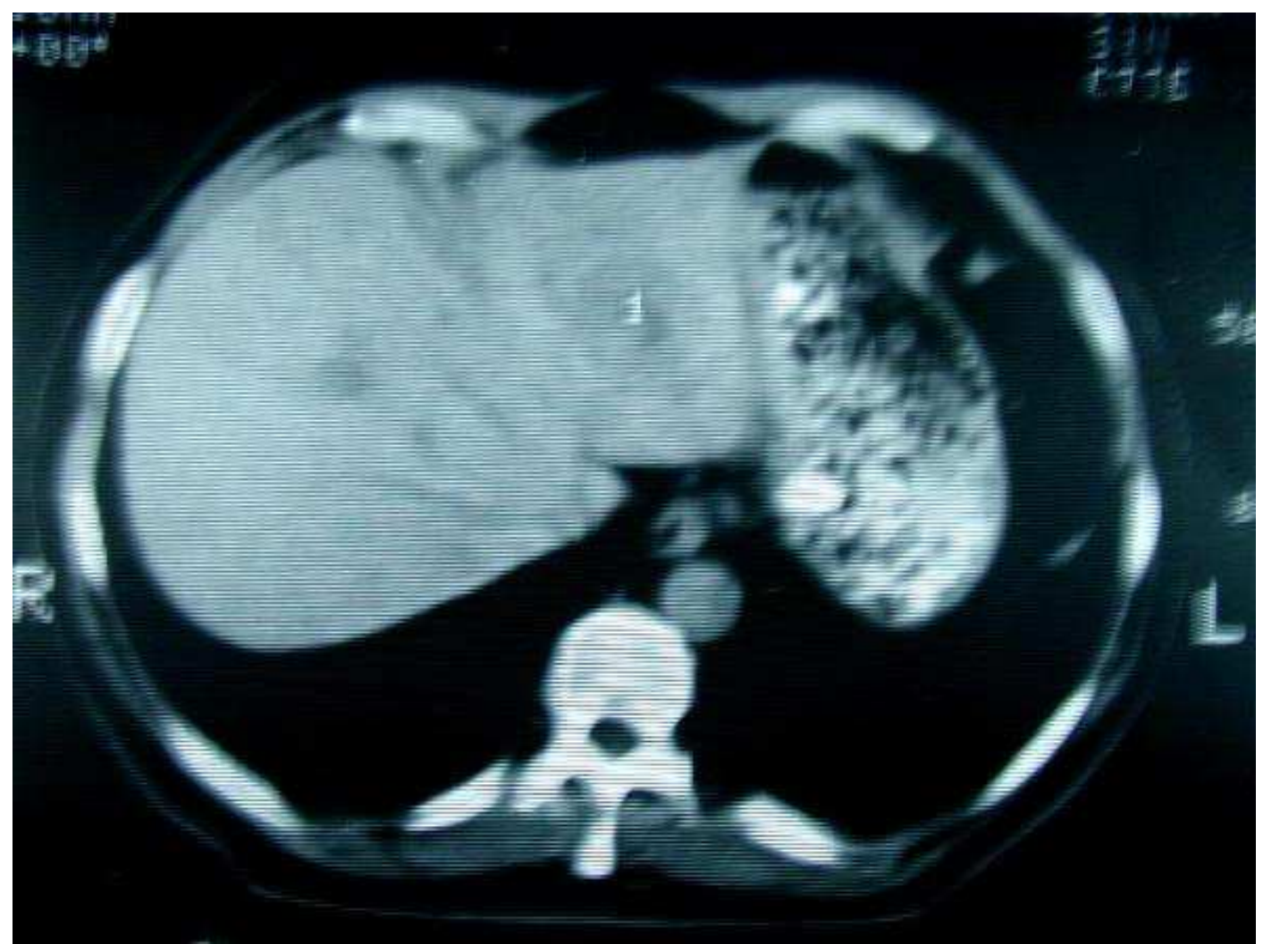

Foto 1: Tomografía axial computarizada que muestra una metástasis hepática

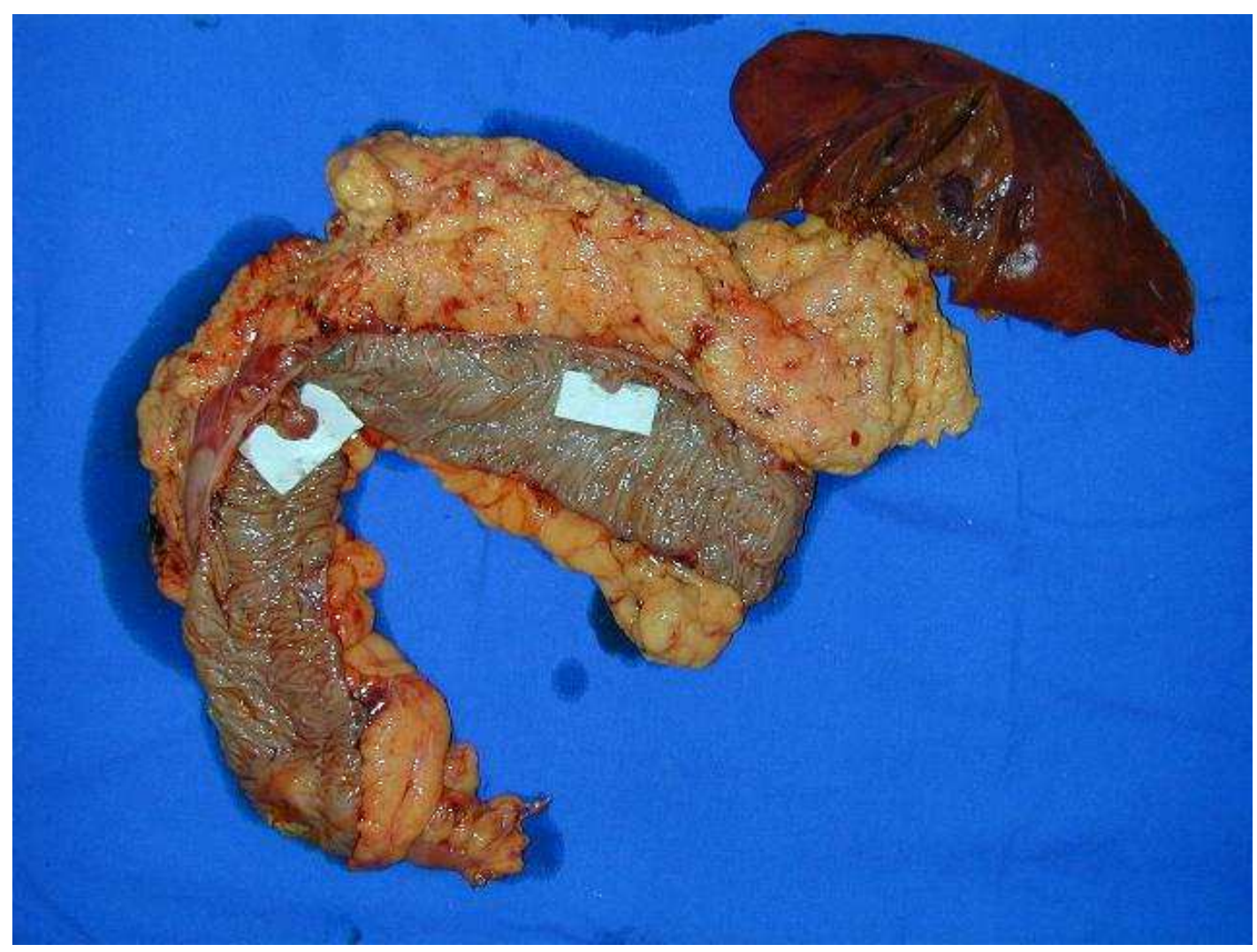

Foto 2: Pieza de colectomía derecha y hemihepatectomía izquierda (Seg. 2, 3 y 4) 


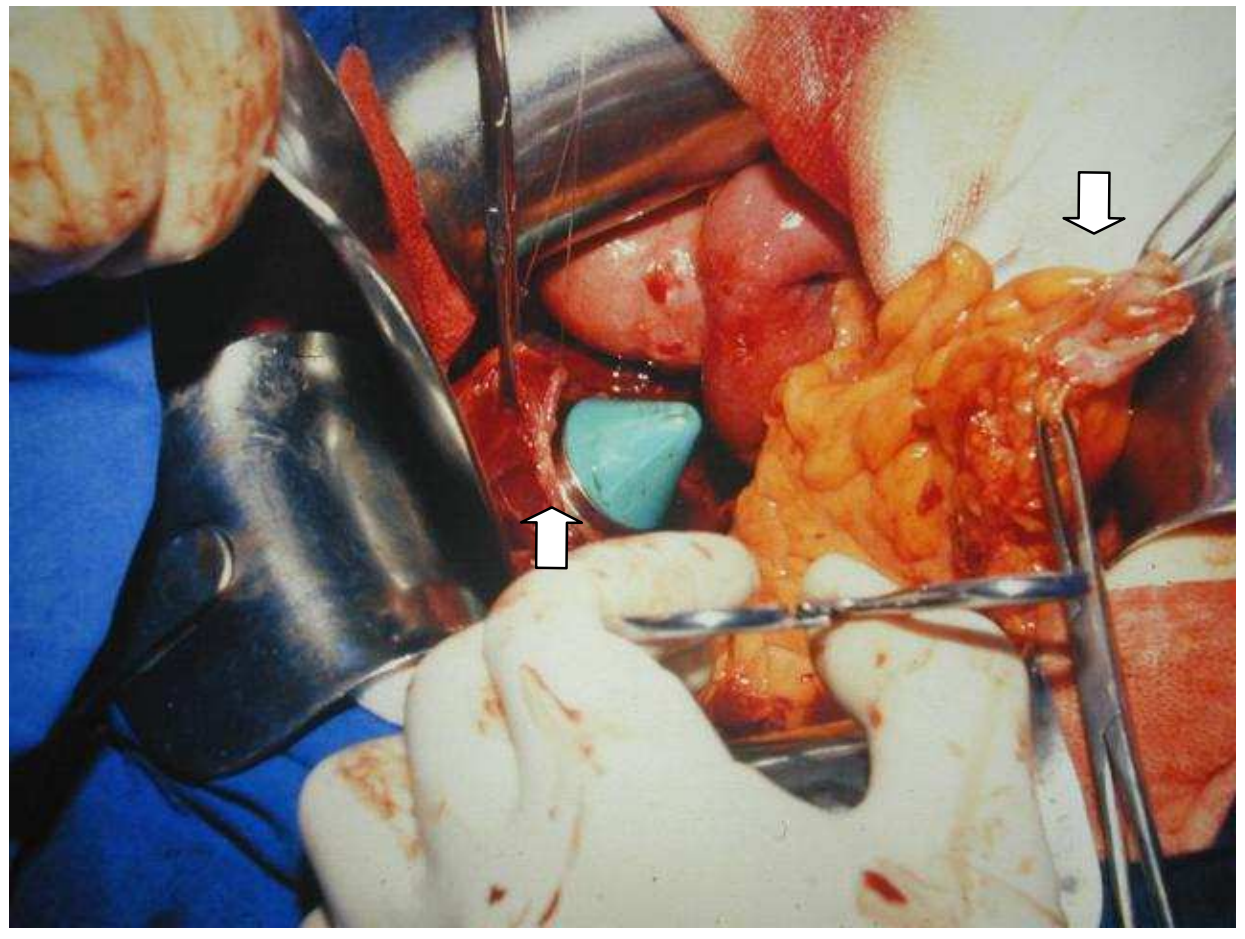

Foto 3: Preparación para sutura mecánica colo-rectal término-terminal con EEA.

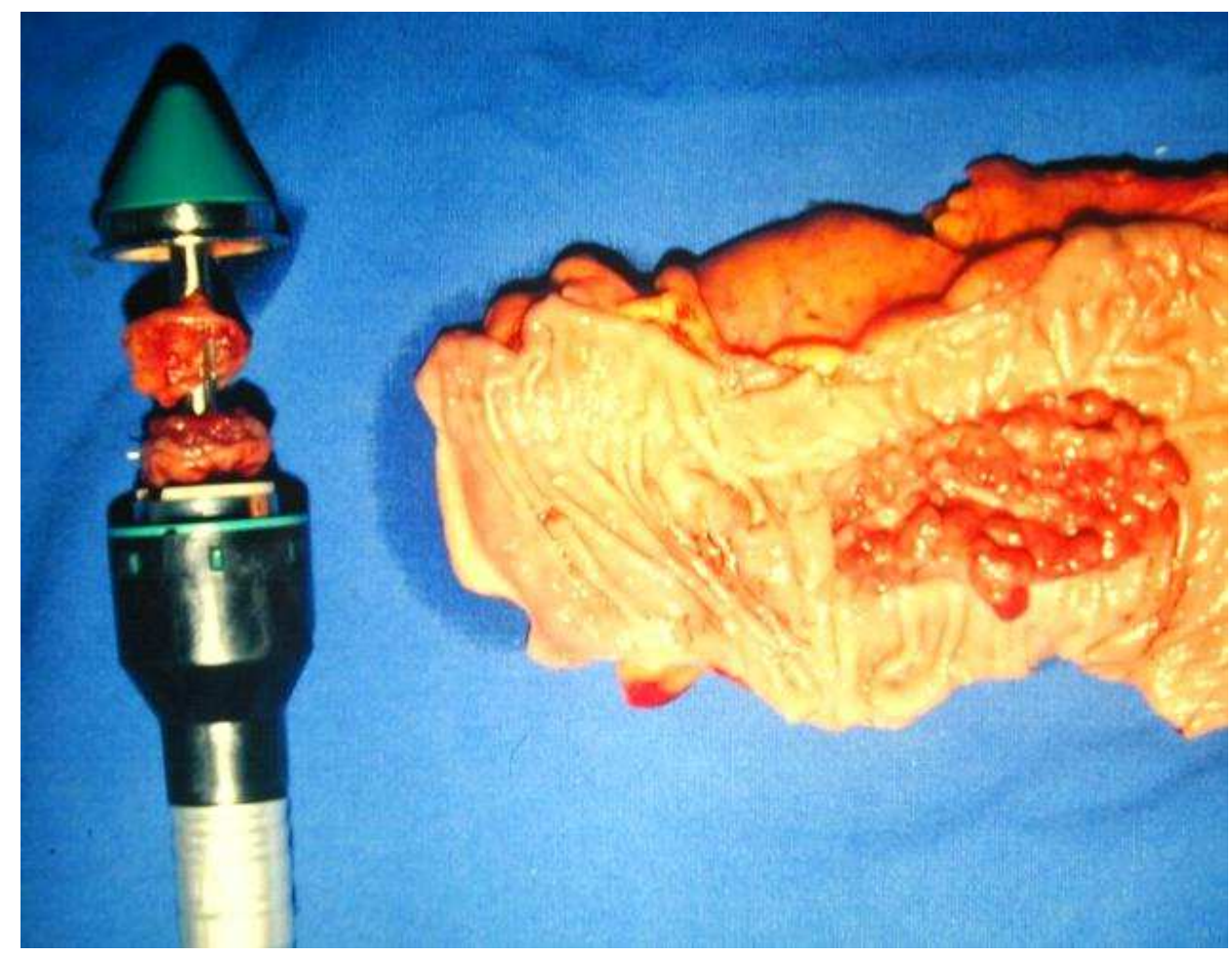

Foto 4: Pieza de resección y "anillos" proximal y distal en el suturador. 


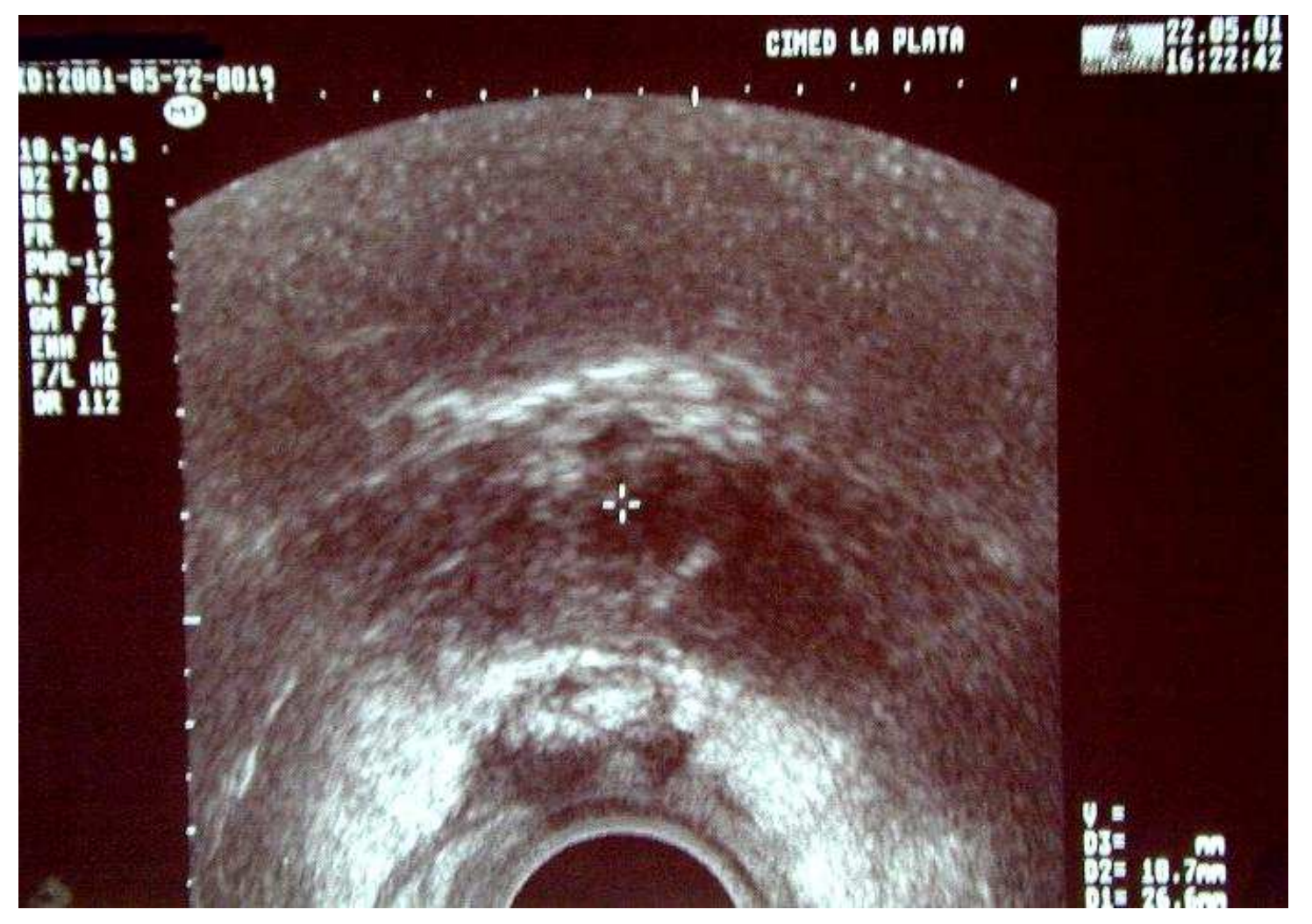

Foto 5: Ecografía endorrectal de un tumor recidivado sobre la anastomosis.

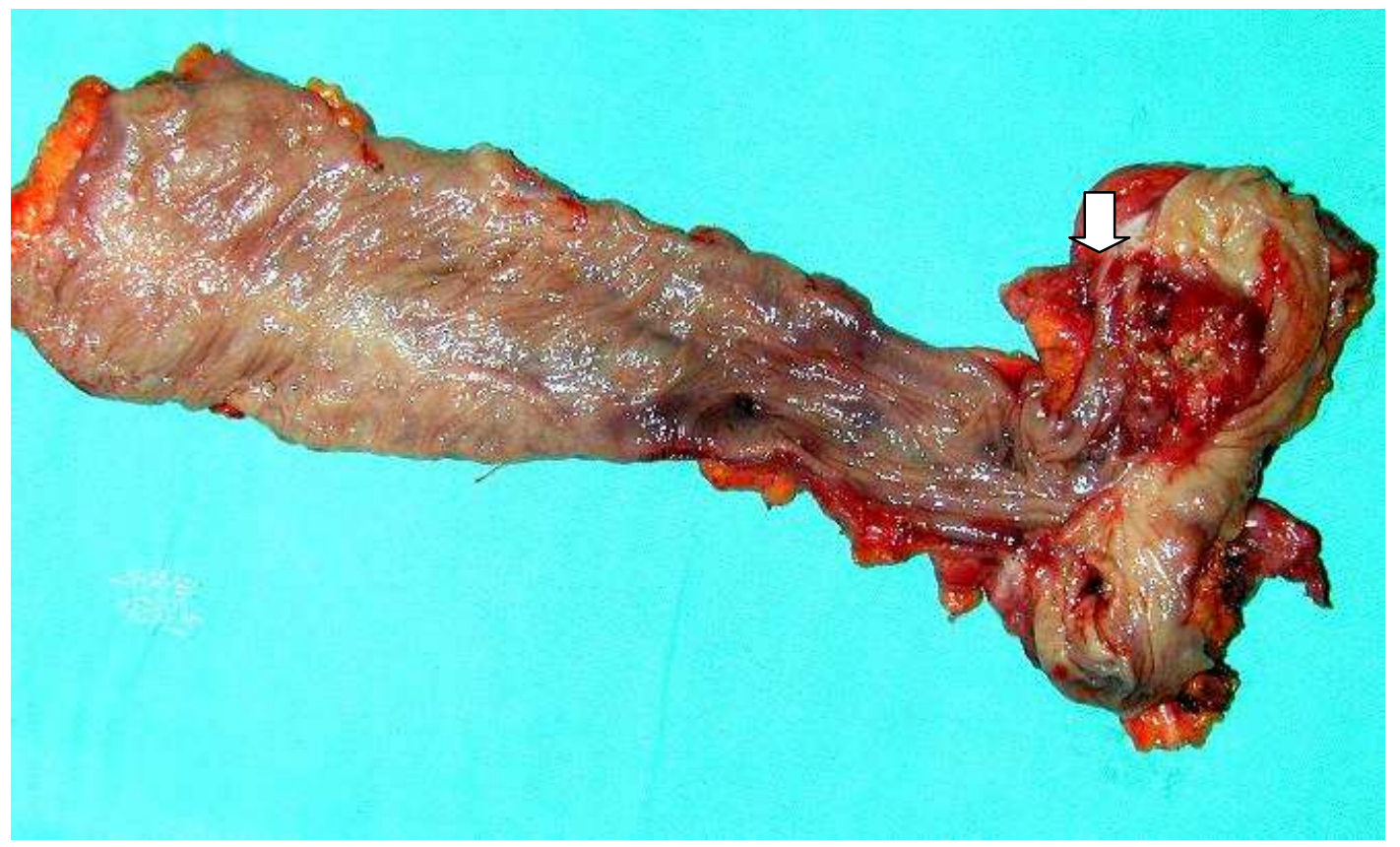

Foto 6: Recidiva en la sutura Colo-Rectal en una Resección Anterior (Op. Dixon). 


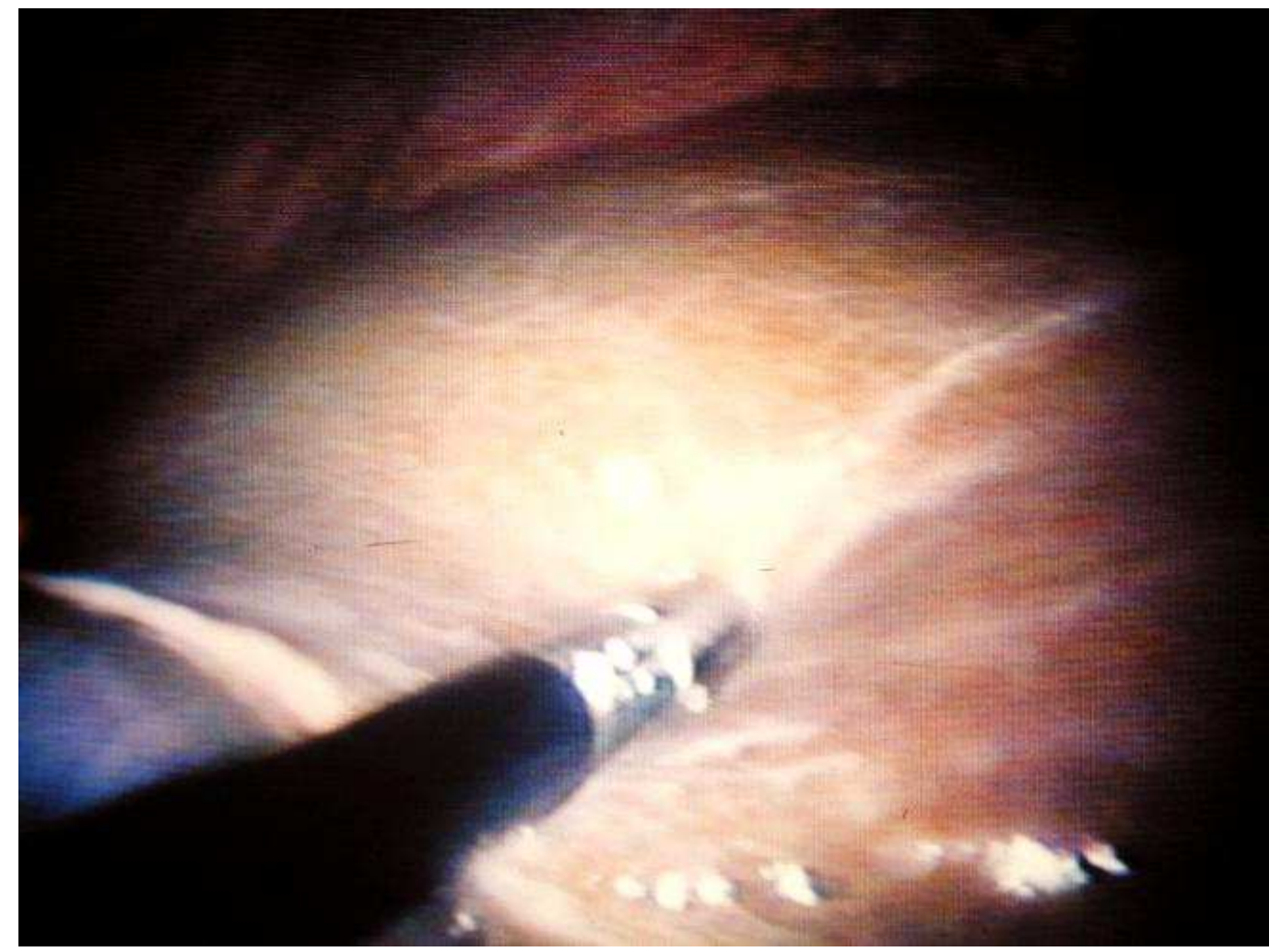

Foto 7: "Palpación" instrumental de la cara diafragmática del hígado derecho.

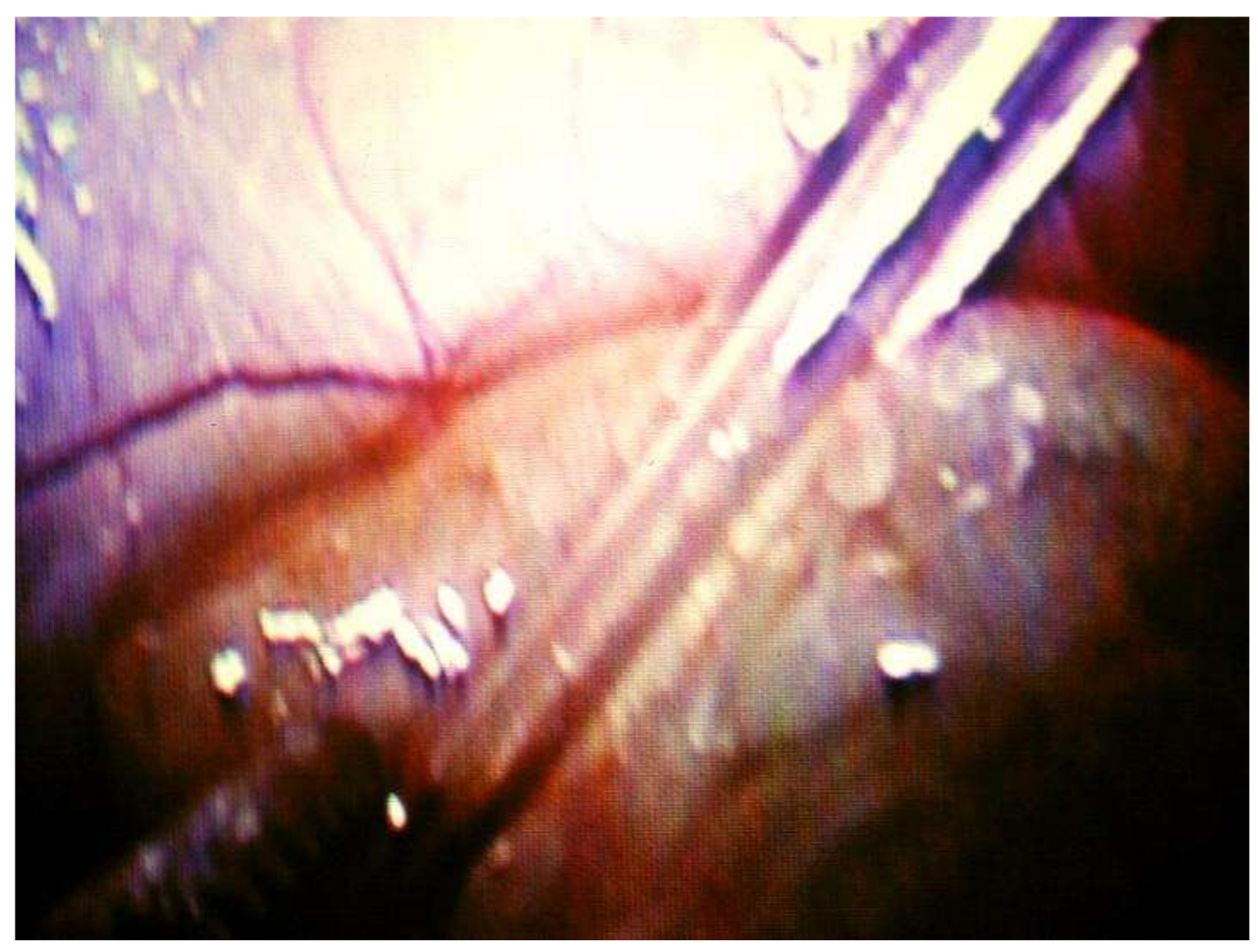

Foto 8: Aspiración con catéter de Ascitis para citología del Espacio de Morrison. 


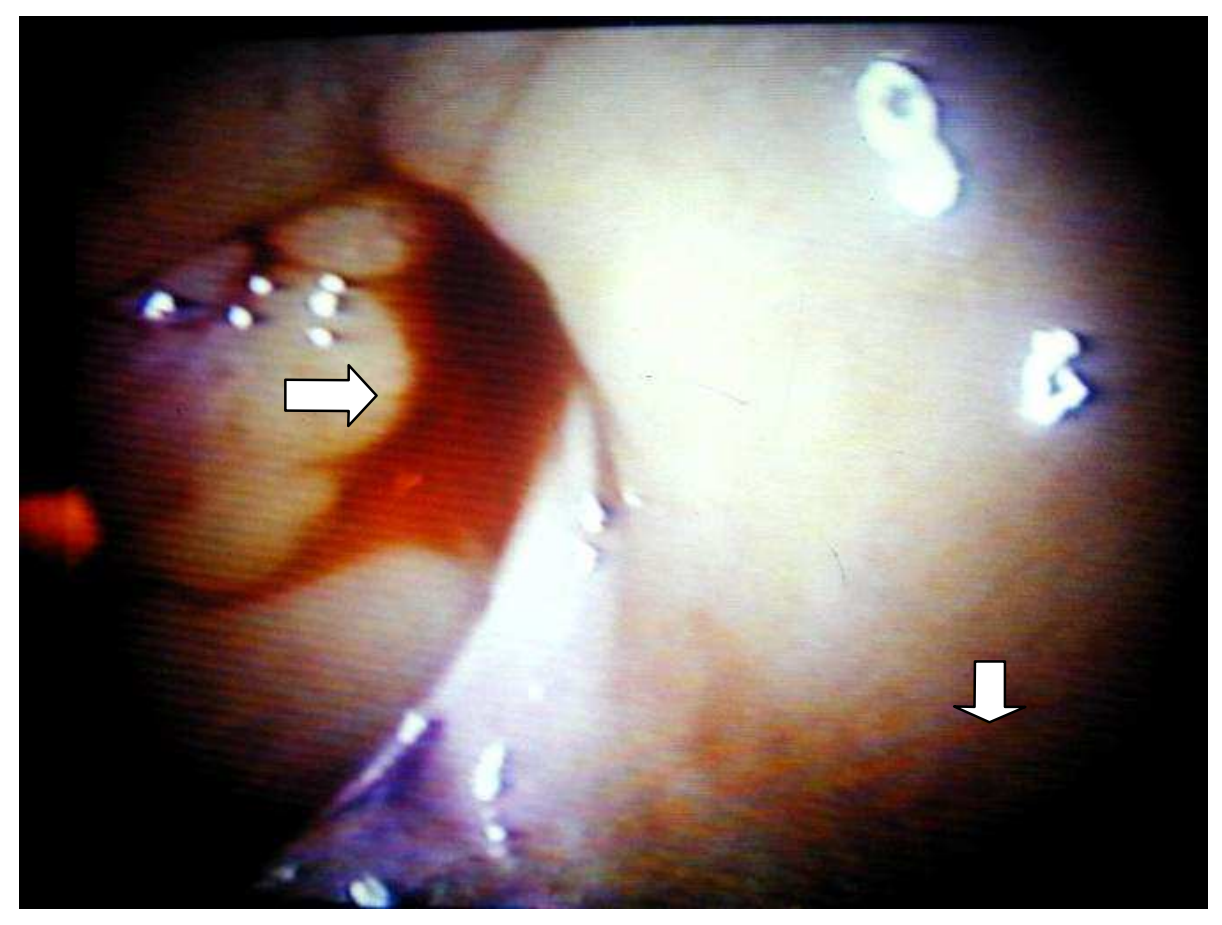

Foto 9: Ascitis hemorrágica en el fondo de saco de Douglas.

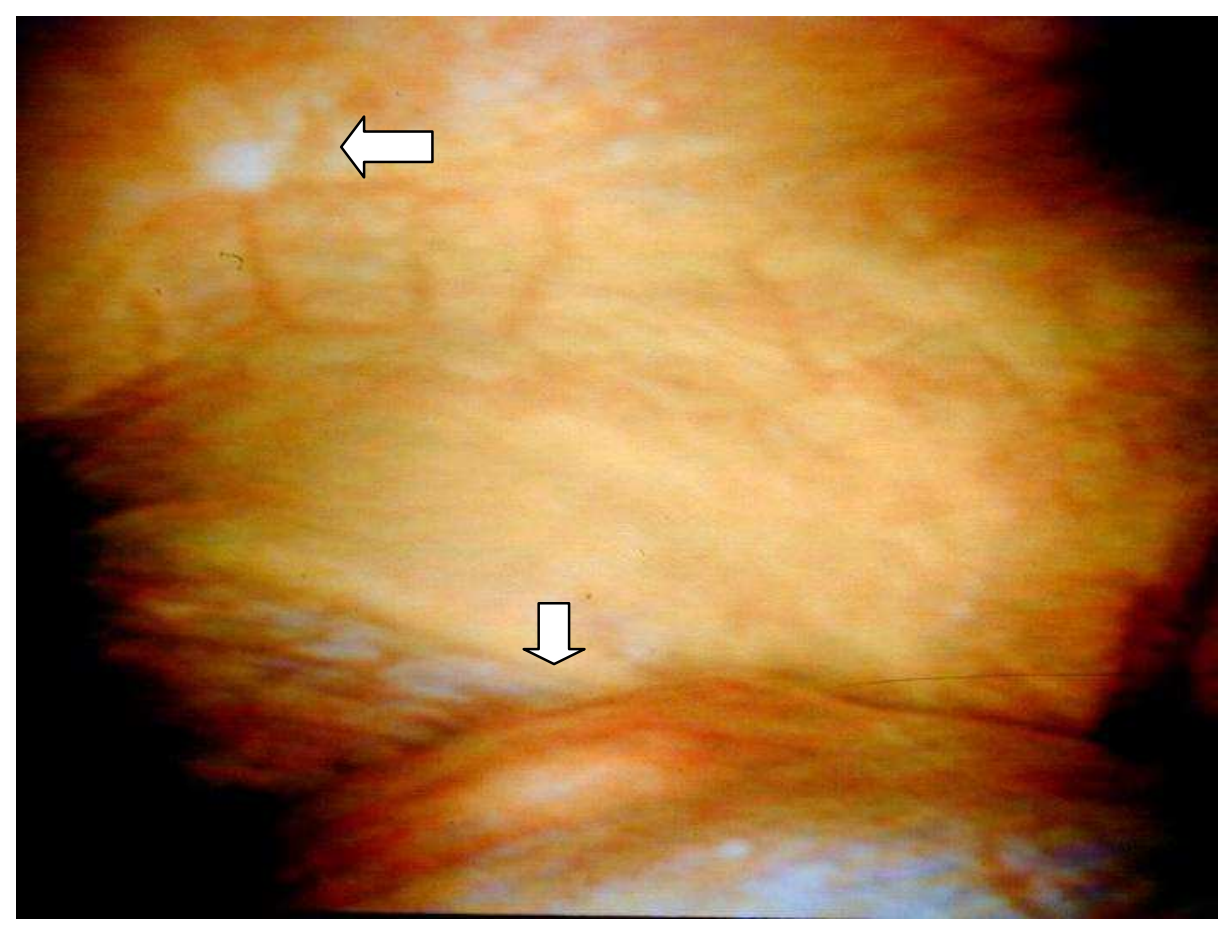

Foto 10: Metástasis hepática superficial y foco de carcinomatosis peritoneal. 


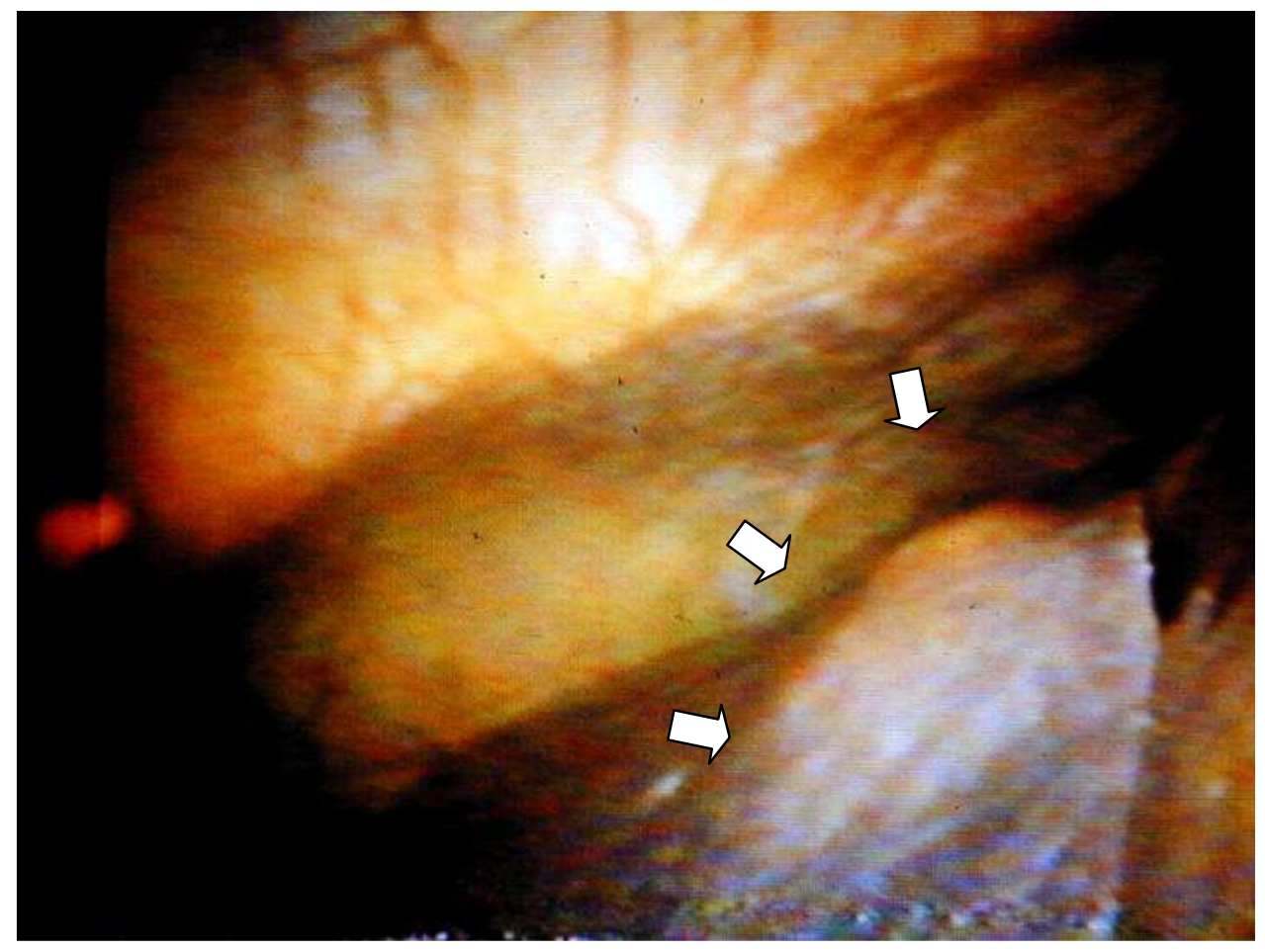

Foto 11: Metástasis superficial en Segmento 3, no detectada en estudios preoperatorios.

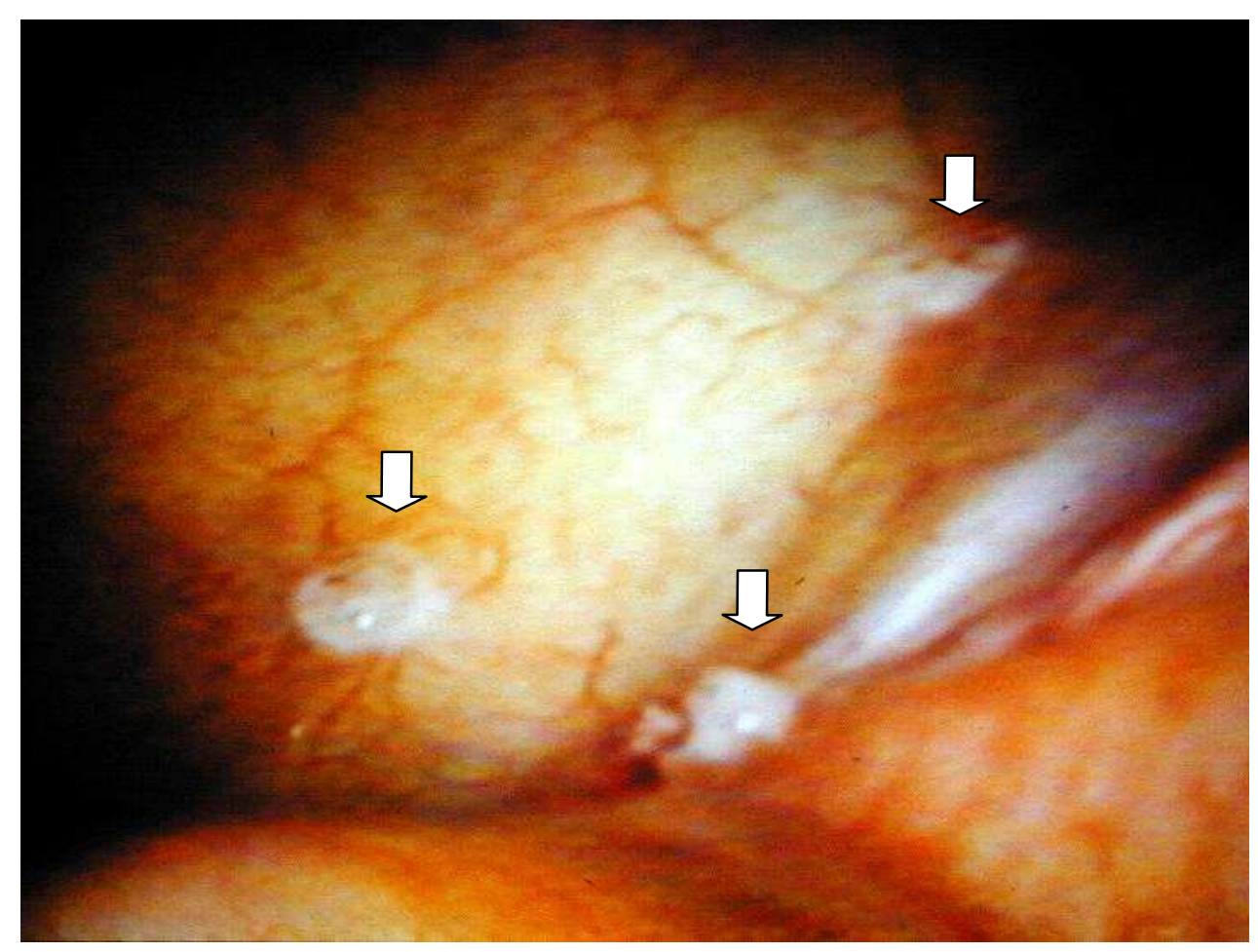

Foto 12: Imágenes de Carcinomatosis Peritoneal en el fondo de saco de Douglas. 


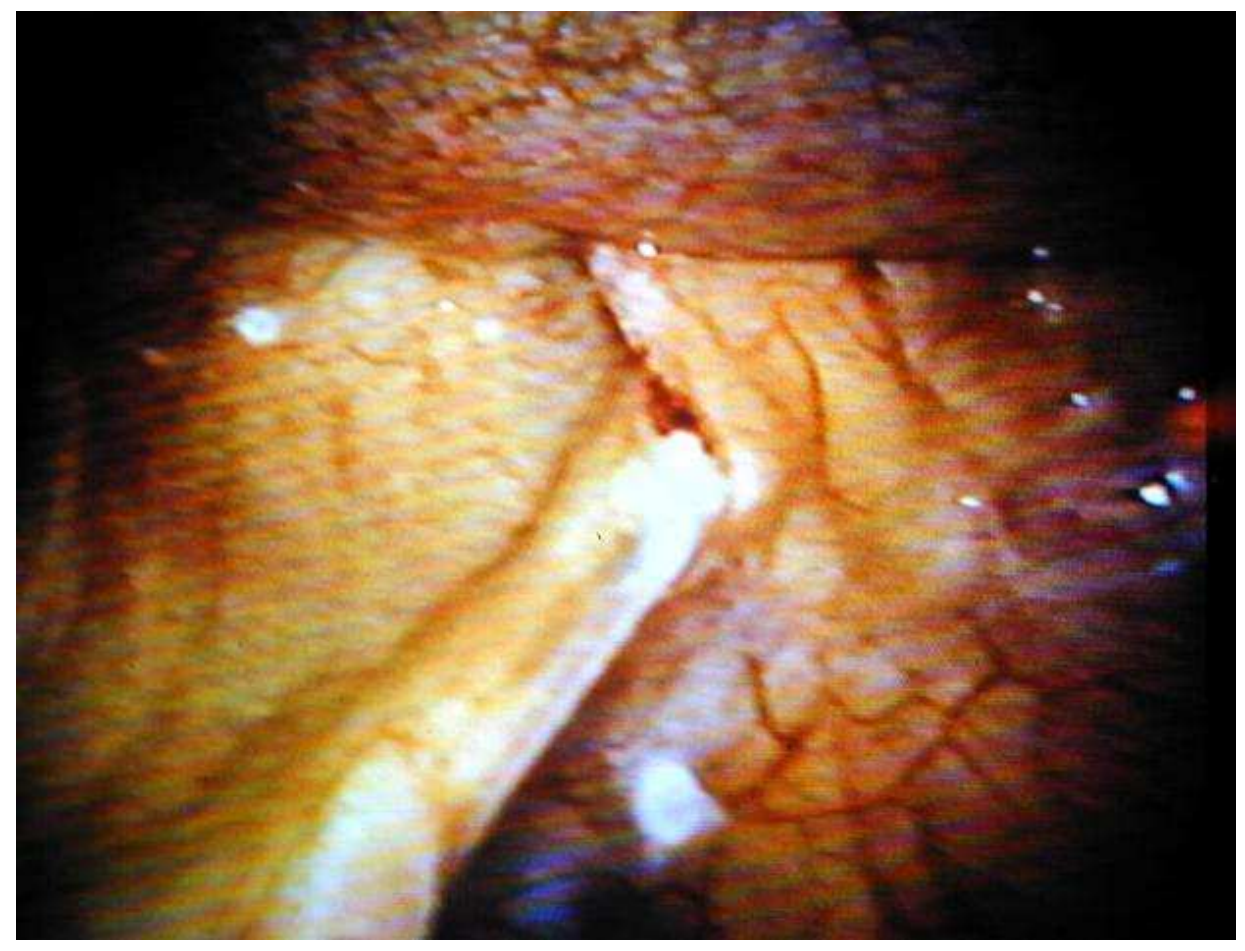

Foto 13: Carcinomatosis Peritoneal en el espacio de Morrison.
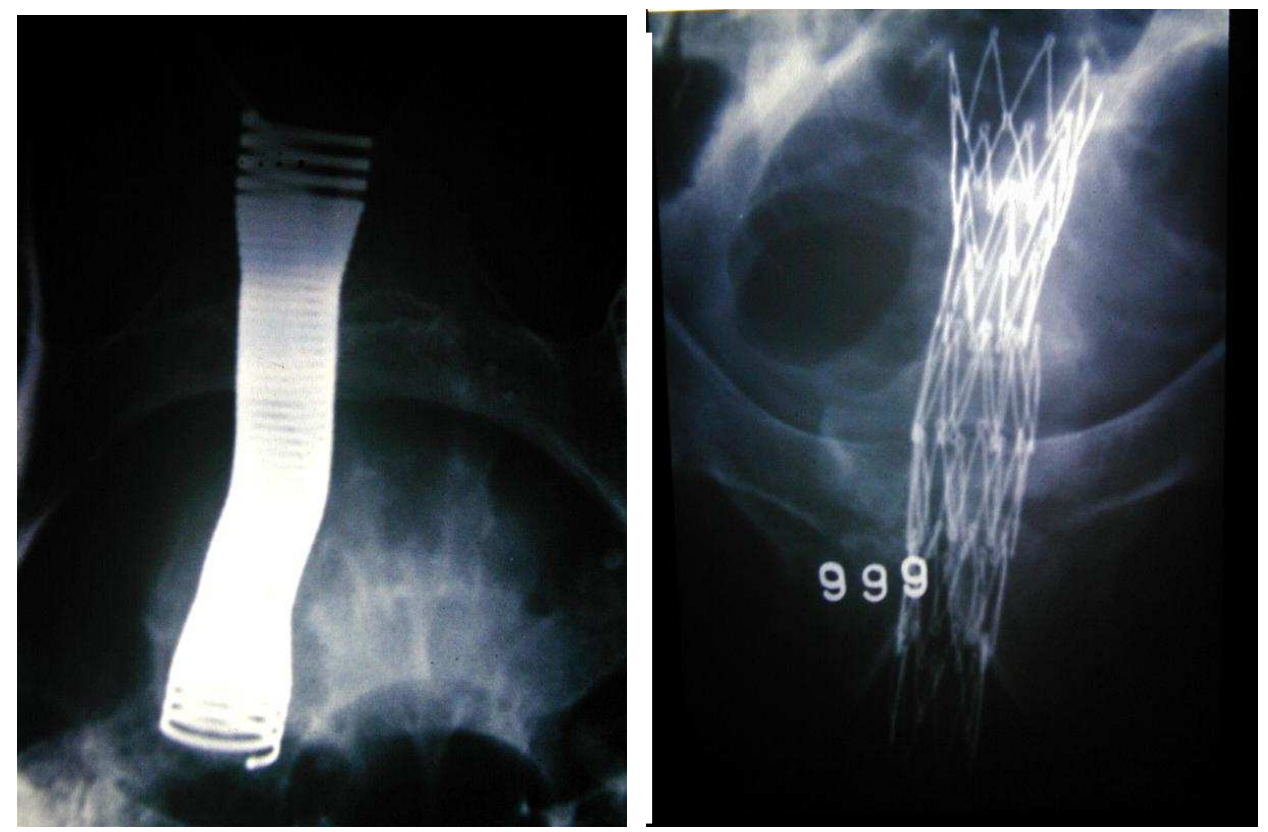

Foto 14: "Stents" transtumorales en cánceres obstructivos recto-sigmoideos. 


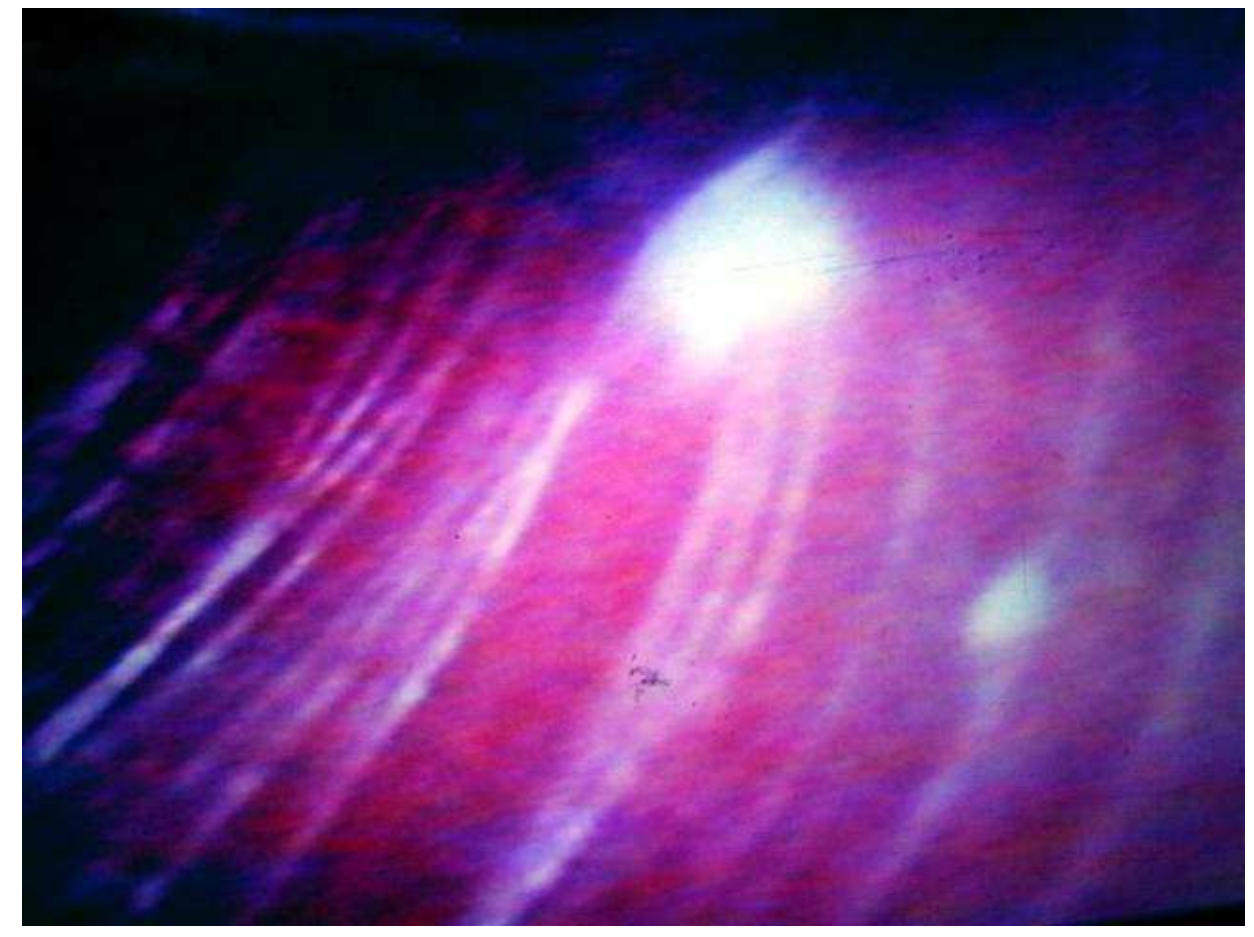

Foto 15: Carcinomatosis peritoneal en cúpula diafragmática izquierda.

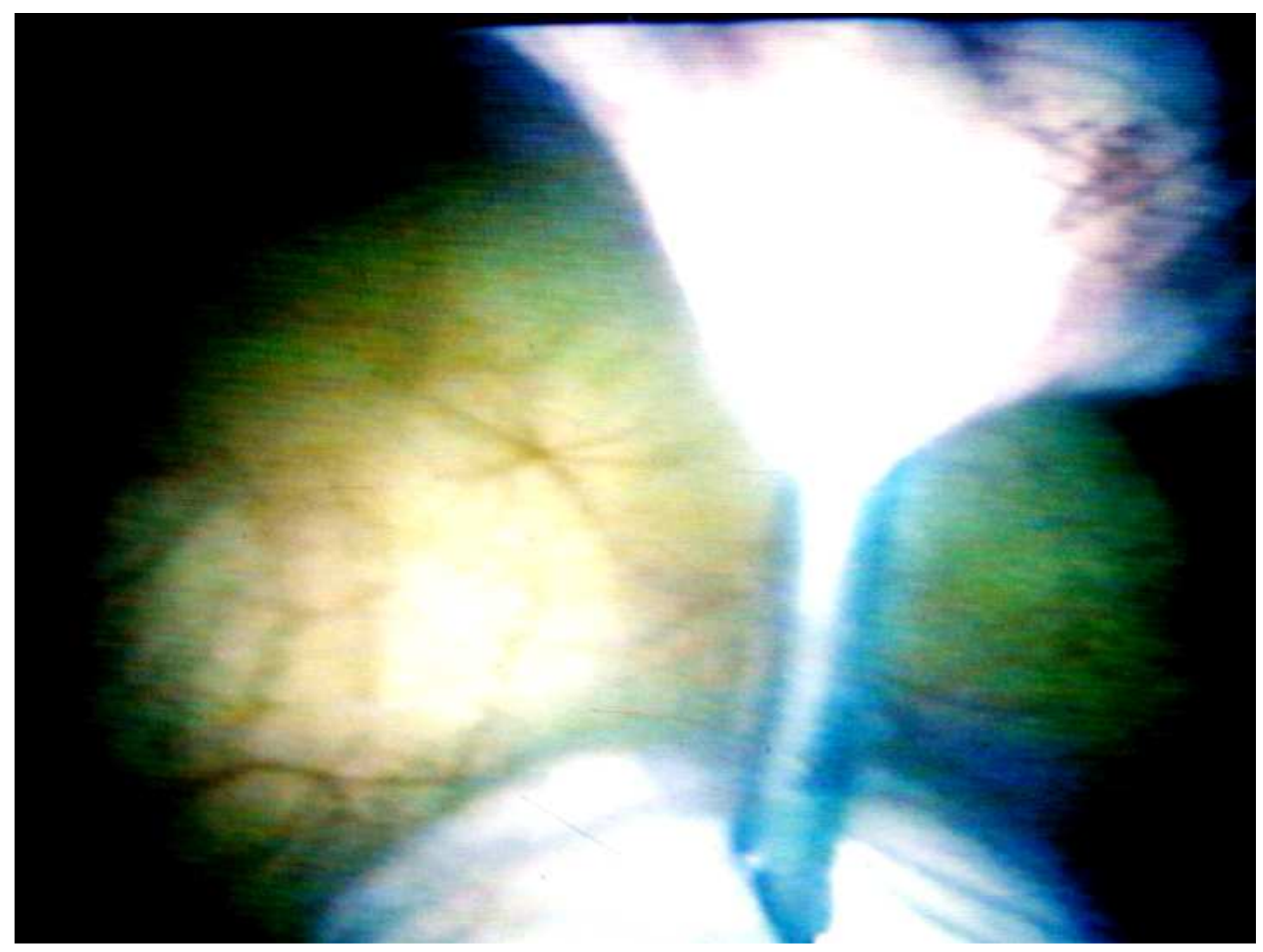

Foto 16: Punción biopsia con Trucut, "encamisado" con trócar nำ 10. 